\title{
WestVirginiaUniversity
}

THE RESEARCH REPOSITORY @ WVU

Graduate Theses, Dissertations, and Problem Reports

2015

\section{Role of Stem-like Cells in Carbon Nanotube-Induced Pulmonary Fibrosis}

Amruta Manke

Follow this and additional works at: https://researchrepository.wvu.edu/etd

\section{Recommended Citation}

Manke, Amruta, "Role of Stem-like Cells in Carbon Nanotube-Induced Pulmonary Fibrosis" (2015).

Graduate Theses, Dissertations, and Problem Reports. 6156.

https://researchrepository.wvu.edu/etd/6156

This Dissertation is protected by copyright and/or related rights. It has been brought to you by the The Research Repository @ WVU with permission from the rights-holder(s). You are free to use this Dissertation in any way that is permitted by the copyright and related rights legislation that applies to your use. For other uses you must obtain permission from the rights-holder(s) directly, unless additional rights are indicated by a Creative Commons license in the record and/ or on the work itself. This Dissertation has been accepted for inclusion in WVU Graduate Theses, Dissertations, and Problem Reports collection by an authorized administrator of The Research Repository @ WVU.

For more information, please contact researchrepository@mail.wvu.edu. 
Role of Stem-like Cells in Carbon Nanotube-Induced Pulmonary Fibrosis

\author{
Amruta Manke \\ Dissertation submitted \\ to the School of Pharmacy \\ at the West Virginia University \\ in partial fulfillment of the requirements for the degree of \\ Doctor of Philosophy \\ in \\ Pharmaceutical and Pharmacological Sciences
}

Yon Rojanasakul, Ph.D., Chair

Vincent Castranova, Ph.D.

Patrick Callery, Ph.D.

Liying Wang, Ph.D.

Grazyna Szklarz, Ph.D.

Department of Pharmaceutical \& Pharmacological Sciences

\author{
Morgantown, West Virginia \\ 2015
}

Keywords: Carbon Nanotube, Fibroblast Stem-like Cell, Lung Fibrosis, Collagen, Oxidative Stress, Fiber Length, Surface Modification

Copyright 2015 Amruta Manke 


\title{
ABSTRACT \\ Role of Stem-like Cells in Carbon Nanotube-Induced Pulmonary Fibrosis
}

\author{
Amruta Manke, B.Pharm, M.S.
}

Recent studies have shown that pulmonary exposure to (CNT) results in rapid and progressive interstitial lung fibrosis in animals without causing persistent lung inflammation, which is normally associated with other known fibrogenic agents. This unusual fibrogenic effect of CNT raises important health issues since the exposure could result in deadly and incurable lung fibrosis. Accumulating evidence indicates the fibrogenic potential of carbon nanotubes, however, the underlying mechanism remains poorly addressed. Recent studies have demonstrated the pathogenic role of mesenchymal stem cells in pulmonary fibrosis that differentiate into myofibroblasts and contribute to disease progression. Understanding the molecular/cellular basis of these fibrosis-associated stem cells during lung fibrosis is of critical importance. However, the concept of stemness in the light of nanomaterial-induced fibrosis remains to be explored. Fibroblast cells being the key players in fibrogenesis, we hypothesized that CNT exposure in fibroblasts induce fibroblast stem-like cells (FSCs) which are critical for the CNT-induced fibrogenic response. The long-term broad objective of this project was to develop an in vitro model predictive of in vivo fibrogenic response and to devise preventive strategies for the disease. The specific aims of this study included i) Determining the involvement of stemness phenotype and underlying mechanism in CNT- induced lung fibrosis the and develop in vitro screening assay which may be predictive of the in vivo fibrogenic response; ii) Investigate the redox regulation of stem-like cells involved in CNT-driven fibrosis; iii) Evaluating the impact of nanoparticle length and surface chemical modification influence stemness phenotype and the resulting fibrogenic response. Our findings from Aim 1 indicated that indeed CNTs induced the side population phenotype (indicative of the fibroblast stem-like cell phenotype) of primary lung fibroblasts. The isolated FSCs displayed an elevated expression of fibrogenic and stem cell markers indicating the reliability of the stem cell isolation method as well as supporting their role in CNT-induced fibrogenesis. The study also developed and put forth an in vitro model of CNTinduced fibrotic nodule formation that correlates the development of stemness phenotype and onset of fibrosis. Furthermore, the results from Aim 2 demonstrated that CNT-induced stemness phenotype was under the redox regulation via identifying the key role of peroxides in CNTinduced FSC generation and collagen expression. Moreover, results from our second study revealed that antioxidants abrogated the effect of CNT on stem-like cell generation suggesting crucial role of redox in stemness generation and the fibrogenic effects. Our outcomes from the Aim 3 demonstrated a length-dependent effect on stemness phenotype, with longer CNT inducing higher FSCs compared to short CNTs as evidenced by side population and aldehyde dehydrogenase assays. Pristine CNTs induced higher FSCs compared to modified CNTs; however the effect was not statistically different. Long SWCNTs induced greater fibrogenic response in vivo compared to short SWCNTs, supporting the potential utility of our in vitro FSC 
model to predict the fibrogenicity of CNTs. Such information will be important for development and safer design and use of nanotechnology.

Findings from this work introduced the concept of fibroblast stem-like cells as a potential key player in the pathogenesis of pulmonary fibrosis; which in turn may help in identifying novel biomarkers and drug targets for early diagnosis and treatment of the disease. Furthermore, the in vitro FSC model developed in this study may be utilized as a rapid screening tool for fibrogenicity testing of not just carbon nanomaterials but also other nanoparticles and antifibrotic agents. 


\section{DEDICATION}

I dedicate this dissertation to my beloved parents, my mother, Mrs. Manisha Manke, my father, Dr. Anil Manke, my sister, Aditi Manke and my husband, Dr. Mayank Ajmera without whose unwavering support and unconditional love this work would not have been possible. 


\section{ACKNOWLEDGEMENTS}

I consider myself extremely fortunate to have worked under the guidance of my mentor Dr. Yon Rojanasakul for his tremendous support, inspiration, and belief in me during all these years of graduate school. It is because of his persistent efforts, that I have been able to progress this far and successfully completes my dissertation. His contribution in shaping my research and career paths has been priceless and I attribute my doctoral education to invaluable training provided by Dr. Yon.

Besides being an amazing teacher and guiding me in every aspect of my dissertation work, Dr. Wang has always been a mother figure for me and has looked out for me for all these years. I am truly grateful to her for letting me work in her laboratory and having me avail of the technical expertise at the National Institute for Occupational Safety and Health regarding my dissertation work.

I would also like to thank my committee members Dr. Castranova, Dr.Callery and Dr. Szklarz for their consistent critical input and insight in my dissertation work. I also want to acknowledge Dr. Castranova for his scientific expertise which has tremendously helped me to improve the scope of my work. I would also like to thank Dr. Cerasela-Zoica Dinu and Dr. Nianqiang Wu for all their assistance with the characterization work.

I would like to thank Dr. Sudjit Luanpitpong for her mentoring since I joined the Rojanasakul laboratory and constant support with the design and execution of all my experiments. I want to acknowledge Dr. Todd Stueckle and Dr. Katie He for being the guiding me throughout these years in my work as for being the emotional support they provided me during the completion of my dissertation study. I want to acknowledge Dr. Kathleen Brundage and Dr. Meenal Elliot at the WVU Flow Core for their expertise and critical input during the flow cytometry experiments.

I owe my deepest gratitude to my parents who have stood like a solid rock for me throughout these years. It was their utmost belief and patience in me which guided me towards the completion of my project. I am truly thankful to my in-laws and my brother-in-law, Dev for their tremendous understanding and moral support for inspiring me to fulfill my goals. A very special thanks to my wonderful family members, including my sister and my grandparents for their persistence and faith in me to reach this goal. Lastly, but most importantly, I am eternally grateful to my husband, Mayank for his constant motivation, sacrifices and love throughout the journey of my dissertation work. I am blessed to have him by my side to provide me the strength, moral support and encouragement to achieve all my goals. Thank you God for guiding me throughout this entire time and making this journey possible.

I would like to acknowledge that my dissertation work was supported by R01-ES022968 and R01-HL095579 from the National Institute of Health and by NSF EPS-1003907 and NSF CBET1434503 from the National Science Foundation. 


\section{ABBREVIATIONS}

CNT, Carbon nanotube

NP, Nanoparticle

SWCNT, Single-walled carbon nanotube

HARN, High aspect ratio nanoparticle

MWCNT, Multi-walled carbon nanotube

MMP, Matrix metalloproteinase

ROS, Reactive oxygen species

MAPK, Mitogen-activated protein kinase

NF- $\kappa \mathrm{B}$, Nuclear factor kappa-light-chain-enhancer of activated B cell

AP-1, Activator protein

ECM, Extracellular matrix

TNF-a, Tumor necrosis factor-alpha

IL-1b, Interleukin-1beta

PDGF, Platelet-derived growth factor

TGF-b, Transforming growth factor-beta

COX-2, Cyclooxygenase-2

iNOS, Inducible nitric oxide synthase

MCP-1, Monocyte chemoattractant protein

STAT-1, Signal transducer and activator of transcription

RTK, Receptor tyrosine kinase

VEGF, Vascular endothelial growth factor

EMT, Epithelial mesenchymal transition

IPF, Idiopathic pulmonary fibrosis

FACS, Fluorescence activated cell sorting 
MSC, Mesenchymal stem cell

$\mathrm{BM}$, Bone marrow

ALDH, Aldehyde dehydrogenase

BALF, Bronchoalveolar lavage fluid

FSC, Fibroblast stem-like cell

NHLF, Normal human lung fibroblast

SP, Side population

Non-SP, Non side population

ABCG2, ATP-binding cassette sub-family G member 2

FTC, Fumitremorgin C

$\alpha$-SMA, Alpha-smooth muscle actin

Col I, Collagen type I

NAC, N-acetyl cysteine

GPX, Glutathione peroxidase

SOD, Superoxide dismutase

DHE, Dihydroethidium

DCF-DA, Dichlorofluorescin diacetate

NF, Non-functionalized/pristine

$\mathrm{COOH}$, Carboxylic group

PEI, Polyethyleneamine

NC, Nitrogen-containing

OH, Hydroxyl

PEG, Polyethylene glycol

ECM, Extracellular matrix

FGF, Fibroblast growth factor 
PDGF, Platelet derived growth factor

WST, 1[2-(4-Iodophenyl)-3-(4-nitrophenyl)-5-(2,4-disulfophenyl)-2H-tetrazolium]

AFM, Atomic force microscopy

FTIR, Fourier transform infrared spectroscopy

DEAB, Diethylaminobenzaldehyde

DPPC, Dipalmitoyl phosphatidylcholine 


\section{TABLE OF CONTENTS}

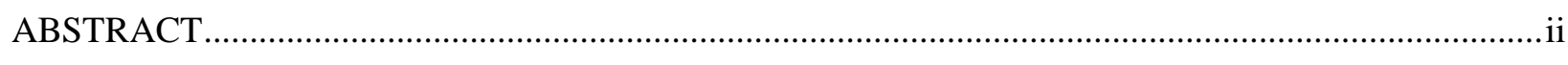

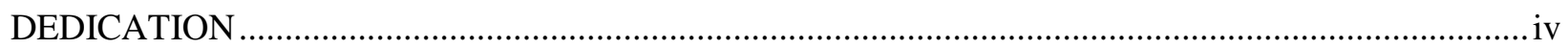

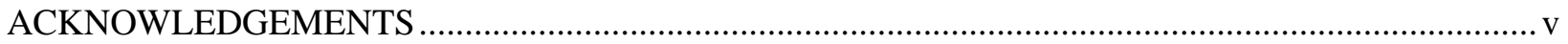

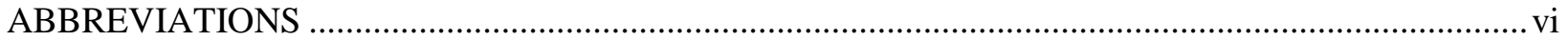

CHAPTER 1: PULMONARY TOXICITY AND FIBROGENIC RESPONSE OF CARBON

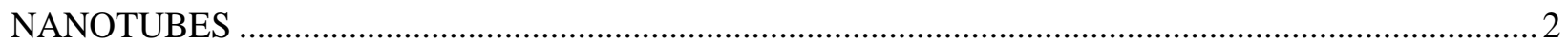

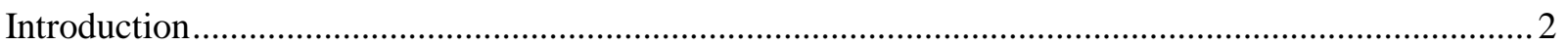

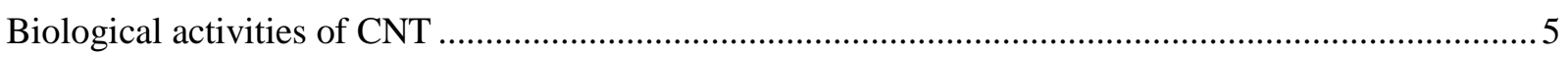

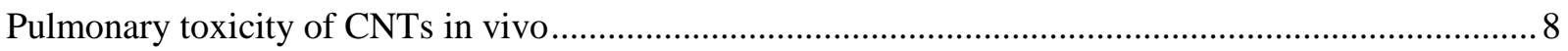

Figure I: Mechanisms of Lung Fibrosis ................................................................................. 11

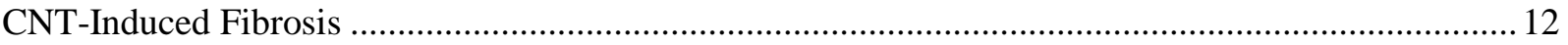

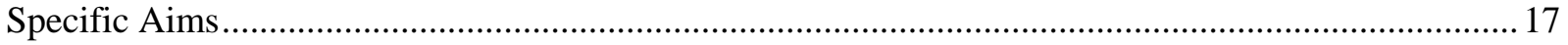

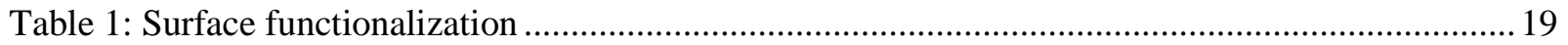

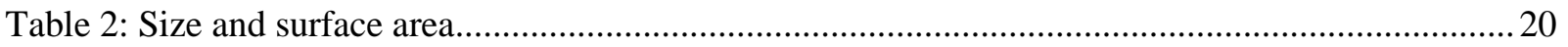

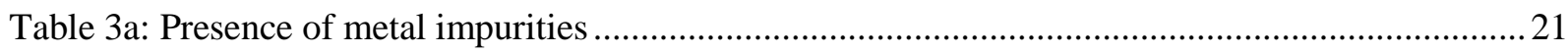

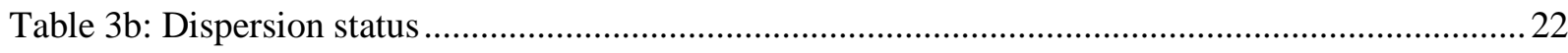

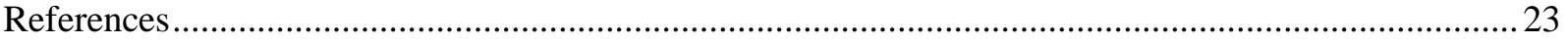

CHAPTER 2: ROLE OF FIBROBLAST STEM-LIKE CELLS IN CARBON NANOTUBE-INDUCED

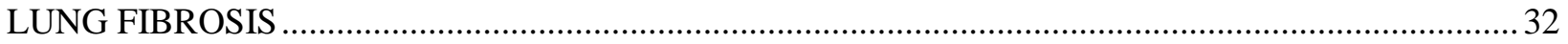

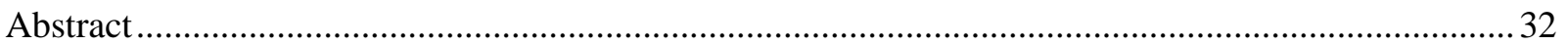

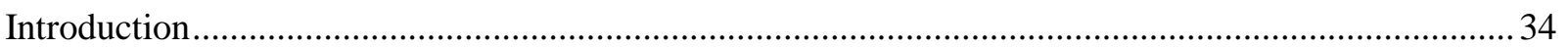

Figure S1: Role of stem-like cells in pulmonary fibrosis ........................................................ 37

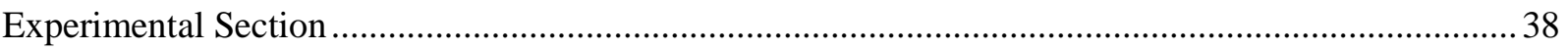

Figure S2: Working model for demonstrating CNT-induced fibroblast stem-like cell induction ......43

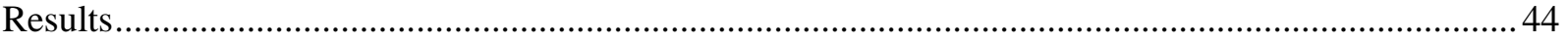

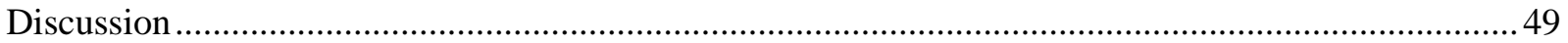

Figure S3: Proposed mechanisms of CNT-induced lung fibrosis ...................................................52

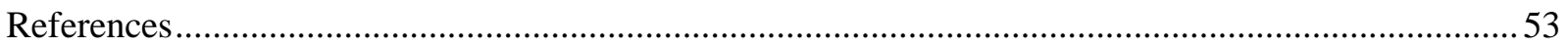

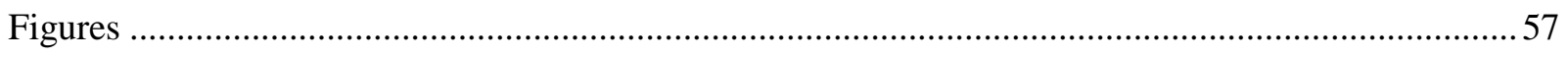

Figure I: Carbon nanotubes (CNT) induce collagen production of human lung fibroblasts ...............57

Figure II: CNT induce stem-like cells as indicated by side population (SP) phenotype....................59

Figure III: CNT-induced SP fibroblasts are a potential source of collagen I and $\alpha$-SMA ..................60 
Figure IV: Enhanced fibrogenic response of CNT-derived SP fibroblasts .................................... 61

Figure V: CNT induce fibroblast nodule formation of human lung fibroblasts...............................62

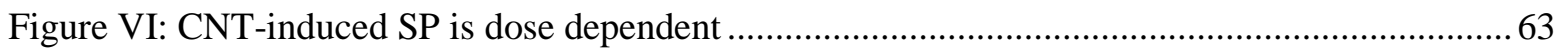

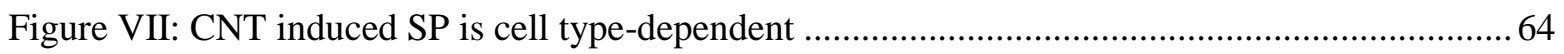

Figure VIII: CNT upregulate ALDH activity of lung fibroblasts ....................................................6 65

CHAPTER 3: ROLE OF REACTIVE OXYGEN SPECIES IN STEMNESS DEVELOPMENT AND

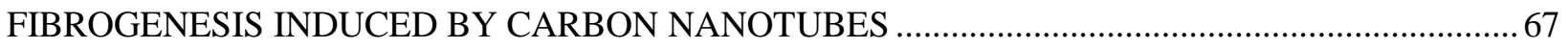

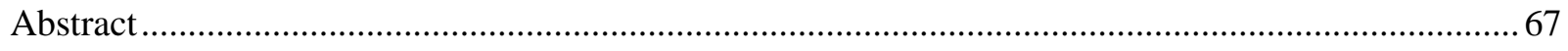

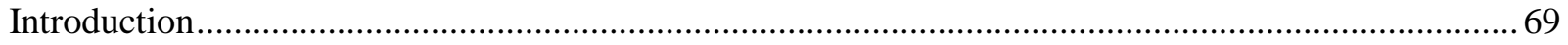

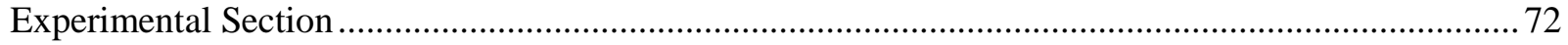

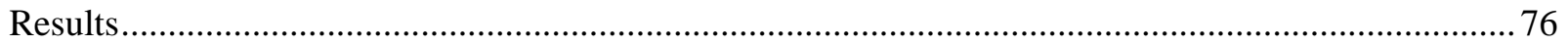

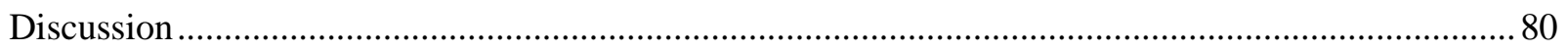

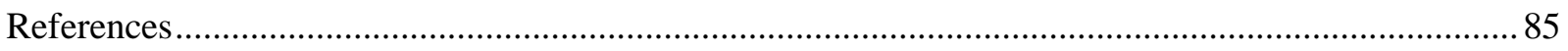

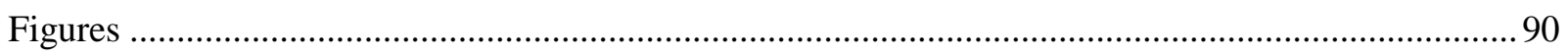

Figure I: Effect of SWCNT on ROS generation .................................................................... 90

Figure II: Effect of SWCNT surface modification and length on ROS generation ...........................91

Figure III: Effect of ROS on SWCNT-induced fibrogenic response ..............................................92

Figure IV: Role of ROS in SWCNT-induced fibroblast stem-like cells ......................................... 93

Figure V: Antioxidant enzyme expression in SWCNT-induced fibroblast stem-like cells ............... 95

Table 1: Physicochemical characterization of SWCNTs .................................................................. 97

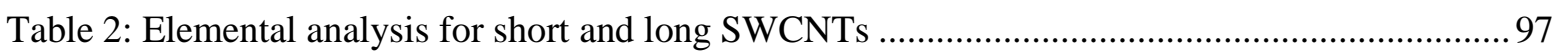

CHAPTER 4: EFFECTS OF FIBER LENGTH AND SURFACE MODIFICATION ON CARBON NANOTUBE-INDUCED FIBROBLAST STEM-LIKE CELLS AND LUNG FIBROSIS ....................99

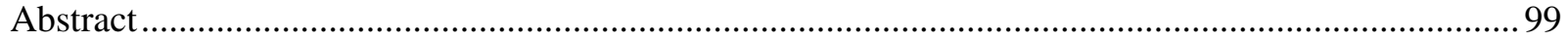

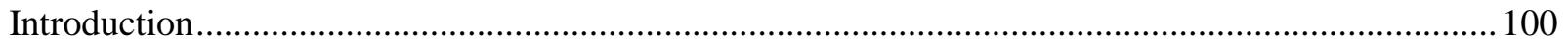

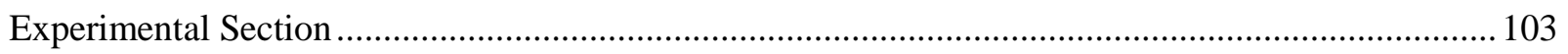

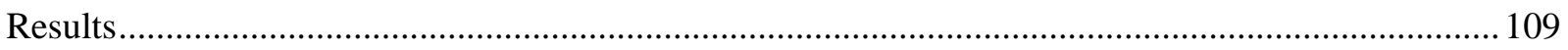

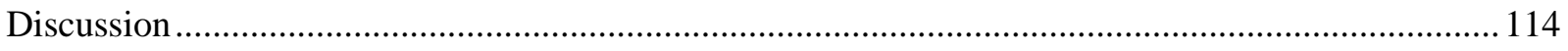

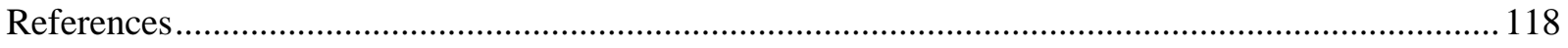

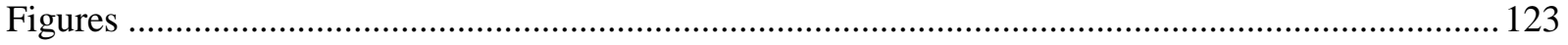

Table I: Physicochemical characterization of Single walled carbon nanotubes (SWCNTs) of different

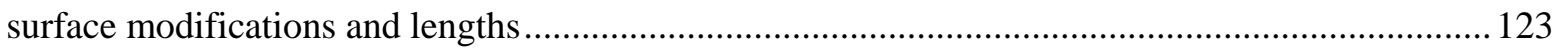

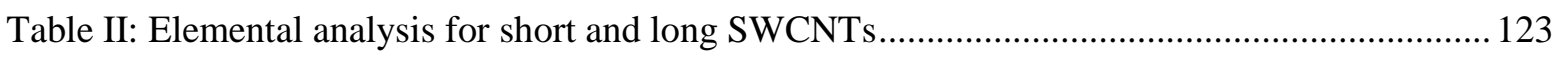


Figure I: FTIR spectra for pristine and surface modified Single walled carbon nanotubes (SWCNTs)

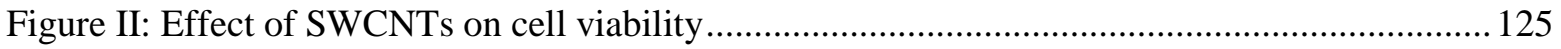

Figure IV: Effect of SWCNT surface modification on FSC generation via Aldefluor ${ }^{\circledR}$ assay ......... 127

Figure V: Effect of SWCNT length on FSC induction determined by side population (SP) assay .. 128

Figure VI: Effect of SWCNT length on FSC generation via Aldeflour ${ }^{\circledR}$ assay .............................. 129

Figure VII: Effect of SWCNT length on fibrogenic response in vitro and in vivo........................... 130

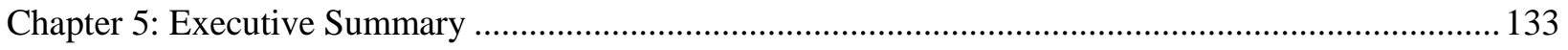

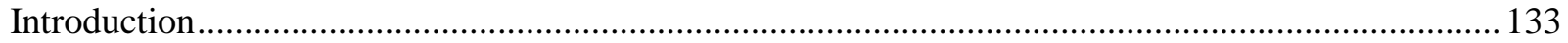

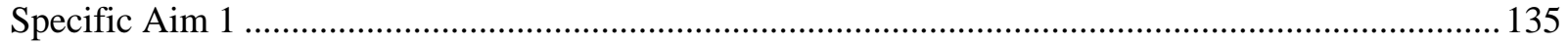

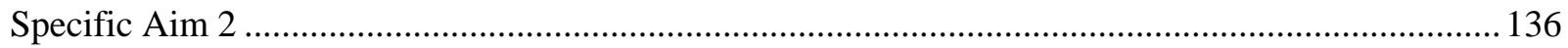

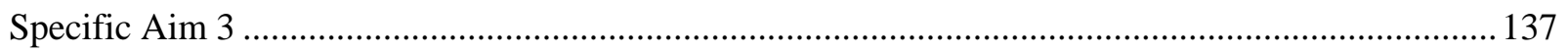

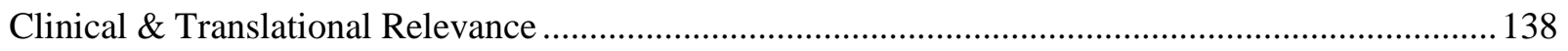

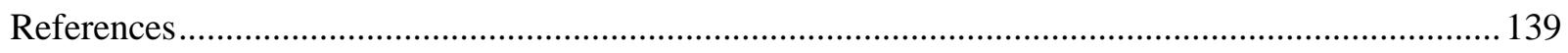


CHAPTER 1 


\section{CHAPTER 1: PULMONARY TOXICITY AND FIBROGENIC RESPONSE OF CARBON NANOTUBES}

\section{Introduction}

In recent years, a variety of nanomaterials have revolutionized the industrial field with their rapidly emerging applications in the areas of biotechnology, electronics, medicinal drug delivery, cosmetics, material science and aerospace engineering. Among the pool of recently developed nanomaterials, carbon nanotubes (CNTs) have generated great interest commercially with their unique physicochemical properties such as high tensile strength and conductivity [1, 2]. With abundant novel applications, the CNT market has been projected to expand substantially within the next decade. However, such massive production is fraught with concerns for environmental and occupational exposure. According to a National Science Foundation (NSF) report, about 6 million workers will be involved with the nanotechnology industry by 2020 including 2 million within the United States, thus indicating a possible prevalence [3]. Human exposures to manufactured nanomaterials are most likely to be observed in workers than the general population [4]. A study reported exposure to polyacrylate paint containing nanoparticle within a group of female workers. Affected workers clinically presented with pleural effusions, progressive pulmonary fibrosis, pleural damage and death [4]. Moreover, a risk assessment study on titanium dioxide nanomaterial observed occupational exposure within factory workers beyond the acceptable limits during the packaging process [5]. However, nanomaterial exposure and dosimetry data are insufficient for humans owing to the difficulty in detection and accurate measurement tools for this unique and rapidly growing nanomaterial industry. The extraordinary properties of CNTs need to compete with reports of CNT-associated toxicities, thus indicating careful monitoring of human health and safety during their use [6]. Depending upon the type of 
exposure, CNTs may penetrate the body through various routes such as the lungs and gut. CNTs are high aspect ratio nanomaterials (HARNs) having at least one of their dimensions of the order of $100 \mathrm{~nm}$ or less in size, as per the British Standards Institution (BSI) (2007). CNT structure facilitates their entry, deposition and residence in the lungs and pleura, resulting in incomplete phagocytosis and clearance from the lungs [7]. Owing to their bio-persistent and nonbiodegradable nature, and particularly the resemblance to needle-like asbestos fibers, CNTs are believed to induce biologically harmful effects. CNTs are similar to asbestos in their fibrous morphology, biopersistence, surface reactivity and the ability to translocate within the alveolar regions and the deeper pleura of the lung [8]. Upon pulmonary exposure, CNTs generate an acute inflammatory response, activate several cell signaling pathways [9, 10], and induce genotoxicity $[11,12]$, mesothelioma $[1,8]$, diffuse interstitial fibrosis and granulomas similar to that observed in asbestos-exposed animals and humans $[13,14]$. However, they differ in their chemical composition, surface charge and the ability to (i) enter mesothelial cells and (ii) induce direct fibrogenic effects $[8,15,16]$. Lung toxicity appears to be the major consequence of CNT exposure, ultimately contributing toward granuloma formation, epithelial hypertrophy and early onset of fibrosis [17-20]. Accumulating evidence in the literature demonstrates the fibrogenic potential of CNTs. Toxicity reports have indicated the ability of CNTs to translocate into the surrounding areas of the lung causing systemic toxicity, granulomatous lesions, interstitial and sub-pleural fibrosis $[14,22,23]$. However, the interactions of CNTs with the host at the molecular and cellular levels remain largely unknown. Identification of molecular targets and intracellular signaling is essential to the development of specific biomarkers for risk assessment and early detection of CNT-induced pathogenesis. The pathologic effects of CNTs are likely to 
be influenced by their physicochemical properties, thus we will first describe the physical and chemical properties of CNTs and their associated cellular toxicities.

\section{Types and properties of CNTs}

As per the British Standards Institute Report (2007), CNTs are HARNs having at least one of their dimensions, i.e. the diameter less than $100 \mathrm{~nm}$ whereas the lengths vary from a wide range of micrometers. CNTs are engineered nanomaterials made of graphene sheets that have been rolled into seamless cylindrical structure. They are manufactured mainly via arc discharge, chemical vapor deposition and laser ablation. All the three methods basically involve thermal elimination of carbon atoms from carbon sources including graphite, or gaseous carbon-bearing compounds such as CO, methane, ethylene or other hydrocarbons [24]. Post-synthesis, CNTs are purified to eliminate residual organics such as soot or amorphous carbon and metals. They are classified into two main types known as single walled carbon nanotubes (SWCNTs) and multiwalled carbon nanotubes (MWCNTs), both demonstrating outstanding chemical and thermal stability. MWCNTs comprise of several single-walled tubes layered onto each other. SWCNTs can be viewed as a single thick-graphite layer rolled into a cylindrical tube [25]. The nanoscale and large surface area of CNTs allow them to interact efficiently with cells, albeit in an undefined manner. Whether CNTs are inherently toxic or is it a wide array of external factors such as length, surface modification, degree of dispersion and the presence of metal impurities playing a role in CNT-induced toxicity is still a subject of intense investigations. Current literature reveals that CNTs based on their type, fiber length, dispersion status and functionality exert considerable variations in toxicities. 


\section{Evidence for adverse pulmonary outcomes following CNT exposure}

Currently, there are no published reports of the adverse health effects in workers handling CNTs. However, given the likelihood of developing robust pulmonary responses after inhalation of particles and fibers, it is rational to assume that at an equivalent lung burden to CNTs, workers may also be susceptible to developing these adverse lung effects. Nevertheless, mounting evidence from animal studies raises serious health concerns for occupational hazards associated with CNT exposure. Due to the lack of safety guidelines and suitable biomarkers for CNT workplace exposure, occupational risk estimates are extrapolated from existing rodent models [7, 28].

\section{Biological activities of CNT}

\section{Oxidative stress}

One of the most frequently reported toxicity endpoints is the formation of ROS, which can be either protective or harmful during biological interactions. Oxidative stress is an imbalance between the production of ROS and their elimination by the host's defense systems. Oxidative stress amounts to DNA damage, lipid peroxidation and activation of signaling networks associated with loss of cell growth, fibrosis and carcinogenesis [29, 30]. Following the exposure to CNTs, ROS are induced intrinsically within the cell, extrinsically or indirectly via the effect of internalized CNTs on mitochondrial respiration. The critical factors driving CNT-induced ROS generation include active redox cycling on the surface of nanoparticles (NPs), oxidative functional groups on the NPs and NP-cell interactions, especially in the lungs where there is a rich pool of ROS producers like neutrophils and macrophages [29]. CNT-induced oxidative stress is mainly followed by inflammation, cell injury, apoptosis and activation of cellular signaling pathways such as mitogen-activated protein kinase (MAPK) and nuclear factor (NF)- 
$\kappa \mathrm{B}$, which are implicated in the pathogenesis of lung fibrosis $[31,32]$. Several studies have demonstrated the role of CNTs in oxidative stress, one of the mechanisms being mitochondrial damage [9].MWCNT exposure induces ROS production in a variety of cell lines as well as in vivo [9, 33, 34]. Likewise, studies have demonstrated SWCNT-induced ROS generation in multiple cell lines $[10,35,36]$ and activation of intracellular signaling pathways including MAPK, Akt, AP-1 and NF-kB in mesothelial cells in a dose-dependent manner [37]. These findings indicate that CNT-induced oxidative stress may serve as an important intermediate endpoint while assessing pulmonary toxicity of CNTs.

\section{Genotoxicity}

Since CNTs have been shown to possess asbestos-like pathogenicity, it is necessary to characterize their genotoxic potential. Both MWCNT and SWCNT have been shown to exert genotoxic effects in number of in vitro settings as evidenced by DNA strand breakage, DNA base oxidation, chromosomal aberrations and gene mutations [38-42]. Intrinsic ROS production, CNT-induced inflammation and oxidative stress are some of the proposed mechanisms for CNTdriven genotoxicity $[43,44]$. More recent studies have revealed the potential toxicity associated with chronic exposure of CNTs which results in a malignant and neoplastic phenotype and tumorigenesis as well a novel feature of stem-like induction in human lung cells [45, 46].

\section{Inflammation}

Inflammation is commonly observed upon inhalation of CNTs. Characterization of the inflammatory process upon CNT exposure is necessary since inflammation is associated with other pathologic disorders such as fibrosis and cancer. Given the interplay between the inflammatory response and ROS generation, both effects are closely linked and one leads to the other [44]. Particle deposition in the lung causes recruitment of inflammatory cells that generate 
ROS, clastogenic factors and cytokines, either harming or stimulating resident lung cells [32].

Oxidative stress produced from CNT exposure activates pro-inflammatory transcription factors such as NF- $\mathrm{kB}$, AP-1 and MAPK [37]. The inflammatory cytokines tumor necrosis factor (TNF)-alpha and interleukin (IL)-1beta are well known mediators of fibrotic lung diseases by activating the pro-fibrotic transforming growth factor (TGF)-b and platelet derived growth factor (PDGF), respectively. Such stimulation leads to differentiation of fibroblasts to myofibroblasts and their production of extracellular matrix (ECM) proteins [32, 47, 48]. Several reports indicate that MWCNTs and SWCNTs induce a panel of pro-fibrotic inflammatory cytokines and chemokines in human lung cells including TNF-a and IL-8 [49], IL-1b, IL-6, IL-10 and monocyte chemoattractant protein (MCP)-1 [9], NLRP3 inflammasome (Paloma"ki et al., 2011), IL-13/33 [50] and inflammatory enzymes such as cyclooxygenase (COX)-2 and inducible nitric oxide synthase (iNOS) [51].

\section{Permeability barrier function}

Alterations in respiratory barrier function is of particular importance to CNT-induced toxicity since respiratory epithelial cells present a protective barrier against inhaled particles and constitute a major determinant of the interaction of the particles with other body compartments. Epithelial cells are responsible for the formation and maintenance of tight junction barrier, only permitting polarized secretory functions and preventing access to xenobiotics and pathogens [52]. Consequently, respiratory barrier function plays a pivotal role in CNT-related inhalation hazards. MWCNTs have been shown to alter the paracellular permeability of airway epithelial cells by interfering with the formation of tight junctions. The permeability altering effect of CNTs was shown to be dependent on fiber length and functionalization [53, 54]. However, the 
underlying mechanisms of alteration and its effect on CNT-induced pathogenesis have not been clearly elucidated.

\section{Pulmonary toxicity of CNTs in vivo}

\section{Pulmonary function}

CNTs can significantly hamper pulmonary function as demonstrated by an increase in expiratory time [20], reduced bacterial clearance activity [22], and decreased lung compliance [55]. Both SWCNT and MWCNT exacerbate ovalbumin-induced allergic airway inflammation in vivo [5658]. Collectively, these studies imply that individuals with pre-existing respiratory conditions such as allergic asthma and bronchitis are more likely to be susceptible to CNT exposure [32].

\section{Pleural disease}

The structural similarity between asbestos and CNTs has raised a concern about the potential damaging effect of CNTs on pleural mesothelium. Studies have demonstrated CNTs to reach the pleural space [59], migrate from subpleural to intrapleural tissue [60], induce mesothelial cell proliferation and mesothelioma formation [61, 62], and cause inflammation and pleural fibrosis [13]. MWCNT injected into the peritoneal cavity of mice or rats generated fiber lengthdependent inflammation/genetic damage and mesothelioma [15]. These findings are important in understanding whether CNTs have the potential to cause asbestos-like pleural lesions and whether workers are at risk of developing mesothelioma after chronic CNT exposure.

\section{Fibrosis}

Over the past few years, there has been a considerable growth in the literature base documenting dose and time-dependent biological effects of SWCNT and MWCNT exposure. Some early reports provided evidence for intrinsic toxicity of CNTs and potential exposure to respirable 
CNT particulate matters in workers $[17,20]$. Pharyngeal aspiration of SWCNT in mice at the dose of $10-40 \mu \mathrm{g} /$ mouse induced acute inflammation, early onset of granulomas, alveolar wall thickening, and progressive fibrosis [17]. Subsequent studies determined the influence of the route of administration and dispersion status on the end toxic response. For instance, a short-term SWCNT inhalation exposure was more effective than pharyngeal aspiration in causing lung toxicity in mice as evidenced by a 4-fold greater inflammation and fibrosis than aspiration of the same mass lung burden owing to aerosolized particle size during inhalation [20, 22]. Poorly dispersed SWCNT in suspension was found to be restricted to the proximal alveolar regions resulting in granulomatous lesions, whereas well-dispersed SWCNT deposited deeper into the interstitial and pleural areas of the lung causing parenchymal granulomas and interstitial fibrosis $[63,64]$. Likewise, the biopersistence of MWCNT has been illustrated by a number of in vivo studies suggesting similar spectrum of dose- and time-dependent pulmonary fibrogenic responses [34, 39, 65]. Contrary to SWCNT, MWCNT was shown to induce a significant increase in fibrosis after pulmonary aspiration compared to inhalation [13]. Acute pulmonary exposure to inhaled MWCNT induced inflammation, fibrosis, and rare pleural penetration indicating that MWCNT can reach the pleura after inhalation [66]. A recent long-term inhalation study demonstrated that MWCNT induced a fibrotic response that persisted up to 336 days postexposure and exhibited particle size-dependent retention in the lungs [67]. Furthermore, inhaled MWCNT were found to translocate to the parietal pleura, the respiratory musculature, liver, kidney, heart and brain where they accumulate with time following exposure [68].

Despite similar qualitative fibrogenic responses, both MWCNT and SWCNT differ significantly in how they are distributed within the lungs. SWCNT is more likely to interact with the lung owing to its greater fiber count per mass than MWCNT [13]. Moreover, MWCNT is known to be 
recognized and phagocytosed by alveolar macrophages $[34,56]$, whereas SWCNT evades macrophages which facilitates its entry into the alveolar interstitium [13]. However, both forms of CNT induce damaging lung responses in vivo at doses physiologically relevant to potential worker exposures. Pulmonary exposure to CNTs has illustrated systemic responses such as increased inflammatory mediators in the blood, diminished ability of coronary arterioles to respond to dilators, oxidative stress in aortic tissue and increased plaque formation in an atherosclerotic mouse model [69-71]. Additional research is needed to understand the mechanisms underlying these pulmonary and systemic responses to CNTs.

Besides the fibrogenic damage, long-term CNT exposure has been shown to promote malignant transformation and induction of tumorigenesis, initiation of lung adenocarcinoma and tumor like morphology in vivo at doses which approximate potential human occupational exposures [72, 73]. 


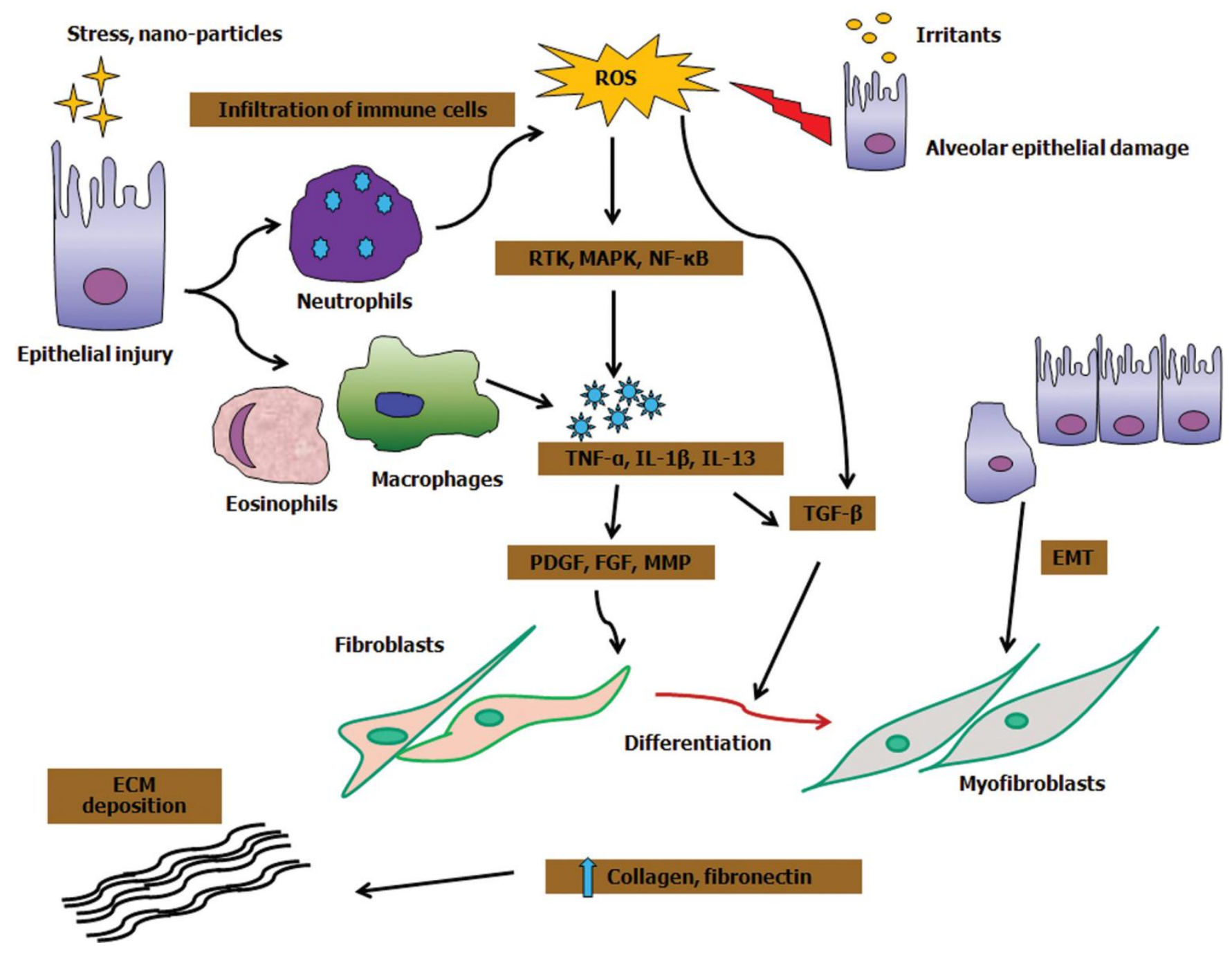

Figure I: Mechanisms of Lung Fibrosis

Irritants such as nano-particles induce epithelial injury resulting in infiltration of immune cells such as neutrophils, eosinophils and alveolar macrophages at the site of tissue injury. Activated neutrophils can exaggerate the ROS response. Moreover, ROS generation upon particle-cell interactions activates cytokine growth receptor cascade. ROS-dependent activation of RTKs, MAPK, Akt and NF- $\kappa B$ results in expression of genes related to inflammation and fibrosis. ROS can also activate TGF- $\beta$ to mediate the fibrogenic effects. Recruitment of leukocytes induces key pro-fibrotic cytokines including TNF-a, IL-1 $\beta$ and IL-13, which can further damage the epithelial cells. TNF- $\alpha$ and IL-1 $\beta$ stimulation upregulates TGF-b and PDGF, respectively, which in turn increase collagen production via fibroblast and myofibroblast proliferation. Alternatively, fibroblasts can directly induce fibrosis via proliferation and differentiation into myofibroblasts. In addition, epithelial cells undergoing EMT expand the pool of fibroblasts and myofibroblasts thereby driving fibrogenesis. 
During the development of fibrosis, several common cellular events occur including epithelial cell injury, infiltration of inflammatory cells, proliferation and transformation of fibroblasts into myofibroblasts, and synthesis and deposition of ECM [9]. Unique to CNTs is their nonbiodegradable and biopersistent nature which likely prolongs the fibrotic process. Multiple factors determine the severity and duration of CNT-induced fibrosis, which are discussed below and are summarized in Figure 1.

\section{CNT-Induced Fibrosis}

\section{Role of ROS}

ROS is widely known to be involved in epithelial cell injury and fibrogenesis [74]. CNT exposure results in ROS-dependent activation of several transcription factors and signaling pathways including NF- $\mathrm{BB}$, signal transducer and activator of transcription (STAT)-1, MAPK and receptor tyrosine kinases (RTK), which are involved in the regulation of inflammation and fibrosis [32]. CNT-induced ROS generation is likely to be a result of frustrated phagocytosis which refers to the failure of the macrophage to entirely engulf the long fibers, thus resulting in an inflammatory condition [1]. Additionally, specific properties of CNTs such as metal contaminants including iron, cobalt, tungsten and vanadium as well as reactive groups on the CNT surface that have been attributed to pulmonary fibrotic response may induce oxidative stress $[21,31,75,76]$. Some of the common metal contaminants associated with pulmonary fibrosis include iron, cobalt, tungsten and vanadium.

\section{Role of pre-existing inflammation}

Little has been reported about the risk and possibility of a fibrogenic response following CNT exposure in conditions with pre-existing inflammation. Studies have reported how bacterial- 
derived products modify CNT-related toxicities. In mice with prior bacterial infection, pharyngeal aspiration of SWCNTs promotes inflammatory response, collagen synthesis, reduces phagocytosis of bacteria by macrophages and bacterial clearance from the lungs, thereby increasing host susceptibility to lung fibrosis [22]. Pre-exposure with lipopolysaccharide, an endotoxin, exaggerates the fibrotic effects of CNTs by (i) intensifying acute inflammatory response [77], (ii) increasing PDGF and its receptor resulting in fibroblast chemotaxis and proliferation [78] and by (iii) elevating the expression of TNF-a and IL-1b resulting in collagen synthesis and ECM deposition [22]. Together, these results support the role of pre-existing inflammation in promoting CNT-induced lung fibrosis.

\section{Role of inflammation}

Numerous inflammatory and pro-fibrotic mediators such as TNF-a, IL-1b and TGF-b have been implicated in the pathogenesis of fibrosis. Infiltration of immune cells such as eosinophils, neutrophils and macrophages results in tissue injury and loss of epithelial integrity, thus promoting tissue repair and fibrosis [79]. As mentioned earlier, CNT exposure initiates an inflammatory cascade of cytokines in association with oxidative stress. There are reports documenting inflammation induced fibrosis following CNT exposure. For example, MWCNTs induce TNF-a resulting in fibrosis in vivo [19]. SWCNTs upon pharyngeal aspiration induce robust inflammation and an early onset of fibrogenic response in vivo characterized by the secretion of TNF-a, IL-1b and TGF-b as well as several biomarkers of oxidative stress. The extent of fibrosis is dose and time dependent [20]. Inflammation-driven fibrosis causes granuloma formation associated with epithelial hypertrophy, alveolar thickening and interstitial fibrosis $[19,22]$. Intratracheal instillation of SWCNTs results in early onset of lung fibrosis driven by the secretion of a panel of inflammatory cytokines [14]. 


\section{Role of angiogenesis}

Angiogenesis is essential in the formation of new blood vessels, wound healing and tissue repair, thus important in fibrogenesis. Vascular endothelial growth factor (VEGF) regulates the angiogenic response by controlling the migration, proliferation and vasculature of endothelial cells. Initial studies demonstrated neovascularization leading to anastomoses between the systemic and pulmonary microvasculature of patients with pulmonary fibrosis [80]. VEGF and TGF-b interact closely with respect to angiogenic and fibrogenic effects. A recent in vitro study showed that SWCNT-induced fibroblast proliferation and collagen production is mediated by VEGF and TGF- $\beta 1$ [10]. This study also suggested a positive feedback loop between TGF-b and VEGF during angiogenesis, which promotes the fibrotic process after SWCNT treatment.

\section{Role of epithelial mesenchymal transition}

Epithelial mesenchymal transition (EMT), a process characterized by the transition of fully differentiated epithelial cells to a mesenchymal phenotype, has been suggested to play a key role in fibrosis by serving as a cellular source of resident fibroblasts/myofibroblasts and by causing a loss of epithelial barrier that acts as a defense during advanced stage fibrosis [81]. However, whether or not EMT is a major source of these interstitial lung cells during fibrosis in vivo is still unclear. EMT is brought about by various external stimuli including growth factors, cytokines and hormones [82]. With regards to CNT-induced EMT, SWCNT exposure induced EMT of lung epithelial cells which contributed significantly to fibroblast expansion [83]. A recent study showed that the activation of the TGF- $\beta / \mathrm{Smad} 2$ signaling plays a critical role in the process of the fibroblast-to-myofibroblast transition and the EMT induced by MWCNTs [84].

\section{Physicochemical properties of CNTs affecting toxicities}


Physicochemical factors alter the cytotoxicity of CNTs with respect to their cellular uptake, internalization, phagocytosis and clearance from the body [26, 27]. For instance, even though the functionalization of CNTs may aid their solubility and dispersion, it has been speculated to facilitate their uptake and internalization into the systemic circulation. More detailed effects of physicochemical properties of CNTs on their biological activities are provided below and are summarized in Tables 1,2 and 3.

\section{Conclusions}

The ability of CNTs to cause acute toxicities and chronic fibrotic effects depends on several physicochemical factors such as particle dimension, dispersion status, functionalization and the presence of transition metals. Understanding these factors will enable the design of safer CNT products and their utilization. The cytotoxic and fibrogenic effects of CNTs appear to be associated with their ability to induce oxidative stress and inflammatory and fibrogenic cytokines. There is a close connection between oxidative stress and inflammatory response, as well as cross-talk between inflammation and fibrosis as indicated by the multifunctional roles of the induced cytokines, e.g. TGF-b, PDGF and MMPs. Interestingly, however, there have been reports showing CNT-induced fibrosis with minimum inflammation and oxidative injury, suggesting alternative pathways and mechanisms of fibrosis. Apart from the molecular and cellular changes, other biological factors such as angiogenesis and EMT can also influence

fibrosis. EMT may contribute to the increased fibroblasts/myofibroblasts during CNT-induced fibrosis through TGF-b, Smad and b-catenin signaling. Similarly, angiogenesis may promote fibrosis through VEGF-mediated fibroblast proliferation and collagen synthesis.

\section{Understanding Mechanism for CNT-Induced Pulmonary Fibrosis}


Given the fibrogenic potential of CNT, major concern exists about the long-term human health risks associated with chronic pulmonary CNT exposures. Several studies have demonstrated the fibrogenic effects of CNTs given their ability to translocate into the surrounding areas in the lung causing granulomatous lesions and interstitial and sub-pleural fibrosis. However, the mechanisms underlying the disease process remain obscure due to the lack of understanding of the cellular interactions and molecular targets involved. Since pulmonary fibrosis is characterized via abnormal tissue repair, collagen production and excessive ECM accumulation, identifying the cells that are the source of ECM production is fundamental to the understanding of fibrosis mechanisms. Currently the paradigm of stem cells is being evaluated in dysfunctional lung remodeling. Recent studies have demonstrated the pathogenic role of putative stem cells in early stages of pulmonary fibrosis [85-87].

The role of stem cells in nanomaterial-induced pulmonary fibrosis is unknown. Since fibroblasts are the key players in fibrogenesis, we hypothesize that CNT exposure in fibroblasts induce fibroblast stem-like cells (FSCs) which are critical for the CNT-induced fibrogenic response.

Our central hypothesis is that upon exposure to fibroblasts CNT are capable of inducing FSC which are crucial for the fibroblast to myofibroblast transformation and the development of fibrosis. We also hypothesize that oxidative stress induced by CNT is essential for the stemness development.

The long term goal of this study was to develop an in vitro model which will be predictive of the NM-induced fibrogenic response in vivo for a) detailed mechanistic study of stem-cell niche in CNT-induced lung fibrogenesis, b) studying the role of oxidative stress in regulating fibrosis 
stem cells and their fibrogenic effects, and c) investigating the ability of different physicochemical parameters of CNT to induce FSC.

\section{Specific Aims}

Aim 1: Characterize the role of fibroblast stem-like cells in CNT-induced lung fibrosis in vitro

1.1 Determine if CNT is capable of inducing FSC from normal lung fibroblasts.

1.2 Determine the functional role of FSC as a source of myofibroblasts and collagen production.

1.3 Evaluate the role of FSCs in fibrotic nodule formation in vitro.

Through this part of the study, we documented the evidence of FSC and their potential role in CNT-induced fibrogenesis in in vitro settings. Additionally, we demonstrated the role of FSCs in fibrogenesis through their upregulation of collagen and alpha-smooth muscle actin. The developed in vitro model investigated whether stemness dictates the fibrogenic response induced by CNT exposure.

\section{Aim 2: Determine whether reactive oxygen species (ROS) production is critical for stemness development in the event of CNT-induced fibrosis}

2.1 Test whether ROS leads to stem cell phenotype in fibroblasts and identify which ROS are important for the stemness development

2.2 Identify the antioxidant enzymes involved in the regulation of ROS required for inducing stemness phenotype in fibroblasts.

The findings from this study reported the effect of oxidative stress on fibroblast stem-like cell generation and fibrogenesis induced by CNT. Our study showed that, ROS, particularly the

peroxide species play a key role in SWCNT-induced stemness development and fibrogenic 
effects. Moreover, this study also documented the effect of fiber length and surface modification on CNT-elicited oxidative stress.

\section{Aim 3: Examine whether physicochemical characteristics of CNT govern the ability to induce the stemness phenotype and thereby the resulting fibrogenic response}

3.1 Test whether surface modifications of single-walled CNT (SWCNT) via different functional groups $\{$ including carboxyl $(\mathrm{COOH})$, nitrogen containing $(\mathrm{NC})$, and hydroxyl $(\mathrm{OH})\}$ can alter the stemness development.

3.2 Test whether the length of SWCNT is capable of driving the stem-like behavior as well as the resulting fibrogenic response.

3.3 Develop a model which determines that the stemness phenotype is a predictive tool of the fibrogenic response in vivo.

The results presented under this study revealed the role of physicochemical parameters of SWCNT, particularly fiber length and surface modification in stemness development. Our data indicated the potential usefulness of the in vitro stemness induction model as a predictive screening tool for fibrogenicity testing of nanomaterials. 


\section{Studies related to surface functionalization, size and surface area, presence of metal impurities and dispersion status}

\section{Table 1: Surface functionalization}

\begin{tabular}{|c|c|c|}
\hline Type of CNT & System & Effect \\
\hline $\begin{array}{l}\text { SWCNT, } \\
\text { Control; and acid functionalized }\end{array}$ & $\begin{array}{l}\text { LA4 mouse lung epithelial cells } \\
\text { and in vivo in CD1 mice }\end{array}$ & $\begin{array}{l}\text { AF-SWCNT more cytotoxic than SWCNT in } \\
\text { vitro; exerted stronger inflammatory response } \\
\text { in vivo than control SWCNT }\end{array}$ \\
\hline $\begin{array}{l}\text { MWCNT, } \\
\text { Functionalized; and non- } \\
\text { functionalized }\end{array}$ & $\begin{array}{l}\text { In vivo bone marrow cells of } \\
\text { Swiss-Webster mice }\end{array}$ & $\begin{array}{l}\text { Functionalized MWCNT induced greater } \\
\text { clastogenic/genotoxic effects than non- } \\
\text { functionalized MWCNT }\end{array}$ \\
\hline $\begin{array}{l}\text { SWCNT, } \\
\text { SWCNT-phenyl- } \mathrm{SO}_{3} \mathrm{H} ; \\
\text { SWCNT-phenyl- } \mathrm{SO}_{3} \mathrm{Na} ; \text { and } \\
\text { SWCNT-phenyl- }(\mathrm{COOH})_{2}\end{array}$ & Human dermal fibroblasts & $\begin{array}{l}\text { Cytotoxicity dependent on the degree of } \\
\text { sidewall functionalization }\end{array}$ \\
\hline $\begin{array}{l}\text { MWCNT, } \\
\text { Pristine; and carboxylated }\end{array}$ & In vivo mice & $\begin{array}{l}\text { The degree of functionalization was inversely } \\
\text { proportional to hepatic toxicity }\end{array}$ \\
\hline $\begin{array}{l}\text { MWCNT, } \\
\text { Pristine; COOH-MWCNT; and } \mathrm{NH}_{2-} \\
\text { MWCNT }\end{array}$ & A549 pneumocytes, in vivo & $\begin{array}{l}\text { pulmonary toxicity, inflammatory response, } \\
\text { irrespective of nanotube functionalization }\end{array}$ \\
\hline $\begin{array}{l}\text { MWCNT, } \\
\text { As-prepared (AP); COOH; PEG; } \\
\mathrm{NH}_{2} ; \text { sw-NH } \mathrm{NH}_{2} ; \text { and PEI-MWCNT }\end{array}$ & $\begin{array}{l}\text { BEAS-2B and THP- } 1 \text { cells, in } \\
\text { vivo }\end{array}$ & $\begin{array}{l}\text { Chronic lung inflammation, fibrosis, and } \\
\text { collagen deposition: PEI-MWCNT induced the } \\
\text { strongest } \\
\text { effects, while } \mathrm{NH}_{2} \text { and sw-NH}-\mathrm{MWCNT} \\
\text { exerted similar effects, and COOH and PEG- } \\
\text { MWCNT induced weaker effects than AP- } \\
\text { MWCNT in vitro and in vivo }\end{array}$ \\
\hline
\end{tabular}

Study

[88] 
MWCNT; CNF; and carbon

nanoparticles

SWCNT,

Purified; and 6-amino-hexanoic acid-

derivatized (AHA-SWCNT)
Human lung tumor cells

Human epidermal keratinocytes
Functionalized carbon nanoparticles most toxic compared to MWCNT and CNF

Functionalization induced mild cytotoxic responses and maintained cell viability
[93]

[94]

\section{Table 2: Size and surface area}

\section{Type of CNT \\ Purified MWCNT, \\ Short $(220 \mathrm{~nm})$; and long $(825 \mathrm{~nm})$ \\ SWCNT, \\ Long (0.5-100 $\mu \mathrm{m})$; and short (0.5-2 \\ $\mu \mathrm{m})$ \\ MWCNT, \\ Long $(5-9 \mu \mathrm{m})$; and short $(0.5-2 \mu \mathrm{m})$}

\section{MWCNT}

Long $(13 \mu \mathrm{m})$; and $(56 \mu \mathrm{m})$;

tangled $(1-5 \mu \mathrm{m})$; and $(5-20 \mu \mathrm{m})$

\section{MWCNT,}

Short (1-10 $\mu \mathrm{m})$; long tangled (10-50 $\mu \mathrm{m})$; long needle-like ( $>50 \mu \mathrm{m})$;

asbestos $(4.6 \mu \mathrm{m})$; and carbon black

\section{MWCNT,}

Long; short; tangled;

Nickel nanowires (long and short)

\section{MWCNT,}

\section{System}

Human acute monocytic

leukemia THP-1 cell line

Human epithelial Calu-3

In vivo

Primary human macrophages

In vivo

Human peritoneal mesothelial

\section{Effect}

Long CNT induced more inflammation

Study

[95]

Long MWCNT and SWCNT caused

significant disruption of barrier function

Length-dependent inflammation and granuloma formation

Enhanced activation of NRLP3 inflammasome and secretion of IL- $1 \beta$, IL- $1 \alpha$ by long MWCNT

Length-dependent retention of CNTs into lung pleura resulting in sustained inflammation and progressive fibrosis

Thin MWCNT more inflammatory and 
Dispersed thin $(50 \mathrm{~nm})$; aggregative $(2-20 \mathrm{~nm})$; and thick $(150 \mathrm{~nm})$

\section{Purified MWCNT,}

Thick $(70 \mathrm{~nm})$ and thin $(9.4 \mathrm{~nm})$

SWCNT (138 m²/g); carbon nanofibers; CNF $\left(21 \mathrm{~m}^{2} / \mathrm{g}\right)$; and asbestos $\left(8 \mathrm{~m}^{2} / \mathrm{g}\right)$

SWCNT; MWCNT; active carbon; carbon black and carbon graphite

MWCNT; CNF; carbon nanoparticles

\section{MWCNT,}

short; and long

MWCNT; (NM400 and NM402) and Crocidolite

\section{SWCNT,}

Long SWCNT fibers $(\sim 13 \mu \mathrm{m})$;

Short SWCNT fibers $(\sim 1-2 \mu \mathrm{m})$ cells

carcinogenic

Murine alveolar macrophages

Thin MWCNT more toxic in vitro and in vivo

[98] and in vivo in rats

In vivo $\mathrm{C} 57 \mathrm{BL} / 6$ mice

SWCNT with high surface area induced more oxidative stress, inflammation, lung damage and fibrosis than $\mathrm{CNF}$ and asbestos

Human fibroblast cells

Human lung tumor cells

Murine macrophages

Human fibroblast cells, in vivo C57BL/6 mice

Long MWCNT induced more cell proliferation in vitro and fibrosis in vivo

Human lung fibroblasts, in vivo Length-dependent ROS generation, TGF- $\beta$ and C57BL/6 mice

Size and aspect ratio-dependent cytotoxicity of

Short > long MWCNT in pro-inflammatory cytokine secretion and oxidative stress collagen I expression

\section{Table 3a: Presence of metal impurities}


associated iron content

MWCNT,

99\% purity; 97\% purity; and acid-

treated $97 \%$ purity (surface oxidation

$8 \%$ )

26wt\% iron-rich SWCNT
Human neuroblastoma cells

Loss of cell viability with reduction in CNT purity

Loss of intracellular thiols and lipid hydroperoxide accumulation in macrophages
Murine RAW 264.7

macrophages

\section{Table 3b: Dispersion status}

\section{SWCNT,}

(poor; and well dispersed)
In vivo $\mathrm{C} 57 \mathrm{BL} / 6$ mice

$$
\text { 2B cells }
$$

Poorly dispersed SWCNT - proximal alveolar regions resulting in granulomatous lesions; well-dispersed CNT-alveolar interstitial and pleural areas causing parenchymal granulomas and interstitial fibrosis

SWCNT,

Survanta dispersed (SD-SWCNT); and non-dispersed (ND-SWCNT)
Human lung epithelial BEAS-
SD-SWCNT more fibrogenic than NDSWCNT both in vitro and in vivo
[105] 


\section{References}

1. Donaldson K, Murphy FA, Duffin R, Poland CA. Asbestos, carbon nanotubes and the pleural mesothelium: a review of the hypothesis regarding the role of long fibre retention in the parietal pleura, inflammation and mesothelioma. Part Fibre Toxicol. 2010;7:5.

2. Maynard AD, Baron PA, Foley M, Shvedova AA, Kisin ER, Castranova V. Exposure to carbon nanotube material: aerosol release during the handling of unrefined single-walled carbon nanotube material. J Toxicol Environ Health Part A. 2004; 67:87-107.

3. Patel V. Global carbon nanotubes market outlook: industry beckons. Nanotech Insights. 2011;2:31-5.

4. Song Y, Li X, Du X. Exposure to nanoparticles is related to pleural effusion, pulmonary fibrosis and granuloma. Eur Respir J. 2009; 34:559-67.

5. DuPont. Nano risk framework output worksheet for: DuPont Crystar 6920 PET poly-(ethylene terephthalate) resin with sepiolite clay, Pangel S-9 as an encapsulated nanodispersed filler. 2008 Available from: http://www.epa.gov/opptintr/nano/dupont2.pdf [last accessed 2 Jan 2013].

6. Kolosnjaj J., Szwarc H., Moussa F. Toxicity studies of carbon nanotubes. Adv. Exp. Med. Biol.2007;620:181-204.

7. Stella GM. Carbon nanotubes and pleural damage: perspectives of nanosafety in the light of asbestos experience. Biointerphases. 2011;6:P1-17.

8. Jaurand M.F., Renier A., Daubriac J. Mesothelioma: Do asbestos and carbon nanotubes pose the same health risk? Part. Fibre Toxicol. 2009;6:16.

9. He X, Young S, Schwegler-Berry D, Chisholm WP, Fernback JE, Ma, Q. Multiwalled carbon nanotubes induce a fibrogenic response by stimulating reactive oxygen species production, activating NFB signaling, and promoting fibroblast-to-myofibroblast transformation. Chemical Res Toxicol. 2011; $24: 2237-48$

10. Azad N, Iyer AK, Wang L, Liu Y, Lu Y, Rojanasakul Y. Reactive oxygen species-mediated p38 MAPK regulates carbon nanotube-induced fibrogenic and angiogenic responses. Nanotoxicology. 2013;7:157-68.

11. Patlolla AK, Hussain SM, Schlager JJ, Patlolla S, Tchounwou PB. Comparative study of the clastogenicity of functionalized and nonfunctionalized multiwalled carbon nanotubes in bone marrow cells of Swiss-Webster mice. Environ Toxicol. 2010a; 25:608-21.

12. Patlolla A, Knighten B, Tchounwou P. Multi-walled carbon nanotubes induce cytotoxicity, genotoxicity and apoptosis in normal human dermal fibroblast cells. Ethn Dis. 2010b;20:S1-65-72.

13. Mercer RR, Hubbs AF, Scabilloni JF, Wang L, Battelli LA, Friend S, et al. Pulmonary fibrotic response to aspiration of multi-walled carbon nanotubes. Particle Fibre Toxicol. 2011;8:21.

14. Park E, Roh J, Kim S, Kang MS, Han YA, Kim Y, et al. A single intratracheal instillation of singlewalled carbon nanotubes induced early lung fibrosis and subchronic tissue damage in mice. Archiv Toxicol. 2011;85:1121-31. 
15. Nagai H, Okazaki Y, Chew SH, Misawa N, Yamashita Y, Akatsuka S, et al. Diameter and rigidity of multiwalled carbon nanotubes are critical factors in mesothelial injury and carcinogenesis. Proc Natl Acad Sci USA. 2011;108:E1330-8.

16. Wang L, Mercer RR, Rojanasakul Y, Qiu A, Lu Y, Scabilloni JF, et al. Direct fibrogenic effects of dispersed single-walled carbon nanotubes on human lung fibroblasts. J Toxicol Environ Health Part A. 2010b;73:410-22.

17. Lam C, James JT, McCluskey R, Hunter RL. Pulmonary toxicity of single-wall carbon nanotubes in mice 7 and 90 days after intratracheal instillation. Toxicol Sci. 2004;77:126-34.

19. Muller J, Huaux F, Moreau N, Misson P, Heilier JF, Delos M, et al. Respiratory toxicity of multi-wall carbon nanotubes. Toxicol Appl Pharmacol. 2005;207:221-31.

20. Shvedova AA, Kisin ER, Mercer R, Murray AR, Johnson VJ, Potapovich AI, et al. Unusual inflammatory and fibrogenic pulmonary responses to single-walled carbon nanotubes in mice. Am $\mathrm{J}$ Physiol Lung Cell Mol Physiol. 2005; 289:L698-708.

21. Warheit DB, Laurence BR, Reed KL, Roach DH, Reynolds GA, Webb TR. Comparative pulmonary toxicity assessment of single-wall carbon nanotubes in rats. Toxicol Sci: Off J Soc Toxicol. 2004; $77: 117-25$.

22. Shvedova AA, Kisin E, Murray AR, Johnson VJ, Gorelik O, Arepalli S, et al. Inhalation vs. aspiration of single-walled carbon nanotubes in C57BL/6 mice: inflammation, fibrosis, oxidative stress, and mutagenesis. Am J Physiol Lung Cell Mol Physiol. 2008;295:L552-65.

23. Jia G, Wang H, Yan L, Wang X, Pei R, Yan T, et al. Cytotoxicity of carbon nanomaterials: singlewall nanotube, multi-wall nanotube, and fullerene. Environ Sci Technol. 2005;39:1378-83.

24. Lam CW, James JT, McCluskey R, Arepalli S, Hunter RL. A review of carbon nanotube toxicity and assessment of potential occupational and environmental health risks. Crit Rev Toxicol. 2006; 36:189-217.

25. Sinha N, Yeow JT. Carbon nanotubes for biomedical applications. IEEE Trans Nanobioscience. 2005;4:180-95.

26. Borm PJ, Robbins D, Haubold S, Kuhlbusch T, Fissan H, Donaldson K, et al. The potential risks of nanomaterials: a review carried out for ECETOC. Part Fibre Toxicol. 2006;3:11.

27. Oberdo“rster G, Maynard A, Donaldson K, Castranova V, Fitzpatrick J, Ausman K, et al. Principles for characterizing the potential human health effects from exposure to nanomaterials: elements of a screening strategy. Particle Fibre Toxicol. 2005;2:8.

28. NIOSH. Current Intelligence Bulletin: Occupational Exposure to Carbon Nanotubes 2010.

29. Knaapen AM, Borm PJ, Albrecht C, Schins RP. Inhaled particles and lung cancer. Part A: mechanisms. Int J Cancer. 2004;109:799-809.

30. Valko M, Rhodes CJ, Moncol J, Izakovic M, Mazur M. Free radicals, metals and antioxidants in oxidative stress-induced cancer. Chem Biol Interact. 2006;160:1-40.

31. Bonner JC. The epidermal growth factor receptor at the crossroads of airway remodeling. Am $\mathbf{J}$ Physiol Lung Cell Mol Physiol. 2002;283:L528-30. 
32. Bonner JC. Lung fibrotic responses to particle exposure. Toxicol Pathol. 2007;35:148-53.

33. Clichici S, Biris AR, Tabaran F, Filip A. Transient oxidative stress and inflammation after intraperitoneal administration of multiwalled carbon nanotubes functionalized with single strand DNA in rats. Toxicol Appl Pharmacol. 2012;259:281-92.

34. Mitchell LA, Gao J, Wal RV, Gigliotti A, Burchiel SW, McDonald JD. Pulmonary and systemic immune response to inhaled multiwalled carbon nanotubes. Toxicol Sci: Off J Soc Toxicol. 2007; 100:203-14.

35. Manna SK, Sarkar S, Barr J, Wise K, Barrera EV, Jejelowo O, et al. Single-walled carbon nanotube induces oxidative stress and activates nuclear transcription factor-kappaB in human keratinocytes. Nano Lett. 2005;5:1676-84.

36. Shvedova AA, Kapralov AA, Feng WH, Kisin ER, Murray AR, Mercer RR, et al. Impaired clearance and enhanced pulmonary inflammatory/fibrotic response to carbon nanotubes in myeloperoxidasedeficient mice. Plos One. 2012;7:e30923.

37. Pacurari M, Yin XJ, Zhao J, Ding M, Leonard SS, Schwegler-Berry D, et al. Raw single-wall carbon nanotubes induce oxidative stress and activate MAPKs, AP-1, NF-kappaB, and Akt in normal and malignant human mesothelial cells. Environ Health Perspect. 2008;116:1211-17.

38. Kisin ER, Murray AR, Keane MJ, Shi XC, Schwegler-Berry D, Gorelik O, et al. Single-walled carbon nanotubes: geno- and cytotoxic effects in lung fibroblast V79 cells. J Toxicol Environ Health A. 2007;70:2071-2079.

39. Muller J, Decordier I, Hoet PH, Lombaert N, Thomassen L, Huaux F, et al. Clastogenic and aneugenic effects of multi-wall carbon nanotubes in epithelial cells. Carcinogenesis. 2008;29:427-433.

40. Sargent LM, Shvedova AA, Hubbs AF, Salisbury JL, Benkovic SA, Kashon ML, et al. Induction of aneuploidy by single-walled carbon nanotubes. Environ Mol Mutagen. 2009;50:708-717.

41. Sargent LM, Hubbs AF, Young SH, Kashon ML, Dinu CZ, Salisbury JL, et al. Single-walled carbon nanotube-induced mitotic disruption. Mutat Res. 2012;745:28-37.

42. Siegrist KJ, Reynolds SH, Kashon ML, Lowry DT, Dong C, Hubbs AF, et al. Genotoxicity of multiwalled carbon nanotubes at occupationally relevant doses. Part Fibre Toxicol. 2014;11:6.

43. Donaldson K, Poland CA. Inhaled nanoparticles and lung cancer - what we can learn from conventional particle toxicology. Swiss Med Wkly. 2012;142:w13547.

44. Oberdörster G. Safety assessment for nanotechnology and nanomedicine: concepts of nanotoxicology. J Intern Med. 2010;267:89-105.

45. Luanpitpong S, Wang L, Castranova V, Rojanasakul Y. Induction of stem-like cells with malignant properties by chronic exposure of human lung epithelial cells to single-walled carbon nanotubes. Part Fibre Toxicol. 2014;11:22.

46. Wang L, Stueckle TA, Mishra A, Derk R, Meighan T, Castranova V, et al. Neoplastic-like transformation effect of single-walled and multi-walled carbon nanotubes compared to asbestos on human lung small airway epithelial cells. Nanotoxicology. 2014;8:485-507. 
47. Mangum JB, Turpin EA, Antao-Menezes A, Cesta MF, Bermudez E, Bonner JC. Single-walled carbon nanotube (SWCNT)-induced interstitial fibrosis in the lungs of rats is associated with increased levels of PDGF mRNA and the formation of unique intercellular carbon structures that bridge alveolar macrophages in situ. Particle Fibre Toxicol. 2006;3:15.

48. Sime PJ, Marr RA, Gauldie D, Xing Z, Hewlett BR, Graham FL, et al. Transfer of tumor necrosis factor-alpha to rat lung induces severe pulmonary inflammation and patchy interstitial fibrogenesis with induction of transforming growth factor-beta1 and myofibroblasts. Am J Pathol. 1998;153:825-32.

49. Brown D, Kinloch I, Bangert U, Windle AH, Walter DM, Walker GS, et al. An in vitro study of the potential of carbon nanotubes and nanofibres to induce inflammatory mediators and frustrated phagocytosis. Carbon. 2007; 45:1743-56.

50. Beamer CA, Girtsman TA, Seaver BP, Finsaas KJ, Migliaccio CT, Perry VK, et al. IL-33 mediates multi-walled carbon nanotube (MWCNT)-induced airway hyperreactivity via the mobilization of innate helper cells in the lung. Nanotoxicology. 2013;7(6):1070-81.

51. Lee JK, Sayers BC, Chun KS, Lao HC, Shipley-Phillips JK, Bonner JC, et al. Multi-walled carbon nanotubes induce COX-2 and iNOS expression via MAP Kinasedependent and -independent mechanisms in mouse RAW264.7 macrophages. Particle Fibre Toxicol. 2012;9:14.

52. Schneeberger EE, Lynch RD. The tight junction: a multifunctional complex. Am J Physiol Cell Physiol. 2004;286:C1213-28.

53. Rotoli BM1, Bussolati O, Barilli A, Zanello PP, Bianchi MG, Magrini A, et al. Airway barrier dysfunction induced by exposure to carbon nanotubes in vitro: which role for fiber length? Human Exp Toxicol. 2009;28:361-8.

54. Rotoli BM, Bussolati O, Bianchi MG, Barilli A, Balasubramanian C, Bellucci S, et al.. Nonfunctionalized multi-walled carbon nanotubes alter the paracellular permeability of human airway epithelial cells. Toxicol Lett. 2008;178:95-102.

55. Wang X, Katwa P, Podila R, Chen P, Ke PC, Rao AM, et al. Multi-walled carbon nanotube instillation impairs pulmonary function in C57BL/6 mice. Part Fibre Toxicol. 2011;8:24.

56. Ryman-Rasmussen JP, Tewksbury EW, Moss OR, Cesta MF, Wong BA, Bonner JC. Inhaled multiwalled carbon nanotubes potentiate airway fibrosis in murine allergic asthma. Am J Respir Cell Mol Biol. 2009;40:349-358.

57. Ronzani C, Casset A, Pons F. Exposure to multi-walled carbon nanotubes results in aggravation of airway inflammation and remodeling and in increased production of epithelium-derived innate cytokines in a mouse model of asthma. Arch Toxicol. 2014;88(2):489-99. 
58. Li J, Li L, Chen H, Chang Q, Liu X, Wu Y, et al. Application of vitamin E to antagonize SWCNTsinduced exacerbation of allergic asthma. Sci Rep. 2014;4:4275.

59. Ryman-Rasmussen JP, Cesta MF, Brody AR, Shipley-Phillips JK, Everitt JI, Tewksbury EW, et al. Inhaled carbon nanotubes reach the subpleural tissue in mice. Nat Nanotechnol. 2009;4:747-751.

60. Poland CA, Duffin R, Kinloch I, Maynard A, Wallace WA, Seaton A, et al. Carbon nanotubes introduced into the abdominal cavity of mice show asbestos-like pathogenicity in a pilot study. Nat Nanotechnol. 2008;3:423-428.

61. Takagi A, Hirose A, Nishimura T, Fukumori N, Ogata A, Ohashi N, et al. Induction of mesothelioma in p53+/- mouse by intraperitoneal application of multi-wall carbon nanotube. J Toxicol Sci. 2008;33:105-116.

62. Xu J, Futakuchi M, Shimizu H, Alexander DB, Yanagihara K, Fukamachi K, et al. Multi-walled carbon nanotubes translocate into the pleural cavity and induce visceral mesothelial proliferation in rats. Cancer Sci.2012;103:2045-2050.

63. Mercer RR, Scabilloni J, Wang L, Kisin E, Murray AR, Schwegler-Berry D, et al. Alteration of deposition pattern and pulmonary response as a result of improved dispersion of aspirated single-walled carbon nanotubes in a mouse model. Am J Physiol Lung Cell Mol Physiol. 2008;294:L87-L97.

64. Murray AR, Kisin ER, Tkach AV, Yanamala N, Mercer R, Young SH, et al. Factoring-in agglomeration of carbon nanotubes and nanofibers for better prediction of their toxicity versus asbestos. Part Fibre Toxicol. 2012;9:10.

65. Porter DW, Hubbs AF, Mercer RR, Wu N, Wolfarth MG, Sriram K, et al. Mouse pulmonary doseand time course-responses induced by exposure to multi-walled carbon nanotubes. Toxicology. 2010;269:136-147.

66. Porter DW, Hubbs AF, Chen BT, McKinney W, Mercer RR, Wolfarth MG, et al. Acute pulmonary dose-responses to inhaled multi-walled carbon nanotubes. Nanotoxicology. 2013;7:1179-1194.

67. Mercer RR, Scabilloni JF, Hubbs AF, Battelli LA, McKinney W, Friend S, et al. Distribution and fibrotic response following inhalation exposure to multi-walled carbon nanotubes. Part Fibre Toxicol. 2013;10:33.

68. Mercer RR, Scabilloni JF, Hubbs AF, Wang L, Battelli LA, McKinney W, et al. Extrapulmonary transport of MWCNT following inhalation exposure. Part Fibre Toxicol. 2013;10:38.

69. Li Z, Hulderman T, Salmen R, Chapman R, Leonard SS, Young SH, et al. Cardiovascular effects of pulmonary exposure to single-wall carbon nanotubes. Environ Health Perspect. 2007;115:377-38228. 
70. Erdely A, Hulderman T, Salmen R, Liston A, Zeidler-Erdely PC, Schwegler-Berry D, et al. Cross-talk between lung and systemic circulation during carbon nanotube respiratory exposure. Potential biomarkers. Nano Lett.2009;9:36-43.

71. Stapleton PA, Minarchick VC, Cumpston AM, McKinney W, Chen BT, Sager TM, et al. Impairment of coronary arteriolar endothelium-dependent dilation after multi-walled carbon nanotube inhalation: a time-course study. Int J Mol Sci. 2012;13:13781-13803.

72. Wang L, Luanpitpong S, Castranova V, Tse W, Lu Y, Pongrakhananon V, et al. Carbon nanotubes induce malignant transformation and tumorigenesis of human lung epithelial cells. Nano Lett. 2011;11:2796-2803.

73. Sargent LM, Porter DW, Staska LM, Hubbs AF, Lowry DT, Battelli L, et al. Promotion of lung adenocarcinoma following inhalation exposure to multi-walled carbon nanotubes. Part Fibre Toxicol. 2014;11:3.

74. Inghilleri S1, Morbini P, Oggionni T, Barni S, Fenoglio C. In situ assessment of oxidant and nitrogenic stress in bleomycin pulmonary fibrosis. Histochem Cell Biol. 2006;125:661-9.

75. Antonini JM. Health effects of welding. Crit Rev Toxicol. 2003;33:61-103.

76. Shvedova AA, Castranova V, Kisin ER, Schwegler-Berry D, Murray AR, Gandelsman VZ, et al. Exposure to carbon nanotube material: assessment of nanotube cytotoxicity using human keratinocyte cells. J Toxicol Environ Health Part A. 2003;66:1909-26.

77. Inoue K, Koike E, Yanagisawa R, Hirano S, Nishikawa M, Takano H. Effects of multi-walled carbon nanotubes on a murine allergic airway inflammation model. Toxicol Appl Pharmacol. 2009;237:306-16.

78. Cesta MF, Ryman-Rasmussen JP, Wallace DG, Masinde T, Hurlburt G, Taylor AJ, et al. Bacterial lipopolysaccharide enhances PDGF signaling and pulmonary fibrosis in rats exposed to carbon nanotubes. Am J Respir Cell Mol Biol. 2010;43:142-51.

79. Wallace WAH, Fitch PM, Simpson AJ, Howie SEM. Inflammation-associated remodelling and fibrosis in the lung - a process and an end point. Int J Exp Pathol. 2007;88:103-10.

80. Turner-Warwick M. Precapillary Systemic-pulmonary anastomoses. Thorax. 1963;18:225-37.

81. Chapman HA. Epithelial-mesenchymal interactions in pulmonary fibrosis. Ann Rev Physiol 2011;73:413-35.

82. Willis BC, Borok Z. TGF-beta-induced EMT: mechanisms and implications for fibrotic lung disease. Am J Physiol Lung Cell Mol Physiol 2007;293:L525-34. 
83. Chang C, Tsai M, Huang H, Chen C, Dai S. Epithelial-mesenchymal transition contributes to SWCNT-induced pulmonary fibrosis. Nanotoxicology. 2012;6(6):600-10.

84.Wang P, Wang Y, Nie X, Braïni C, Bai R, Chen C. Multiwall carbon nanotubes directly promote fibroblast-myofibroblast and epithelial-mesenchymal transitions through the activation of the TGF$\beta /$ Smad signaling pathway. Small. 2015;11(4):446-55.

85. Walker N, Badri L, Wettlaufer S, Flint A, Sajjan U, Krebsbach PH, Keshamouni VG, Peters-Golden M, LamaVN. Resident tissue-specific mesenchymal progenitor cells contribute to fibrogenesis in human lung allografts. Am J Pathol. 2011 Jun;178(6):2461-9.

86. Hashimoto N, Jin H, Liu T, Chensue SW, Phan SH. Bone marrow-derived progenitor cells in pulmonary fibrosis. J Clin Invest. 2004;113(2):243-52.

87. Phillips RJ, Burdick MD, Hong K, Lutz MA, Murray LA, Xue YY, et al., Circulating fibrocytes traffic to the lungs in response to CXCL12 and mediate fibrosis. J Clin Invest. 2004 Aug;114(3):438-46.

88. Saxena R, Williams W, McGee J. Enhanced in-vitro and in-vivotoxicity of polydispersed acidfunctionalized single-wall carbon nanotubes. Nanotoxicology. 2007;1:291-300.

89. Sayes CM, Liang F, Hudson JL, Mendez J, Guo W, Beach JM, et al. Functionalization density dependence of single-walled carbon nanotubes cytotoxicity in-vitro. Toxicol Lett. 2006;161:135-142.

90. Jain S, Thakare VS, Das M, Godugu C, Jain AK, Mathur R, et al. Toxicity of multiwalled carbon nanotubes with end defects critically depends on their functionalization density. Chem Res Toxicol. 2011;24:2028-2039.

91. Coccini T, Manzo L, Roda E. Safety evaluation of engineered nanomaterials for health risk assessment: an experimental tiered testing approach using pristine and functionalized carbon nanotubes. ISRN Toxicol.2013;825427.

92. Li R, Wang X, Ji Z, Sun B, Zhang H, Chang CH, et al. Surface charge and cellular processing of covalently functionalized multiwall carbon nanotubes determine pulmonary toxicity. ACS Nano. 2013;7:2352-2368.

93. Magrez A, Kasas S, Salicio V, Pasquier N, Seo JW, Celio M, et al. Cellular toxicity of carbon-based nanomaterials. Nano Lett. 2006;6:1121-1125.

94. Zhang LW, Zeng L, Barron AR, Monteiro-Riviere NA. Biological interactions of functionalized single-wall carbon nanotubes in human epidermal keratinocytes. Int J Toxicol. 2007;26:103-113.

95. Sato Y, Yokoyama A, Shibata K, Akimoto Y, Ogino S, Nodasaka Y, et al. Influence of length on cytotoxicity of multi-walled carbon nanotubes against human acute monocytic leukemia cell line THP-1 in-vitro and subcutaneous tissue of rats in-vivo. Mol Biosyst. 2005;1:176-182.

96. Palomäki J, Välimäki E, Sund J, Vippola M, Clausen PA, Jensen KA,et al. Long, needle-like carbon nanotubes and asbestos activate the NLRP3 inflammasome through a similar mechanism. ACS Nano. 2011;5:6861-6870.

97. Murphy FA, Poland CA, Duffin R, Al-Jamal KT, Ali-Boucetta H, Nunes A, et al. Length-dependent retention of carbon nanotubes in the pleural space of mice initiates sustained inflammation and progressive fibrosis on the parietal pleura. Am J Pathol. 2011;178:2587-2600. 
98. Fenoglio I, Aldieri E, Gazzano E, Cesano F, Colonna M, Scarano D, et al. Thickness of multiwalled carbon nanotubes affects their lung toxicity. Chem Res Toxicol. 2012;25:74-82.

99. Tian F, Cui D, Schwarz H, Estrada GG, Kobayashi H. Cytotoxicity of single-wall carbon nanotubes on human fibroblasts. Toxicol In-vitro. 2006;20:1202-1212.

100. Bussy C, Pinault M, Cambedouzou J, Landry MJ, Jegou P, Mayne-L'hermite M, et al. Critical role of surface chemical modifications induced by length shortening on multi-walled carbon nanotubes-induced toxicity. Part Fibre Toxicol. 2012;9:46.

101. Vietti G, Ibouraadaten S, Palmai-Pallag M, Yakoub Y, Bailly C, Fenoglio I, et al. Towards predicting the lung fibrogenic activity of nanomaterials: experimental validation of an in-vitro fibroblast proliferation assay. Part Fibre Toxicol. 2013;10:52.

102. Manke A, Luanpitpong S, Dong C, Wang L, He X, Batelli L, et al. Effect of fiber length on carbon nanotube-induced fibrogenesis. Int J Mol Sci. 2014;15:7444-7461.

103. Vittorio O, Raffa V, Cuschieri A. Influence of purity and surface oxidation on cytotoxicity of multiwalled carbon nanotubes with human neuroblastoma cells. Nanomedicine. 2009;5:424-431.

104. Kagan VE, Tyurina YY, Tyurin VA, Konduru NV, Potapovich AI, Osipov AN, et al. Direct and indirect effects of single walled carbon nanotubes on RAW 264.7 macrophages: role of iron. Toxicol Lett. 2006;165:88-100.

105. Wang L, Castranova V, Mishra A, Chen B, Mercer RR, Schwegler-Berry D, et al. Dispersion of single-walled carbon nanotubes by a natural lung surfactant for pulmonary in-vitro and in-vivo toxicity studies. Part Fibre Toxicol.2010;7:31. 
CHAPTER 2 


\title{
CHAPTER 2: ROLE OF FIBROBLAST STEM-LIKE CELLS IN CARBON NANOTUBE-INDUCED LUNG FIBROSIS
}

\begin{abstract}
Among the pool of engineered nanomaterials, carbon nanotubes (CNTs) have generated great interest commercially with their unique physicochemical properties and diverse applications; however, the risk of their adverse health effects is not well understood. Recent studies have shown that CNTs can induce pulmonary fibrosis, an incurable lung disease, but the underlying mechanism is unclear. Since fibrosis is associated with aberrant tissue repair and extracellular matrix (ECM) accumulation, identifying the cells that are responsible for the repair and ECM production is fundamental to the understanding of fibrosis mechanism. We hypothesized that CNTs induce fibroblast stem-like cells (FSCs) and that such induction is essential to the development of fibrosis. Fluorescence activated cell sorting (FACS) was used to isolate FSCs from CNT-treated normal human lung fibroblasts. The expression of stem cell markers and fibrogenic markers was performed using Western blotting, immunofluorescence staining and confocal microscopy. Our results demonstrated for the first time that CNTs can induce FSCs from lung fibroblasts as evidenced by their side population (SP) property, aldehyde dehydrogenase (ALDH) activity, and the expression of stem cell markers ABCG2 and ALDH1A1. Furthermore, these cells, isolated from SP-positive FSCs, showed a high expression of type I collagen and alpha-smooth muscle actin, which are key biomarkers of fibrosis, as compared to non-SP cells. We showed that CNTs induced fibroblastic nodule formation in primary human lung fibroblast cultures resembling the fibroblastic foci in clinical fibrosis and promoted FSCs that are highly fibrogenic and a potential driving force of fibrogenesis. The
\end{abstract}


developed model could potentially be used as an alternative screening assay to predict the fibrogenicity of CNTs and other nanomaterials for their safer design and risk assessment.

Key words: Carbon nanotube (CNT), fibroblast stem-like cell (FSC), side population (SP), collagen I, stemness, fibrogenesis. 


\section{Introduction}

Engineered nanomaterials have increasingly been used for a wide array of applications in the fields as diverse as electronics, aerospace engineering, energy, consumer products, and medicinal drug delivery. Among them, carbon nanotubes (CNTs) have generated great interest commercially with their unique physicochemical properties such as high tensile strength and conductivity [1-3]. The global market for CNTs is estimated to reach a trillion dollars in the next decade, with their use affecting millions of workers and users [3, 4]. However, despite their numerous applications, inhalation of these nanoparticles exerts negative effects on the normal physiological functions of lungs and causes pulmonary toxicity. They are particularly scrutinized given their high aspect ratio similar to asbestos fibers which induce inflammatory and fibrotic lung reactions, pleural mesothelioma and lung cancer [4-6]. Unique to CNTs is their nonbiodegradable and biopersistent nature which likely prolongs the fibrotic process. Moreover, CNT structure facilitates their entry, deposition and residence in the lungs, resulting in impaired clearance from the lungs $[6,7]$. Collectively, these features reinforce the safety concerns about their pathogenicity and potential adverse effects on the health of exposed workers and the general population.

At present, human data regarding fibrogenicity assessment of CNTs is lacking and information on in vivo toxicity is limited, especially for single-walled CNTs (SWCNTs). Initial findings demonstrated that SWCNTs are capable of causing rapid and progressive interstitial fibrosis in murine models given their ability to translocate into the surrounding areas in the lung causing inflammation, granulomatous lesions and sub-pleural fibrosis [8-11].

Classical pulmonary fibrosis is characterized by epithelial cell injury, infiltration of inflammatory cells, proliferation and transformation of fibroblasts into myofibroblasts, 
irreversible deposition of excessive extracellular matrix (ECM) within the interstitium of the lung [12]. Given the fibrogenic potential of CNTs, major concern exists about the long-term human health risks associated with chronic respiratory CNT exposures. The mechanisms underlying CNT-induced lung fibrosis remain obscure due to the lack of understanding of the cellular interactions and molecular targets involved. There is evidence suggesting the role of a multitude of factors including oxidative stress, inflammation, epithelial mesenchymal transition (EMT), angiogenesis and pro-fibrogenic mediators [13-16]. However, the specific mechanism underlying CNT-induced fibrosis remains unclear.

Many lung diseases driven by the maladaptive proliferation of myofibroblast cells result in dysfunctional lung remodeling that affects the regenerative capacity of resident stem cells. Current paradigms define the origin of these proliferative myofibroblasts as bone marrow, vascular and epithelium-derived [17]. However, recent studies suggest that stem cells differentiate into myofibroblasts thereby contributing to tissue fibrosis [18]. In human idiopathic pulmonary fibrosis (IPF), observational studies suggest dysregulation of a number of epithelial progenitor cell types, with reactivation of developmental pathways. Despite the potential benefits of stem cells in lung regeneration and repair, there is no direct evidence for the role of these cells in parenchymal fibrosis, although there are some circumstantial evidences to support this possibility [19]. For instance, TGF- $\beta$ overexpression within the lungs of premature infants stimulates mesenchymal stem cells (MSCs) to differentiate into myofibroblasts [20], whilst another study showed that administration of intravenous bone marrow (BM)-derived MSCs following lung irradiation contributed to fibroblasts and myofibroblasts in areas of damage [21]. Similarly, MSCs isolated from bronchoalveolar lavage fluid (BALF) were found to contribute to fibrogenesis in human lung allografts [22]. Nearly $80 \%$ of collagen-producing lung fibroblasts 
were identified as bone marrow derived in a bleomycin model of pulmonary fibrosis [23], whereas another study suggested the role of fibroblast precursors and circulating fibrocytes in lung injury and fibrosis [24]. A recent study of kidney fibrosis showed that $35 \%$ of total myofibroblasts originating from BM-derived MSCs [25]. These findings indicate that stem or stem-like cells are a critical factor in the development of lung fibrosis. Understanding the molecular/cellular basis of these cells during lung fibrosis is of critical importance.

Recent findings from our laboratory and other groups have demonstrated that SWCNTs can directly interact with interstitial lung fibroblasts to exert their direct fibrogenic effects both in vivo and in vitro in the absence of persistent inflammation and cell damage [26, 26-28]. The cellular fibrogenic effect of CNTs provides a platform to develop an in vitro fibroblast model for assessing the fibrogenic potential of CNTs. Therefore, we proposed that fibroblasts can be a source of stem-like cells upon exposure to CNTs. The primary goal of this study was to determine the existence of fibroblast stem-like cells (FSCs) upon CNT exposure and studied their role in CNT-induced fibrogenesis under in vitro settings. This part of the study was focused on the ability of CNT to induce FSCs.

\section{Rationale:}

Recent studies suggest the role of stem cells in the fibroblast to myofibroblast differentiation and contribution to parenchymal fibrosis. Moreover, previous findings from our group revealed the expression of universal stem cell markers in human lung fibrotic tissues [29] as well CNT-induced lung fibrosis tissues, thus providing evidence for the clinical relevance of stem cells in fibrosis. 
Figure S1: Role of stem-like cells in pulmonary fibrosis

\section{Why Stem Cells???}

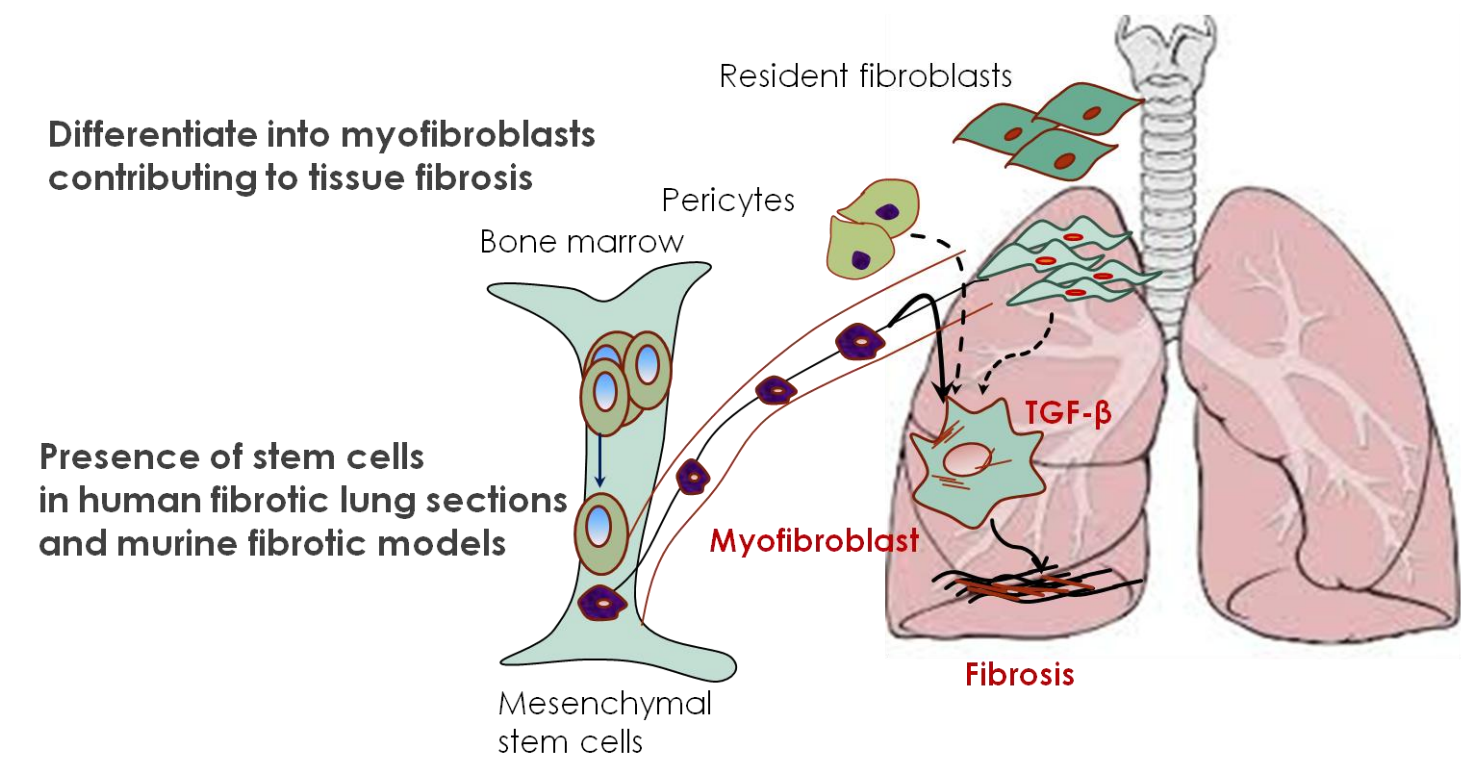

Stem-like cell induction is a critic al factor in the development of lung fibrosis 


\section{Experimental Section}

\section{SWCNT Preparation}

SWCNTs were prepared by plasma purified chemical vapor deposition process and were obtained from Cheap Tubes Inc. (Brattleboro, VT, USA). They were dispersed in culture medium containing $5 \%$ serum by water-bath sonication. Before exposure to the cells, the SWCNT dispersion was lightly sonicated (Sonic Vibra Cell Sonicator, Sonic \& Material Inc., Newtown, CT, USA) with the power, frequency, and amplitude settings of $130 \mathrm{~W}, 20 \mathrm{kHz}$, and $60 \%$ respectively for $10 \mathrm{~s}$.

\section{Chemicals and Reagents}

Antibodies for collagen type I and TGF- $\beta$ were obtained from Fitzgerald (Concord, MA, USA) and Cell Signaling Technology, Inc. (Beverly, MA, USA), respectively. $\beta$-actin antibody and horseradish peroxidase (HRP)-conjugated secondary antibodies were obtained from Santa Cruz Biotechnology (Santa Cruz, CA, USA). The antioxidant catalase was obtained from Roche Molecular Biochemicals (Indianapolis, IN, USA). Antibody for collagen type I was from Fitzgerald (Acton, MA). Human-derived TGF- $\beta$ was obtained from R\&D Systems (Minneapolis, MN). Poly-L-lysine and Hoechst 33342 were obtained from Sigma Aldrich (St. Louis, MO). Antibodies for $\alpha$-SMA and ALDH1A1 were from Abcam (Cambridge, MA). Antibody for ABCG2 (BRCP1) was from Milipore (Billerica, MA), and horseradish peroxidase (HRP)conjugated secondary antibodies were obtained from Cell Signaling Technology (Beverly, MA). DAPI and Alexa Fluor secondary antibodies were obtained from Molecular Probes (Grand Island, NY). 
Atomic Force Microscopy (AFM) (Some experiments were performed in the laboratory of Dr. Cerasela-Zoica Dinu)

AFM was used to determine the length and diameter distribution of SWCNT samples using Digital Instrument Nanoscope II (Model No. MFP-3D-AFM, Asylum Research, Goleta, CA, USA). A Si tip (50-90 kHz AC240TS, Asylum Research, Goleta, CA, USA) was used to perform tapping mode in air. SWCNT samples were deposited on mica surfaces $(9.5 \mathrm{~mm}$ diameter, 0.15 -

$0.21 \mathrm{~mm}$ thickness, Electron Microscopy Sciences, Hatfield, PA USA) and allowed to dry overnight under vacuum. Scan angel was set as 0 , scan rate was set as $0.5 \mathrm{~Hz}$, and resolution was set as 512. Scan images of $20 \times 20$ or $10 \times 10 \mu \mathrm{m}$ areas were acquired. For each sample, at least 30 individual SWCNT particles were counted and measured to obtain average length and diameter distribution.

\section{Cell Culture}

Normal human lung fibroblasts (NHLFs) were obtained from Lonza (Walkersville, MD, USA). The cells were maintained in Fibroblast Basal Medium (Lonza, CC-4126, Walkersville, MD, USA) containing growth supplements. The cells were cultured at $37^{\circ} \mathrm{C}$ in $5 \% \mathrm{CO}_{2}$ incubator and were passaged at preconfluent densities using a medium containing $0.05 \%$ trypsin.

\section{Cytotoxicity Assay}

Cytotoxicity assay was carried out using WST-1 cell viability assay kit (Roche Molecular Biochemicals, Indianapolis, IN, USA) as per the manufacturer's instructions. Cells were plated in triplicate in 96-well plates at the density of $2.0 \times 10^{4}$ cells/well in CS-C medium. Following overnight culture, the cells were incubated with the indicated concentrations of SWCNT for $48 \mathrm{~h}$. After incubation, WST-1 reagent was added and the cells were incubated for an additional $4 \mathrm{~h}$. 
The plates were then read at the wavelength of $420 \mathrm{~nm}$ using a microplate reader (Model 3550; BioRad, Richmond, CA, USA).

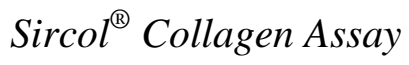

Soluble collagen content was determined by Sircol assay ${ }^{\circledR}$ (Biocolor Ltd., Belfast, UK), according to the manufacturer's protocol. Briefly, lung fibroblasts $\left(1 \times 10^{5}\right.$ cells/well $)$ were cultured in 6-well plates and treated with SWCNTs of different lengths at the indicated concentrations for 24 and $48 \mathrm{~h}$. Equal amount of Sirius red reagent (Biocolor Ltd., Belfast, UK) and cell culture supernatant $(50 \mu \mathrm{L})$ were added together and mixed for $30 \mathrm{~min}$. The collagendye complex was then precipitated by centrifugation at $13,000 \times \mathrm{g}$ for $5 \mathrm{~min}$, washed with ethanol, and dissolved in $0.5 \mathrm{M} \mathrm{NaOH}$. A $200 \mu \mathrm{L}$ aliquot of the mixture was transferred to a 96well plate and analyzed for optical absorbance at $540 \mathrm{~nm}$.

\section{Isolation of FSC using Flow Cytometry}

Cell subsets markedly enriched for stem cell activity are characterized by the ability to efflux the vital dye Hoechst 33342 via multidrug-like transporter ABCG2. Following appropriate treatments, the cells were harvested using $0.05 \%$ trypsin. Hoechst was added at the final concentration of $5 \mu \mathrm{g} / \mathrm{ml}$ to stain the cells. Flow cytometry experiments included Hoechststained lung fibroblasts, unstained fibroblasts, and cell suspensions incubated with Hoechst 33342 and the dye uptake inhibitor, fumitremorgin C (FTC). Gates were set according to the controls. The Hoechst dye was excited with a UV laser and its fluorescence was measured with both 450/20 filter (Hoechst Blue) and 675 LP filter (Hoechst Red), sorting was performed using FACS ARIA (BD Biosciences, San Jose, CA, USA). 


\section{Western Blotting}

Collagen protein expression was determined by Western blotting. After specific treatments, cells were incubated in lysis buffer containing $20 \mathrm{mM}$ Tris- $\mathrm{HCl}(\mathrm{pH} 7.5), 1 \%$ Triton X-100, $150 \mathrm{mM}$ sodium chloride, $10 \%$ glycerol, $1 \mathrm{mM}$ sodium orthovanadate, $50 \mathrm{mM}$ sodium fluoride, $100 \mathrm{mM}$ phenylmethylsulfonyl fluoride, and a commercial protease inhibitor mixture (Roche Molecular Biochemicals, Indianapolis, IN, USA) at $4{ }^{\circ} \mathrm{C}$ for $20 \mathrm{~min}$. Cell lysates were collected and protein concentrations were determined using a bicinchoninic acid protein assay kit (Pierce Biotechnology, Rockford, IL, USA). Equal amount of protein per sample (40 $\mu \mathrm{g})$ was resolved under denaturing conditions by 10\% SDS-PAGE and transferred onto a nitrocellulose membrane. The membranes were blocked for $1 \mathrm{~h}$ in 5\% nonfat dry milk in TBST $(25 \mathrm{mM}$ Tris- $\mathrm{HCl}, \mathrm{pH} 7.4$, $125 \mathrm{mM}$ sodium chloride, $0.05 \%$ Tween 20 ) and incubated with appropriate primary antibodies at $4{ }^{\circ} \mathrm{C}$ for $12 \mathrm{~h}$. Membranes were washed thrice with TBST for $10 \mathrm{~min}$ and incubated with HRPlabeled isotype-specific secondary antibodies for $1 \mathrm{~h}$ at room temperature. The immune complexes were then detected by enhanced chemiluminescence detection system (Supersignal ${ }^{\circledR}$ West Pico, Pierce, Rockford, IL, USA). The bands were quantified via densitometry using Image J. software, version 10.2 (GraphPad Software Inc., La Jolla, CA, USA). Mean densitometry data from independent experiments were normalized to results in cells from control experiments.

\section{Growth and Counts of Fibroblastic Nodules}

Cells at the density of $3 \times 10^{4}$ cells/well were seeded onto poly-L-lysine-coated glass cover slips in 24-well plates and allowed to adhere overnight. The cells were then deprived of serum for $8 \mathrm{~h}$ and then treated with SWCNT, MWCNT, or TGF- $\beta$ for $16 \mathrm{~h}$, which is the optimal time for fibroblastic nodule formation. For each culture, three cover slides were analyzed and counted (Leica Microsystems, Bannockburn, IL) by two independent observers blinded to the treatment. 


\section{Immunofluorescence}

For immunofluorescence staining, cells were seeded on rat type I collagen-coated cover slips (5 $\mu \mathrm{g} / \mathrm{cm}^{2}$ ), fixed with $3.7 \%$ paraformaldehyde for $15 \mathrm{~min}$, incubated in $50 \mathrm{mM}$ glycine for $5 \mathrm{~min}$, permeabilized and blocked with $0.5 \%$ saponin, $1.5 \%$ BSA, and $1.5 \%$ normal goat serum for 30 min. Coverslips were then incubated with the appropriate primary antibodies at $4{ }^{\circ} \mathrm{C}$ overnight followed by secondary Alexa Fluor 488-, 546-, or 647-conjugated antibodies and phalloidin (Molecular Probes) for $2 \mathrm{~h}$. After washing, cells were mounted on a coverslip using ProLong ${ }^{\circledR}$ Gold antifade reagent with DAPI (Molecular Probes). Cells were visualized with a Zeiss LSM 510 confocal microscope on an Axiolmager Z1 platform using a 40x objective lens (Carl Zeiss, Jena, Germany).

\section{Aldehyde Dehydrogenase Assay}

Human lung fibroblasts exposed to SWCNT for $24 \mathrm{~h}$ were analyzed using an Aldefluor ${ }^{\circledR}$ assay kit (Stem Cell Technologies, Vancouver, B.C., Canada). Dead cells, cell debris, doublets and aggregates were excluded by forward and side scattering and pulse-width gating. Cells were suspended in Aldefluor assay buffer containing ALDH substrate, BODIPY"TM-aminoacate (BAA) $(1 \mu \mathrm{M})$ for $30-60$ min per $1 \times 10^{6}$ cells. After staining cells with the activated Aldefluor ${ }^{\circledR}$ reagent, the single cell dissociation was maintained on ice during all subsequent procedures. In each experiment, a sample of cells was stained under identical conditions with $1.5 \mathrm{mM}$ of the specific ALDH inhibitor diethylaminobenzaldehyde (DEAB) as a negative control. Flow cytometric sorting was conducted using a FACS ARIA (BD Biosciences, San Jose, CA, USA). Aldefluor fluorescence was excited at $488 \mathrm{~nm}$, and fluorescence emission was detected using a standard fluorescein isothiocyanate (FITC) 530/30-nm band-pass filter by a FACS Calibur ${ }^{\mathrm{TM}}$ machine (BD Biosciences, San Jose, CA). High side scatter ALDH ${ }^{\text {tve }}$ and low $\mathrm{ALDH}^{-\mathrm{ve}}$ were selected. 
Statistical Analysis

The data represent mean \pm S.D. from three or more independent experiments. ANOVA was performed to determine statistical significance between treatment and control groups using Graph Pad Prism 6.0 (GraphPad Software Inc., La Jolla, CA, USA) at a confidence level of * $p<$ 0.05 .

Figure S2: Working model for demonstrating CNT-induced fibroblast stem-like cell induction

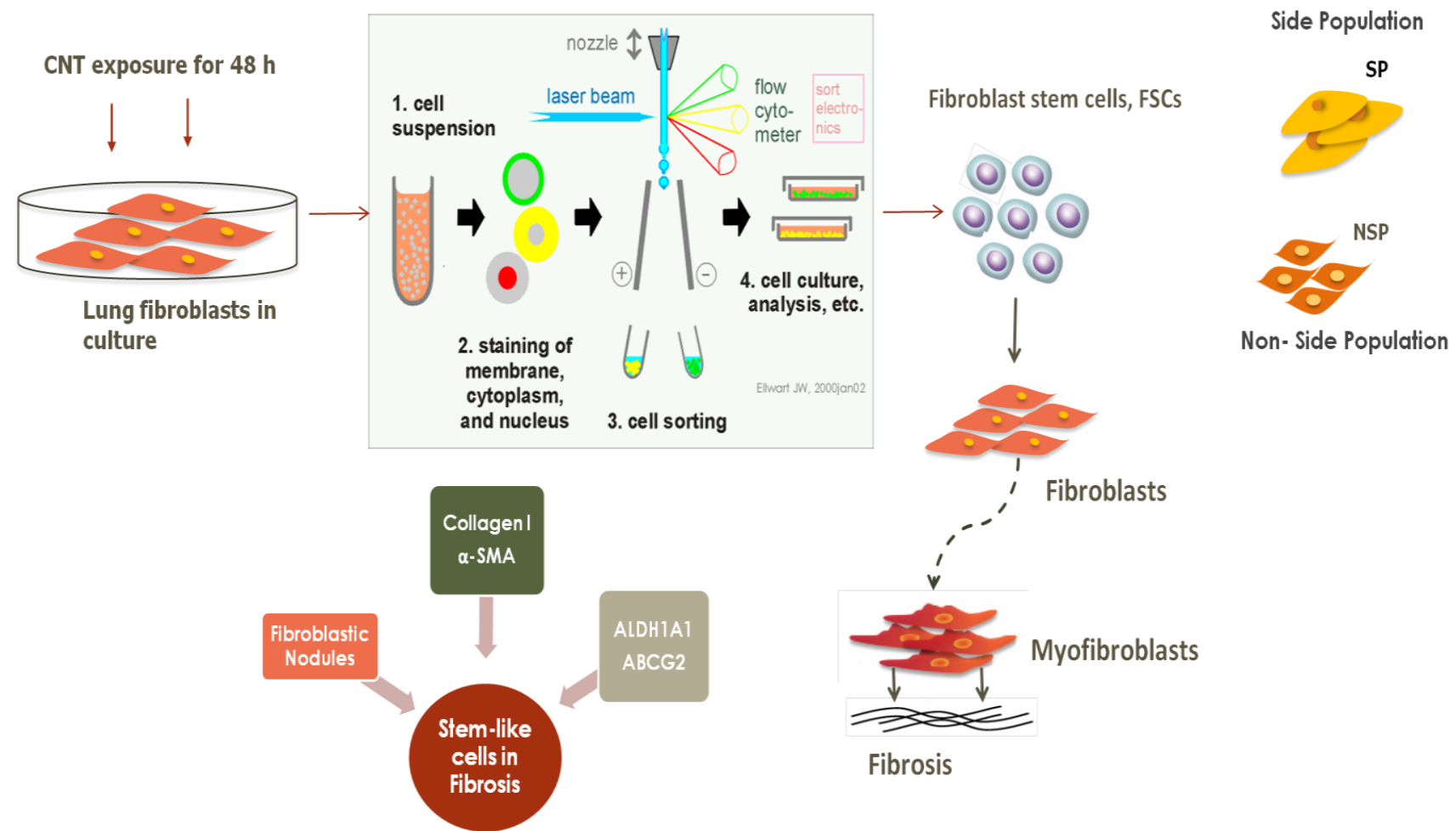




\section{Results}

\section{CNT Characterization and Dose Calculation}

Pristine SWCNTs were characterized using atomic force microscopy. Table 1 provides information on the purity, length and diameter characteristics for the SWCNTs used in this study. SWCNTs differed slightly in their diameter and their length both in the solution and dry forms with a specific surface area of $407 \mathrm{~m}^{2} / \mathrm{g}$. SWCNTs were dispersed using serum and were lightly sonicated prior to culture exposure. The SWCNT doses used in the in vitro exposure studies were calculated based on in vivo CNT exposure data normalized to alveolar surface area in mice [29]. The doses that induced positive in vivo fibrogenic response were $10-80 \mu \mathrm{g} / \mathrm{mouse}$ lung $(0.5$ $\mathrm{mg} / \mathrm{kg}$ body weight) [30-32]. Dividing this dose by the average alveolar surface area in mice $\left(\sim 500 \mathrm{~cm}^{2}\right)[32]$ indicates the in vitro surface area dose of $0.02-0.16 \mu \mathrm{g} / \mathrm{cm}^{2}$.

\section{Effect of SWCNTs on Cell Viability and Type I Collagen Expression}

Cultured normal human lung fibroblasts were exposed to SWCNTs and analyzed for cellular toxicity (Figure 3). This study was performed to optimize the experimental doses of SWCNT that are relevant to in vivo lung fibrosis. Lung fibroblasts were treated with different concentrations of SWCNT for $48 \mathrm{~h}$ and analyzed for cell viability by WST-1 assay (Figure 3A). The doses of $0.02-0.6 \mu \mathrm{g} / \mathrm{cm}^{2}$ were used in this study since they are physiologically relevant and derived from pulmonary exposure data in mice, i.e., $10-80 \mu \mathrm{g} / \mathrm{mouse}$ which corresponds to $0.02-$ $0.16 \mu \mathrm{g} / \mathrm{cm}^{2}$ of mouse lung alveolar surface area $[9,27,28]$. SWCNTs induced a dose-dependent decrease in cell viability of the cultured fibroblasts. We also investigated the collagen-inducing effect of SWCNTs in lung fibroblasts. To avoid the interfering effect of cell toxicity on collagenic activity of the cells, we performed experiments using low non-cytotoxic doses of SWCNT (Figure 3B, 3C). SWCNTs induced a substantial increase in collagen expression as 
determined by Western blot assay. Analysis of soluble collagen content by Sircol $^{\circledR}$ assay confirmed the fibrogenic effect of SWCNTs (Figure 3D)

\section{CNTs Induce Side Population Phenotype of Lung Fibroblasts}

Adult stem cells are known to efflux Hoechst dye slowly due to their high expression of ABCG2. Flow cytometric analysis was used to identify these stem cells with a distinct low Hoechst staining pattern referred to as side population (SP) $[33,34]$. An increase in SP population was reported in the lung of mice with fibrosis, suggesting the involvement of SP-positive stem cells in lung fibrogenesis [25]. To determine the potential role of stem-like fibroblasts in CNTinduced fibrogenesis, we first determined the change of SP subpopulation upon CNT treatment. Primary human lung fibroblasts were treated with SWCNT at the concentration of $0.15 \mu \mathrm{g} / \mathrm{cm}^{2}$ for $48 \mathrm{~h}$, after which they were incubated with $5 \mu \mathrm{g} / \mathrm{mL}$ of Hoechst 33342 in the presence or absence of $25 \mu \mathrm{M}$ fumitremorgin $\mathrm{C}$ (FTC), an inhibitor of ATP- binding cassette (ABC) transporter (Figure 4A). SWCNTs were able to induce the SP subpopulation and the percentage of SP was approximately 5\% in SWCNT-treated fibroblasts versus less than $0.5 \%$ in vehicletreated control cells (Figure 4B). We also tested the expression of $\alpha$-SMA, the myofibroblast marker in CNT-induced SP fibroblasts. SP cells overexpressed $\alpha$-SMA compared to non-SP cells, suggesting the fibroblast to myofibroblast transition in both SW and MWCNT-induced stem-like fibroblasts (Figure 4C).

\section{Side Population is a Potential Source of Collagen I and alpha-SMA}

Increased $\alpha$-SMA is a characteristic feature indicating the transformation of fibroblasts to myofibroblasts, which is known to be the main source of collagen production [12]. To determine whether isolated SP and non-SP were able to induce myofibroblast phenotype, we isolated the

stem-like cells from SWCNT-treated $\left(0.15 \mu \mathrm{g} / \mathrm{cm}^{2}\right)$ fibroblasts based on their SP phenotype 
using flow cytometry based cell sorting (Figure 5A). Sorted SP and non-SP fibroblasts were further evaluated for collagen I and $\alpha$-SMA expression. Figures 5B and 5C reveal a substantially higher expression of collagen I and SMA in the SP versus non-SP cells, thus confirming that SP fibroblasts could be key originating sources of collagen production and the myofibroblasts, and may play a crucial role in fibrogenesis.

\section{Increased Stem Cell Marker and Collagen Expression in CNT-Derived SP Fibroblasts}

Recent studies indicate the functional role of stem cells at the early onset of pulmonary fibrosis. To determine the role of stem-like fibroblasts in CNT-induced fibrogenesis, we isolated the stem-like cells from SWCNT-treated $\left(0.15 \mu \mathrm{g} / \mathrm{cm}^{2}\right)$ fibroblasts based on their SP phenotype as earlier described. Sorted SP and non-SP fibroblasts were further evaluated for the universal stem cell marker ABCG2 [35] and type I collagen expression by immunofluorescence (Figure 6). Figures $6 \mathrm{~A}, 6 \mathrm{~B}$ reveals a substantially higher expression of ABCG2 in the SP versus non-SP cells, thus confirming the stem-like phenotype of SP fibroblasts and the reliability of stem cell isolation by FACS. Importantly, type I collagen expression was significantly higher in the SP versus non-SP population. It is widely known that fibroblasts play a key role in fibrogenesis through its ability to synthesize and secrete ECM proteins including type I collagen, which characterizes fibrosis [36, 37]. Our results thus reveal the potential role of SP cells in fibrogenesis via simultaneous expression of stem cell and fibrosis markers. Furthermore, the increases in stem cell markers ABCG2 and ALDH1A1 via immunofluorescence [35, 38] were validated via Western blotting (Figure 6C, 6D).

\section{CNTs Induce Fibroblastic Nodule Formation of Human Lung Fibroblasts}

Formation of fibrotic nodules has been described as a means to quantify fibrosis and to screen anti-fibrotic agents [39, 40]. Fibrotic nodules are defined by a collagenous core with an 
accumulation of extracellular matrix and a bounding cell layer detached from the alveolar wall [41, 42]. In this part of the study we tested whether SP cells are capable of forming fibrous nodules in a 3D in vitro model as compared to non-SP cells. A 3D biomimetic model of fibroblastic foci was developed by growing primary human lung fibroblasts in culture on a polyL-lysine substrate, while TGF- $\beta$ was used as a positive inducer of fibrosis (Figure 7). The formation of $3 \mathrm{D}$ cell clusters that are referred to as fibroblastic nodules after treatment of the cells with TGF- $\beta(1 \mathrm{ng} / \mathrm{mL})$ for $16 \mathrm{~h}$. Interestingly, treatment of the cells with SWCNT induced the fibroblastic nodules, whereas vehicle-treated control cells showed minimal nodule formation (Figure 7A). Quantitative analysis for the number of fibroblastic nodules demonstrated the dosedependent effect of SWCNT treatment (Figure 7B). To substantiate the functional role of stemlike fibroblasts in CNT fibrogenesis, the sorted SP and non-SP cells from CNT-treated fibroblasts were assessed for their ability to form fibroblastic nodules. SP cells had a substantially higher capability to form fibroblastic nodules than the non-SP fibroblasts (Figure 7C). Altogether, these findings support the role of stem-like fibroblasts in CNT-induced fibrogenesis.

\section{Supplemental Data}

\section{CNTs Induce Fibroblast-Stem Cells in a Dose and Cell Type-Dependent Manner}

To determine if CNT-induced stem-like fibroblast generation was dose dependent, the doses of $0.02-0.2 \mu \mathrm{g} / \mathrm{cm}^{2}$ were used since they are physiologically relevant and derived from pulmonary exposure data in mice (Figure 8A). SWCNTs induced a dose-dependent FSC induction correlating with the collagen I and $\alpha$-SMA response of the cultured fibroblasts (Figure 8B). In order to optimize the time of exposure to CNTs and the resulting SP generation, cultured lung fibroblasts were exposed to SWCNTs at 24,48 , and $72 \mathrm{~h}$ time points. $48 \mathrm{~h}$ exposure was found 
to be critical for SWCNT-driven stem-like fibroblast induction (Figure 8C). Nanomaterialmediated cell toxicity has been shown to vary depending upon the cell type that the material interacts with. To investigate if SP generation was cell type dependent, using three different models for lung fibroblasts (primary normal human lung fibroblasts, 3T3 mouse embryonic lung fibroblasts, and WI-38 human lung fibroblasts), SP generation was found to be cell type dependent (Figure 8A, 8B, 8C). These findings demonstrated that CNT dose, exposure time and exposed cell type are key determinants for the resulting stem-like fibroblast induction.

\section{CNT-Induced FSC Generation Using Aldehyde Dehydrogenase (ALDH) Expression as a Marker for}

\section{Stem-like Cells}

A high level of ALDH activity serves as a functional marker for stem/progenitor cells and allows for simple, efficient isolation of cells with primitive features [43]. Human stem and progenitor cells typically have more ALDH activity than mature cells, and this quantitative difference allows stem cells to be resolved from other cells [44]. Lung fibroblasts were treated with SWCNT at $0.15 \mu \mathrm{g} / \mathrm{cm}^{2}$ for $24 \mathrm{~h}$ after which they were incubated with $0.3 \mathrm{mM}$ activated Aldeflour dye in the presence or absence of $1.5 \mathrm{mM}$ ALDH inhibitor, diethylaminobenzaldehyde (DEAB) (Figure 10). SWCNT induced ALDH positive (+ve) cells indicated by the ALDH Hi fraction (Figure 10A) and the percentage of ALDH +ve population of cells was approximately 6 $\%$ in SWCNT-treated fibroblasts versus less than $0.5 \%$ in vehicle-treated control cells (Figure 10B). 


\section{Discussion}

Currently, there is an urgent need for efficient in vitro models for fibrogenicity testing of nanomaterials. The large and rapidly expanding number of engineered nanomaterials makes it impossible to test them all in animals due to time constraints and prohibitive cost [45]. In this study, we developed and tested a fibroblast cell assay as a rapid, low cost, predictive in vitro model that demonstrates stem-like cell induction as a mechanism critical for the development of lung fibrosis.

Fibrosis is a progressive disorder associated with abnormal wound healing, excessive collagen deposition and ECM accumulation [12,46]. Identifying the cells that are capable of repairing the injured tissue and are the source of ECM production is fundamental to the understanding of fibrosis mechanisms. Recent studies have indicated the pathogenic role of stem and progenitor cells in pulmonary fibrosis at the early onset of lung fibrosis in murine models [20-25]. The fibrogenic potential of CNTs has been well documented [8-11, 13-16]; however, the concept of stemness in the light of nanomaterial-induced fibrosis has not been explored. Since fibroblasts are known to induce collagen and ECM deposition, which are hallmarks of fibrosis $[26,27,45]$, the present study was designed to investigate whether CNT exposure in lung fibroblasts can induce FSCs and whether these stem-like cells possess fibrogenic activities. FSCs were induced by exposing primary human lung fibroblasts to CNTs. These cells were used in this study because they are of human origin and a better representation of pathological process than immortalized cell lines that are popularly used but may possess defective genes affecting fibrosis development. Our results demonstrated FSC generation from normal lung fibroblasts postSWCNT exposure. The isolated FSCs from FACS analysis were further characterized for potential fibrosis and stem cell markers to determine their putative role in fibrogenesis. 
To optimize the experimental doses of SWCNT that are relevant to in vivo lung fibrosis, lung fibroblasts were treated with different concentrations of SWCNT for $48 \mathrm{~h}$ and analyzed for cell viability by WST-1 assay. The doses of $0.02-0.2 \mu \mathrm{g} / \mathrm{cm}^{2}$ were used in this study since they are physiologically relevant and derived from in vivo pulmonary exposure data in mice, i.e., 10$80 \mu \mathrm{g} /$ mouse corresponding to mouse lung alveolar surface area $[9,27,28]$. The collageninducing effect of SWCNTs was not due to their proliferative activity since fibroblast cell growth was not increased by the SWCNT treatment as indicated by WST-1 assay. An increased expression of the myofibroblast marker $\alpha$-SMA in SWCNT-treated cells indicated the transformation of fibroblasts to myofibroblasts, and their production of extracellular matrix proteins $[47,48]$.

We demonstrated the existence of FSCs as evidenced by the SP phenotype of lung fibroblasts post-CNT exposure. SWCNT treatment produced a significantly higher percentage of SP population, thereby signifying the potential role of stem-like fibroblasts in CNT-induced fibrogenesis. CNT-induced SP upregulated both collagen I and $\alpha$-SMA compared to the non-SP, indicating that the stem-like fibroblasts are a potential key source of collagen production and may play a crucial role in fibrogenesis. Furthermore, the elevated expression of stem cell markers, ABCG2 and ALDH1A1, in SP versus non-SP cells as evidenced by Western blotting and immunofluorescence confirmed the stem phenotype of SP fibroblasts and the reliability of our employed method of stem cell isolation via FACS.

An important pathological feature of human lung fibrosis is the presence of fibroblastic foci, which are aggregates of lung fibroblasts and myofibroblasts and the newly deposited collagen [39-41]. Here we verified the in vitro model of CNT-induced fibroblastic nodule formation that correlates the development of stem cell phenotype and onset of fibrosis. Using 
fibroblastic nodule generation as a model for lung fibrosis has the following advantages: (i) clinical resemblance to human lung fibrotic lesions; (ii) rapid and quantitative or semiquantitative analysis, (iii) fewer cell numbers needed per assay; and (iv) potential for highthroughput screening [29]. SWCNT treatment induced a dose-dependent fibrotic nodule formation which also correlated with the SWCNT dose-driven collagen expression observed in Figure 2A. Furthermore, SP fibroblasts demonstrated higher potency in fibroblastic nodule generation compared to non-SP fibroblasts, hence supporting their key role in fibrogenesis.

Although considerable experimental data related to CNT toxicity at the cellular and whole animal levels have been published, the results are often conflicting [49]. Therefore, a systematic understanding of CNT toxicity in terms of different cell lines and animal species, multidimensional evaluation methods, and exposure conditions is needed but has not yet been developed. In agreement with other studies, we demonstrated that stemness phenotype is cell line, dose and time-dependent, indicating that the dose and exposure time of SWCNT are critical for stemness induction. To obtain accurate results, future studies must establish standards and reliable detection methods, use standard CNT samples as a reference control, and study the impact of various factors systematically.

The Aldeflour ${ }^{\mathrm{TM}}$ detection system is an alternative method to side population assay to identify human stem/progenitor cells on the basis of their ALDH activity. Using ALDH as a marker for stem cells, we validated the stem cell phenotype of SWCNT-induced FSCs as indicated by the significantly increased ALDH activity in SWCNT-treated cells compared to untreated controls.

In summary, we have developed an in vitro model for CNT-induced lung fibrosis involving CNT-driven FSC generation and studied their putative role in fibrogenesis. The 
isolated FSCs were found to be key sources of collagen I and $\alpha$-SMA, whereby they may play a crucial role in fibrogenesis. Besides being potential sources of collagen production, stem-like fibroblasts substantially elevated the expression universal stem cell markers including ABCG2 and ALDH1A1, validating the SP phenotype model of CNT-induced lung fibrogenesis. SP lung fibroblasts were potent in fibroblastic nodule formation compared to the non-SP cells supporting their key role in fibrogenesis. The developed model could potentially be used as an alternative assay to predict the fibrogenicity of CNTs and other nanomaterials for their safer design and risk assessment. The novel role of FSCs in CNT-induced collagen production and $\alpha$-SMA expression provides new insights into the mechanisms of pulmonary fibrosis. In addition, the findings from this study could potentially benefit in the development of early detection biomarkers and treatment strategies for the disease.

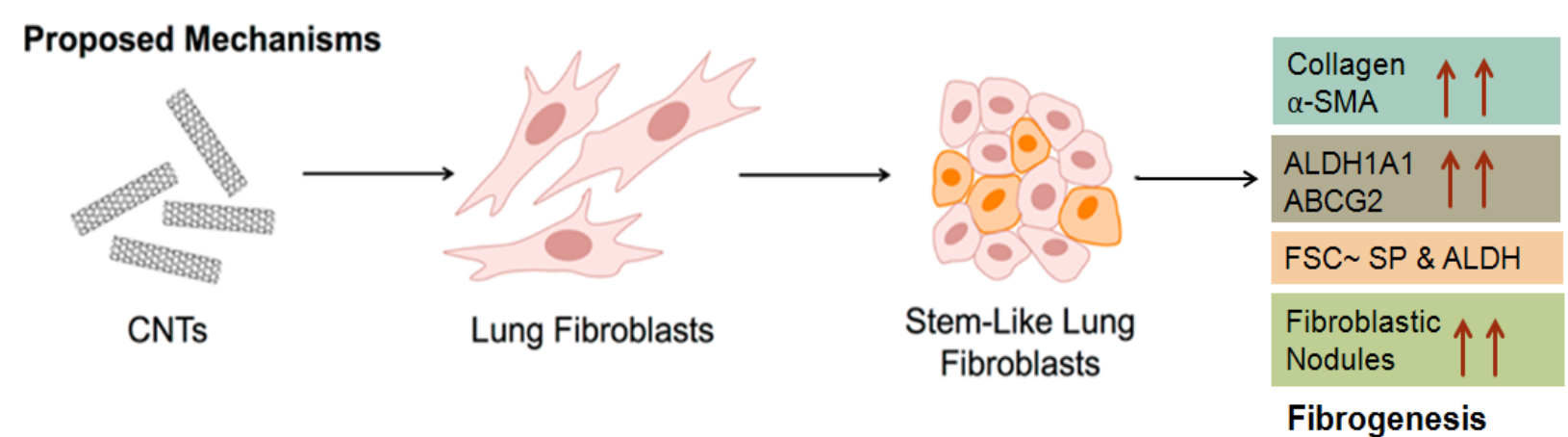

Figure S3: Proposed mechanisms of CNT-induced lung fibrosis 


\section{References}

1. Oberdörster G. Safety assessment for nanotechnology and nanomedicine: Concepts of nanotoxicology. J Intern Med. 2010 01;267(1):89-105.

2. Lam C, James JT, McCluskey R, Arepalli S, Hunter RL. A review of carbon nanotube toxicity and assessment of potential occupational and environmental health risks. Crit Rev Toxicol. 2006 03;36(3):189-217.

3. Patel V. Global carbon nanotubes market outlook: Industry beckons. Nanotech Insights. 2011;2:31-5.

4. Lam C, James JT, McCluskey R, Hunter RL. Pulmonary toxicity of single-wall carbon nanotubes in mice 7 and 90 days after intratracheal instillation. Toxicol Sci. 2004 01;77(1):126-34.

5. Kolosnjaj J, Szwarc H, Moussa F. Toxicity studies of carbon nanotubes. Adv Exp Med Biol. 2007;620:181-204.

6. Jaurand MF, Renier A, Daubriac J. Mesothelioma: Do asbestos and carbon nanotubes pose the same health risk? Part Fibre Toxicol. 2009 06/12;6:16.

7. Stella GM. Carbon nanotubes and pleural damage: Perspectives of nanosafety in the light of asbestos experience. Biointerphases. 2011 06;6(2):P1-P17.

8. Shvedova AA, Kisin E, Murray AR, Johnson VJ, Gorelik O, Arepalli S, et al. Inhalation vs. aspiration of single-walled carbon nanotubes in C57BL/6 mice: Inflammation, fibrosis, oxidative stress, and mutagenesis. Am J Physiol Lung Cell Mol Physiol. 2008 10;295(4):L552-65.

9. Shvedova AA, Kisin ER, Mercer R, Murray AR, Johnson VJ, Potapovich AI, et al. Unusual inflammatory and fibrogenic pulmonary responses to single-walled carbon nanotubes in mice. Am J Physiol Lung Cell Mol Physiol. 2005 11;289(5):L698-708.

10. Mercer RR, Scabilloni J, Wang L, Kisin E, Murray AR, Schwegler-Berry D, et al. Alteration of deposition pattern and pulmonary response as a result of improved dispersion of aspirated single-walled carbon nanotubes in a mouse model. Am J Physiol Lung Cell Mol Physiol. 2008 01;294(1):L87-97.

11. Park E, Roh J, Kim S, Kang M, Han Y, Kim Y, et al. A single intratracheal instillation of singlewalled carbon nanotubes induced early lung fibrosis and subchronic tissue damage in mice. Arch Toxicol. 2011 09;85(9):1121-31.

12. Leask A, Abraham DJ. TGF-beta signaling and the fibrotic response. FASEB J. 2004 05;18(7):81627.

13. Chang C, Tsai M, Huang H, Chen C, Dai S. Epithelial-mesenchymal transition contributes to SWCNT-induced pulmonary fibrosis. Nanotoxicology. 2012 09;6(6):600-10.

14. Mangum JB, Turpin EA, Antao-Menezes A, Cesta MF, Bermudez E, Bonner JC. Single-walled carbon nanotube (SWCNT)-induced interstitial fibrosis in the lungs of rats is associated with increased 
levels of PDGF mRNA and the formation of unique intercellular carbon structures that bridge alveolar macrophages in situ. Part Fibre Toxicol. 2006 Nov 29;3:15.

15. He X, Young S, Schwegler-Berry D, Chisholm WP, Fernback JE, Ma Q. Multiwalled carbon nanotubes induce a fibrogenic response by stimulating reactive oxygen species production, activating NF$\kappa \mathrm{B}$ signaling, and promoting fibroblast-to-myofibroblast transformation. Chem Res Toxicol. 2011 12/19;24(12):2237-48.

16. Azad N, Iyer AKV, Wang L, Liu Y, Lu Y, Rojanasakul Y. Reactive oxygen species-mediated p38 MAPK regulates carbon nanotube-induced fibrogenic and angiogenic responses. Nanotoxicology. 2013 03;7(2):157-68.

17. Foronjy RF, Majka SM. The potential for resident lung mesenchymal stem cells to promote functional tissue regeneration: Understanding microenvironmental cues. Cells. 2012 12;1(4):874.

18. LeBleu VS, Taduri G, O'Connell J, Teng Y, Cooke VG, Woda C, et al. Origin and function of myofibroblasts in kidney fibrosis. Nat Med. 2013 08;19(8):1047-53.

19. Sage EK, Loebinger MR, Polak J, Janes SM. The role of bone marrow-derived stem cells in lung regeneration and repair. StemBook. 2008.

20. Popova AP, Bozyk PD, Bentley JK, Linn MJ, Goldsmith AM, Schumacher RE, et al. Isolation of tracheal aspirate mesenchymal stromal cells predicts bronchopulmonary dysplasia. Pediatrics. 2010 11;126(5):e1127-33.

21. Epperly MW, Guo H, Gretton JE, Greenberger JS. Bone marrow origin of myofibroblasts in irradiation pulmonary fibrosis. Am J Respir Cell Mol Biol. 2003 08;29(2):213-24.

22. Walker N, Badri L, Wettlaufer S, Flint A, Sajjan U, Krebsbach PH, et al. Resident tissue-specific mesenchymal progenitor cells contribute to fibrogenesis in human lung allografts. Am J Pathol. 2011 06;178(6):2461-9.

23. Hashimoto N, Jin H, Liu T, Chensue SW, Phan SH. Bone marrow-derived progenitor cells in pulmonary fibrosis. J Clin Invest. 2004 01;113(2):243-52.

24. Phillips RJ, Burdick MD, Hong K, Lutz MA, Murray LA, Xue YY, et al. Circulating fibrocytes traffic to the lungs in response to CXCL12 and mediate fibrosis. J Clin Invest. 2004 08;114(3):438-46.

25. Banerjee ER, Henderson, William Reed, Jr. Characterization of lung stem cell niches in a mouse model of bleomycin-induced fibrosis. Stem Cell Res Ther. 2012 05/29;3(3):21.

26. Wang L, Mercer RR, Rojanasakul Y, Qiu A, Lu Y, Scabilloni JF, et al. Direct fibrogenic effects of dispersed single-walled carbon nanotubes on human lung fibroblasts. J Toxicol Environ Health A. 2010;73(5):410-22.

27. Wang L, Castranova V, Mishra A, Chen B, Mercer RR, Schwegler-Berry D, et al. Dispersion of single-walled carbon nanotubes by a natural lung surfactant for pulmonary in vitro and in vivo toxicity studies. Part Fibre Toxicol. 2010 10/19;7:31. 
28. Murray AR, Kisin ER, Tkach AV, Yanamala N, Mercer R, Young S, et al. Factoring-in agglomeration of carbon nanotubes and nanofibers for better prediction of their toxicity versus asbestos. Part Fibre Toxicol. 2012 04/10;9:10.

29. Luanpitpong S, Wang L, Manke A, Martin KH, Ammer AG, Castranova V, et al. Induction of stemlike cells with fibrogenic properties by carbon nanotubes and its role in fibrogenesis. Nano Lett. 2014 06/11;14(6):3110-6.

30. Mercer RR, Hubbs AF, Scabilloni JF, Wang L, Battelli LA, Friend S, et al. Pulmonary fibrotic response to aspiration of multi-walled carbon nanotubes. Part Fibre Toxicol. 2011 07/22;8:21.

31. Mercer RR, Scabilloni JF, Hubbs AF, Battelli LA, McKinney W, Friend S, et al. Distribution and fibrotic response following inhalation exposure to multi-walled carbon nanotubes. Part Fibre Toxicol. 2013 07/30;10:33.

32. Porter DW, Hubbs AF, Mercer RR, Wu N, Wolfarth MG, Sriram K, et al. Mouse pulmonary doseand time course-responses induced by exposure to multi-walled carbon nanotubes. Toxicology. 2010 03/10;269(2-3):136-47.

33. Majka SM, Beutz MA, Hagen M, Izzo AA, Voelkel N, Helm KM. Identification of novel resident pulmonary stem cells: Form and function of the lung side population. Stem Cells. 2005 09;23(8):1073-81.

34. Golebiewska A, Brons NHC, Bjerkvig R, Niclou SP. Critical appraisal of the side population assay in stem cell and cancer stem cell research. Cell Stem Cell. 2011 02/04;8(2):136-47.

35. Ding X, Wu J, Jiang C. ABCG2: A potential marker of stem cells and novel target in stem cell and cancer therapy. Life Sci. 2010 04/24;86(17-18):631-7.

36. Ramos C, Montaño M, García-Alvarez J, Ruiz V, Uhal BD, Selman M, et al. Fibroblasts from idiopathic pulmonary fibrosis and normal lungs differ in growth rate, apoptosis, and tissue inhibitor of metalloproteinases expression. Am J Respir Cell Mol Biol. 2001 05;24(5):591-8.

37. Fan D, Takawale A, Lee J, Kassiri Z. Cardiac fibroblasts, fibrosis and extracellular matrix remodeling in heart disease. Fibrogenesis Tissue Repair. 2012 09/03;5(1):15.

38. Douville J, Beaulieu R, Balicki D. ALDH1 as a functional marker of cancer stem and progenitor cells. Stem Cells Dev. 2009 01/20;18(1):17-25.

39. Li Y, Kilani RT, Hartwell R, Ghahary A. MAP kinase mediates silica-induced fibrotic nodule formation and collagen accumulation in fibroblasts. J Cell Physiol. 2012 01;227(1):328-38.

40. Xu Q, Norman JT, Shrivastav S, Lucio-Cazana J, Kopp JB. In vitro models of TGF-beta-induced fibrosis suitable for high-throughput screening of antifibrotic agents. Am J Physiol Renal Physiol. 2007 08;293(2):F631-40.

41. Cha S, Groshong SD, Frankel SK, Edelman BL, Cosgrove GP, Terry-Powers J, et al. Compartmentalized expression of c-FLIP in lung tissues of patients with idiopathic pulmonary fibrosis. Am J Respir Cell Mol Biol. 2010 02;42(2):140-8. 
42. Liu G, Friggeri A, Yang Y, Milosevic J, Ding Q, Thannickal VJ, et al. miR-21 mediates fibrogenic activation of pulmonary fibroblasts and lung fibrosis. J Exp Med. 2010 08/02;207(8):1589-97.

43. Burger PE, Gupta R, Xiong X, Ontiveros CS, Salm SN, Moscatelli D, et al. High aldehyde dehydrogenase activity: A novel functional marker of murine prostate stem/progenitor cells. Stem Cells. 2009 09;27(9):2220-8.

44. Moreb JS. Aldehyde dehydrogenase as a marker for stem cells. Curr Stem Cell Res Ther. 2008 $12 ; 3(4): 237-46$.

45. Mishra A, Rojanakaul Y, Chen BT, Castranova V, Mercer RB, Wang L. Assessment of pulmonary fibrogenic potential of multiwalled carbon nanotubes in human lung cells. J Nanomater. 2012;930931:111.

46. Manke A, Luanpitpong S, Dong C, Wang L, He X, Battelli L, et al. Effect of fiber length on carbon nanotube-induced fibrogenesis. Int J Mol Sci. 2014 04/29;15(5):7444-61.

47. Bonner JC. Lung fibrotic responses to particle exposure. Toxicol Pathol. 2007 Jan;35(1):148-53.

48. Sime PJ, Marr RA, Gauldie D, Xing Z, Hewlett BR, Graham FL, et al. Transfer of tumor necrosis factor-alpha to rat lung induces severe pulmonary inflammation and patchy interstitial fibrogenesis with induction of transforming growth factor-beta1 and myofibroblasts. Am J Pathol. 1998 09;153(3):825-32.

49. Liu Y, Zhao Y, Sun B, Chen C. Understanding the toxicity of carbon nanotubes. Acc Chem Res. 2013 03/19;46(3):702-13. 
Figures

\begin{tabular}{cccc} 
Purity & \multicolumn{2}{c}{ Length } & Diameter \\
& $\begin{array}{c}\text { Solution Form } \\
(\mu \mathrm{m})\end{array}$ & $\begin{array}{c}\text { Dry Form } \\
(\mu \mathrm{m})\end{array}$ & $(\mathrm{nm})$ \\
\hline & & & \\
& & $12.9 \pm 0.55$ & $18.76 \pm 8.62$
\end{tabular}

Table 1: Physicochemical Characterization of SWCNTs. The table describes the purity, diameter and length distribution measured via AFM.
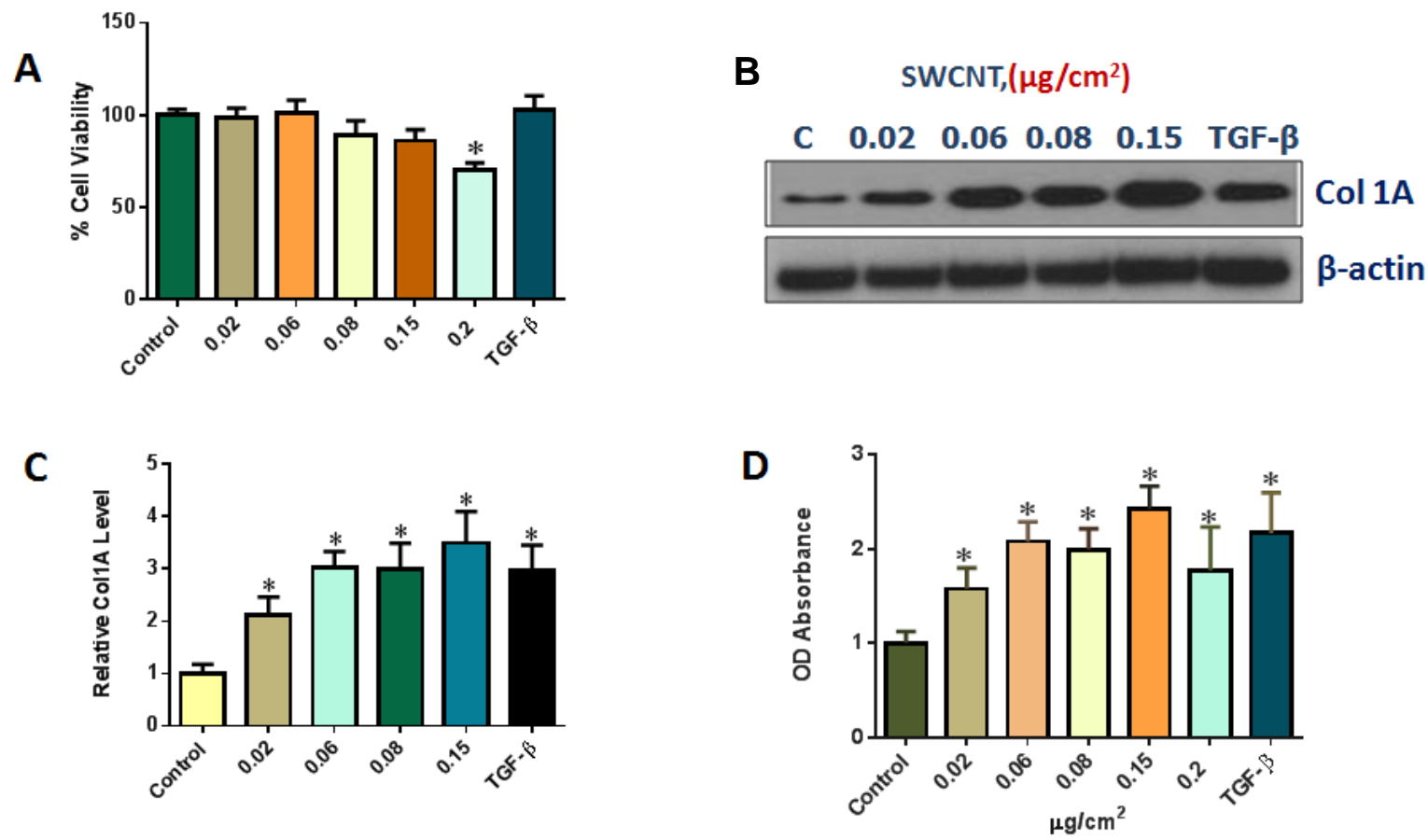

Figure I: Carbon nanotubes (CNT) induce collagen production of human lung fibroblasts Subconfluent monolayers of cells were treated with various concentrations $\left(0-0.2 \mu \mathrm{g} / \mathrm{cm}^{2}\right)$ of SWCNT, or TGF- $\beta$ ( $1 \mathrm{ng} / \mathrm{mL})$ for $48 \mathrm{~h}$. A) Analysis of cell toxicity and proliferation using WST-1 assay. B) Western blot analysis of type I collagen and $\alpha$-SMA. $\beta$-actin was used to confirm equal loading of the samples. C and D) Quantitative analysis of type I collagen and $\alpha$ - 
SMA. E) Soluble collagen content by Sircol assay. Data are means $\pm \operatorname{SD}(\mathrm{n}=3) .{ }^{*} p<0.05$ versus control cells. 


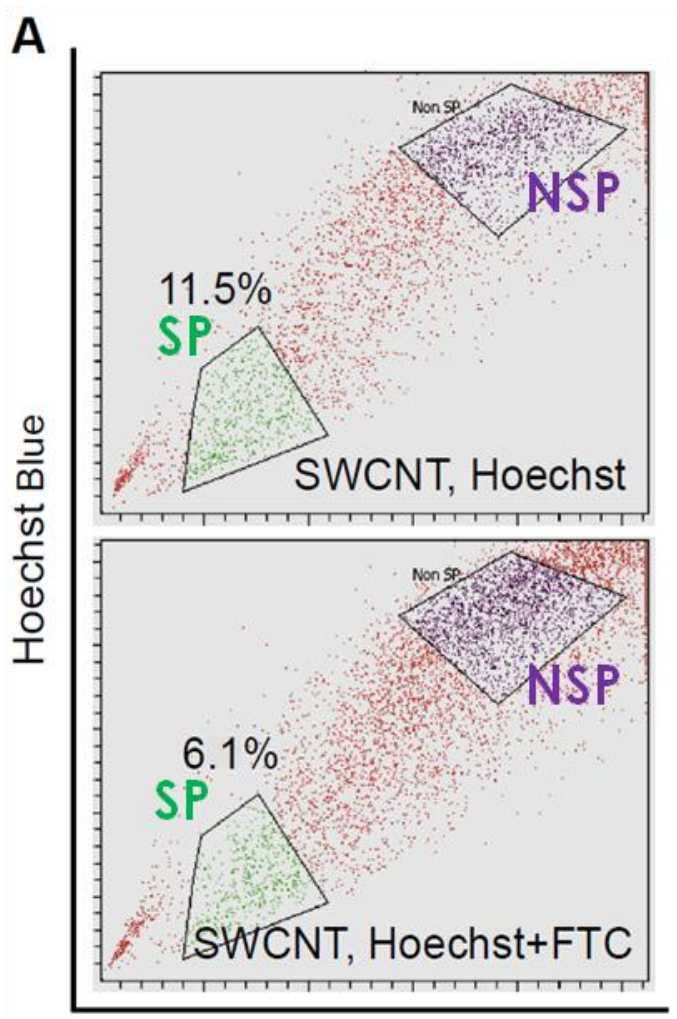

Hoechst Red
B

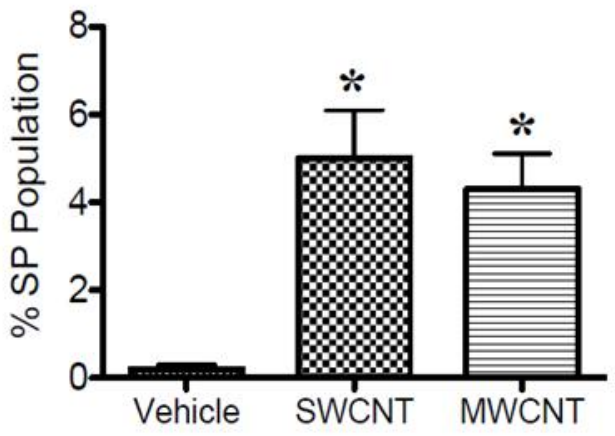

C

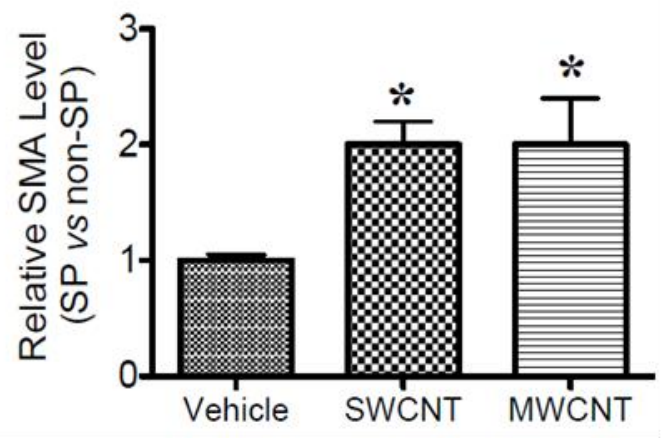

Figure II: CNT induce stem-like cells as indicated by side population (SP) phenotype

A) SWCNT-treated human lung fibroblasts isolated into SP and NSP with and without the inhibitor fumitremorgin $\mathrm{C}(\mathrm{FTC})$ as indicated by the \% population. B) \% SP population in SWCNT and MWCNT-treated lung fibroblasts as compared to vehicle-treated control. C) Relative fold change in $\alpha$-SMA expression (SP versus non-SP cells) in CNT-treated cells compared to vehicle-treated control. D) Data are means $\pm \mathrm{SD}(\mathrm{n}=3) .{ }^{*} p<0.05$ versus control cells. 
A

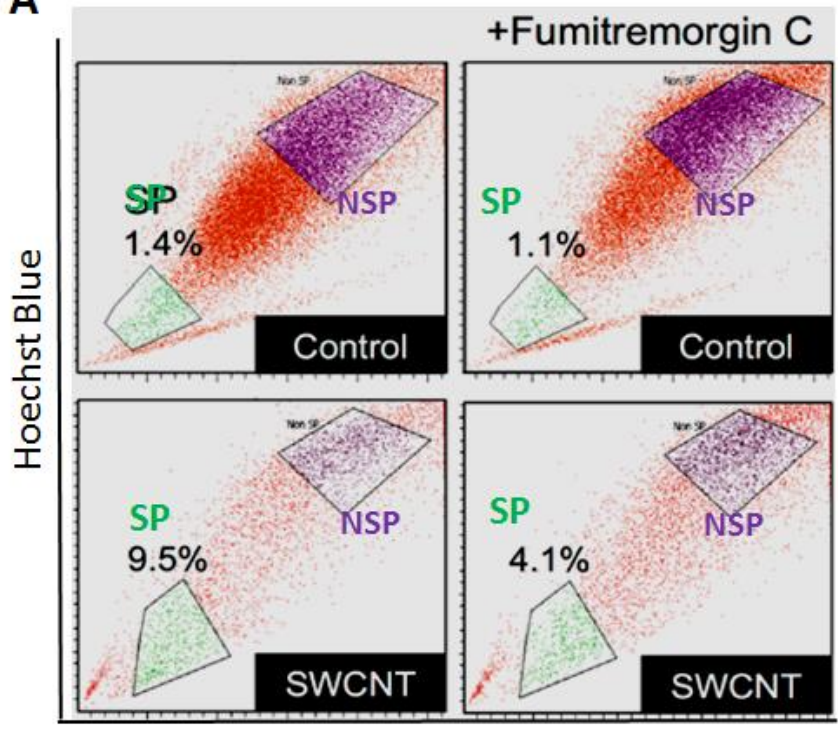

Hoechst Red
B
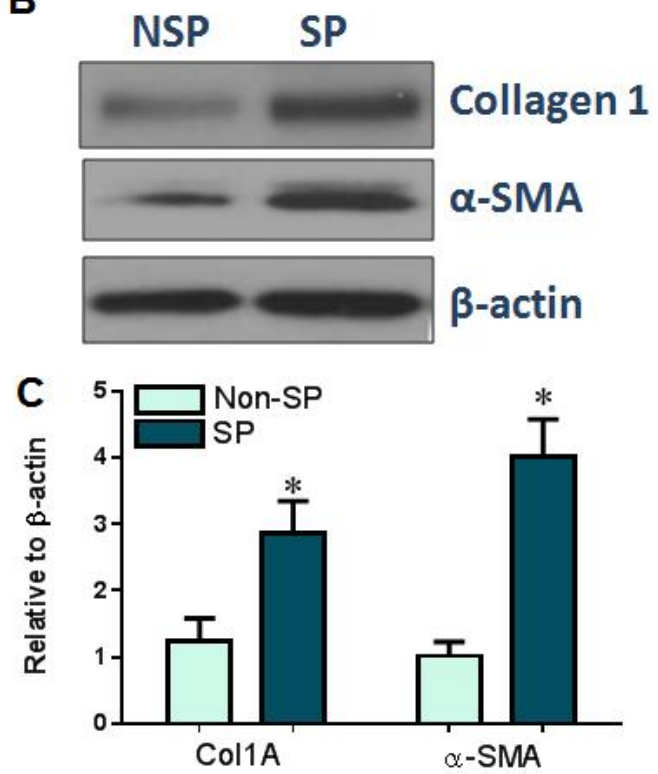

Figure III: CNT-induced SP fibroblasts are a potential source of collagen I and a-SMA

A) SWCNT-treated human lung fibroblasts isolated into SP and NSP with and without the inhibitor fumitremorgin C (FTC) as indicated by the \% population. B) Quantitative analysis of \% SP population in SWCNT and MWCNT-treated lung fibroblasts. C) Type I collagen and $\alpha$-SMA expression in SWCNT-induced SP versus non-SP cells. D) Quantitative analysis of type I collagen and $\alpha$-SMA. Data are means \pm SD $(n=3) .{ }^{*} p<0.05$ versus Non-SP cells. 


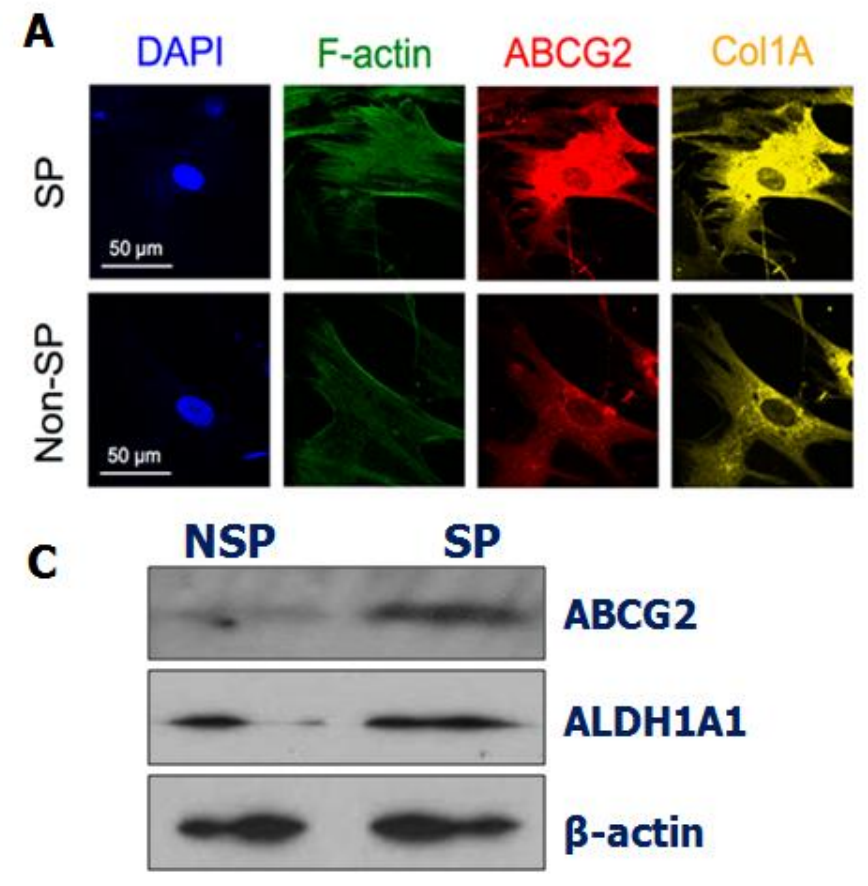

B
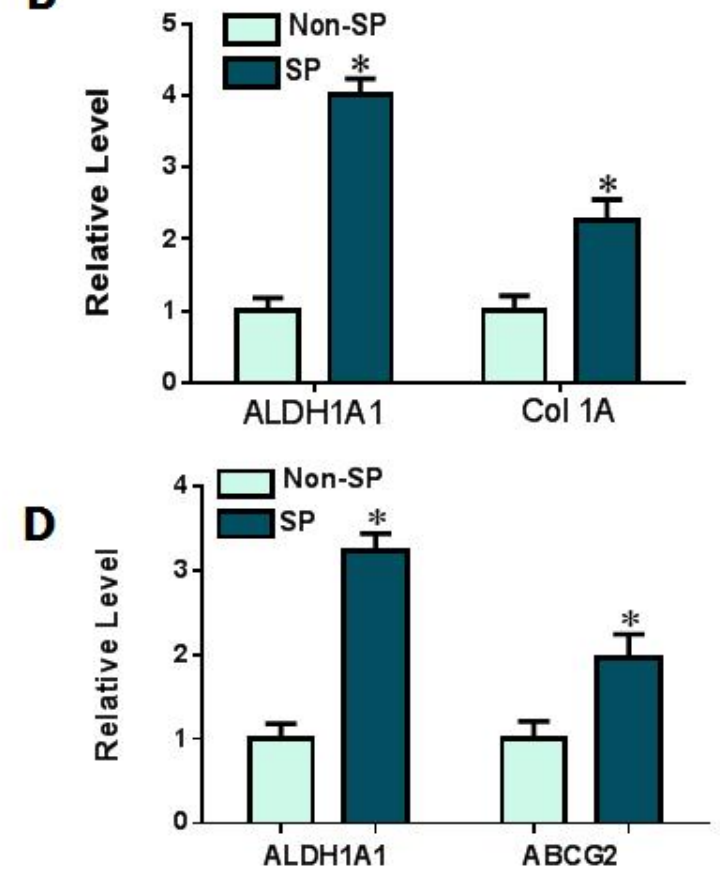

Figure IV: Enhanced fibrogenic response of CNT-derived SP fibroblasts

Cells were treated with SWCNT $\left(0.15 \mu \mathrm{g} / \mathrm{cm}^{2}\right)$ for $48 \mathrm{~h}$ and stained with Hoechst 33342 dye for side population (SP) analysis. SP fibroblasts were characterized and isolated by FACS. A) Fluorescence micrographs of the sorted SP fibroblasts and parental control non-SP fibroblasts immunostained for phalloidin (F-actin, green), stem cell marker ABCG2 (red), and type I collagen (yellow) by confocal fluorescence microscopy. B) Quantitative analysis of ABCG2 and type I collagen expression. C) ABCG2 and ALDH1A1 stem cell marker expression in CNTinduced SP versus non-SP stem-like fibroblasts. D) Quantitative analysis of type I collagen and $\alpha$-SMA. Data are means $\pm \mathrm{SD}(\mathrm{n}=3) .{ }^{*} p<0.05$ versus Non-SP fibroblasts. 
A

Control, BSA

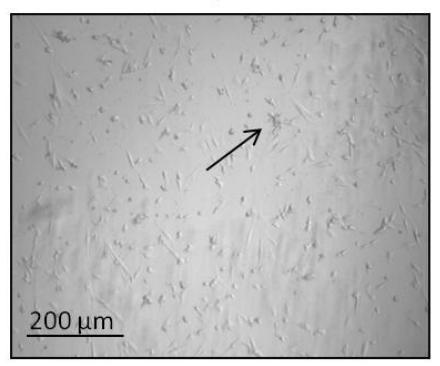

SWCNT $0.15 \mu \mathrm{g} / \mathrm{cm}^{2}$

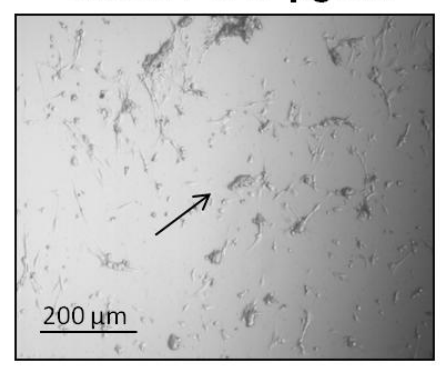

SWCNT $0.1 \mu \mathrm{g} / \mathrm{cm}^{2}$

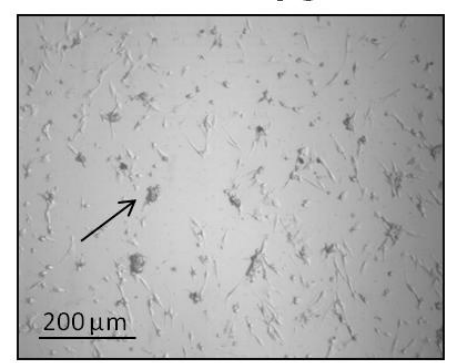

TGF- $\beta 1 \mathrm{ng} / \mathrm{mL}$

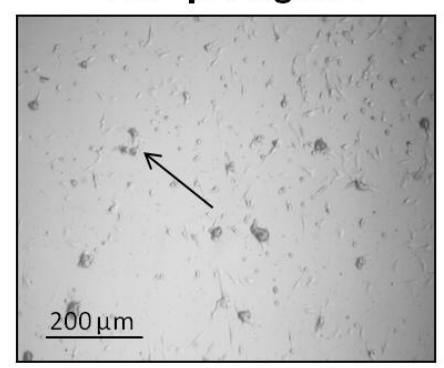

B

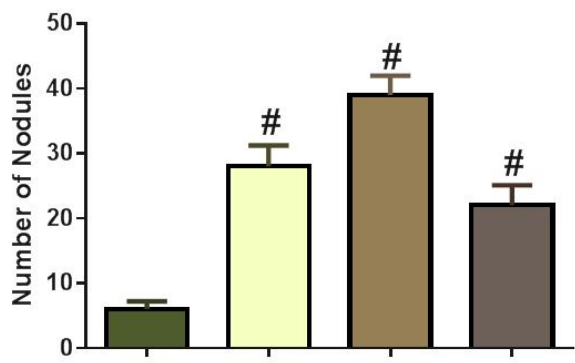

C
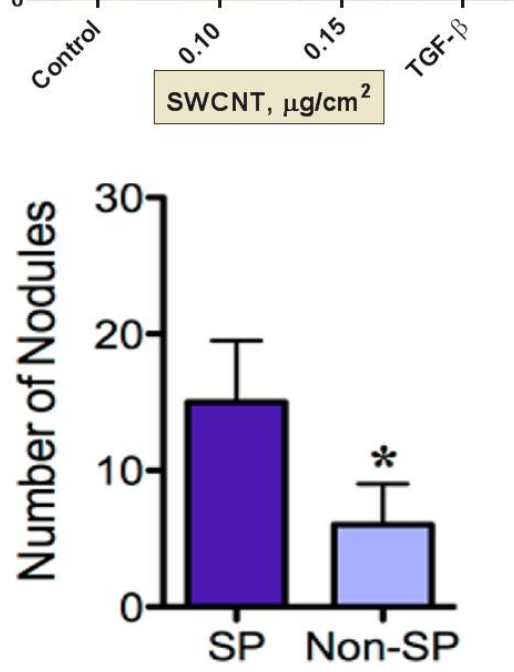

Figure V: CNT induce fibroblast nodule formation of human lung fibroblasts

Cells at the density of $3 \times 10^{4}$ cells/24-well were grown on a poly-L-lysine-coated glass substrate and treated with various concentrations $\left(0-0.15 \mu \mathrm{g} / \mathrm{cm}^{2}\right)$ of SWCNT or TGF- $\beta(1 \mathrm{ng} / \mathrm{mL})$ for 16 h. A) Phase contrast micrographs comparing 3D fibroblastic nodules in control and treated fibroblasts. B) Quantitative analysis of fibroblastic nodules in SWCNT and TGF- $\beta$ treated lung fibroblasts versus control. C) Quantitative analysis of fibrotic nodules in SWCNT-induced SP versus non-SP cells. Data are means $\pm \mathrm{SD}(\mathrm{n}=3)$. $\# p<0.05$ versus control cells; ${ }^{*} p<0.05$ versus SP fibroblasts. 
A
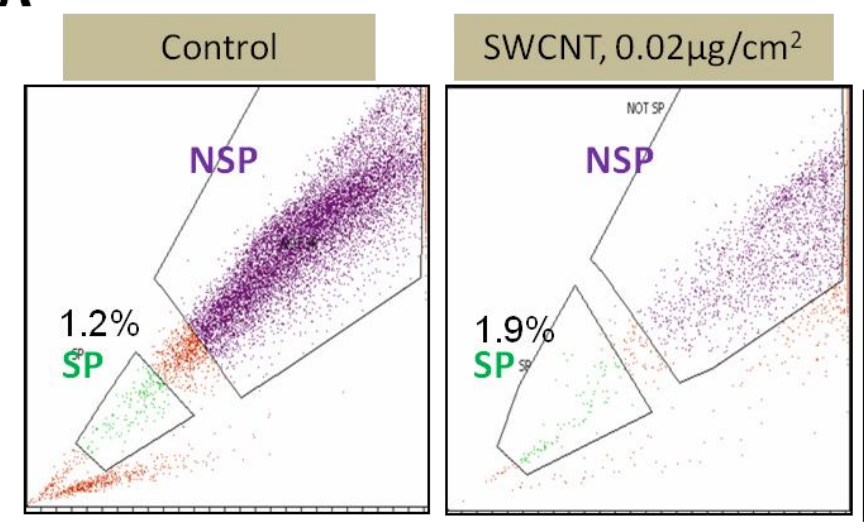

SWCNT, $0.15 \mu \mathrm{g} / \mathrm{cm}^{2}$

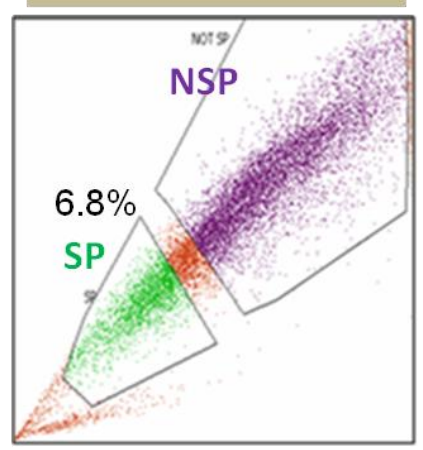

\section{SWCNT, $0.2 \mu \mathrm{g} / \mathrm{cm}^{2}$}

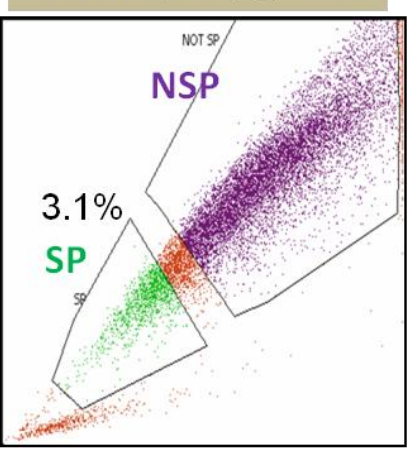

\section{SWCNT, $0.08 \mu \mathrm{g} / \mathrm{cm}^{2}$}

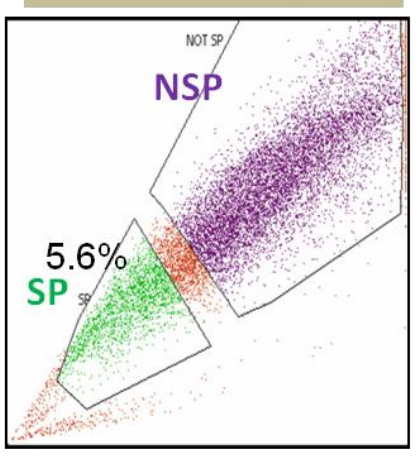

B

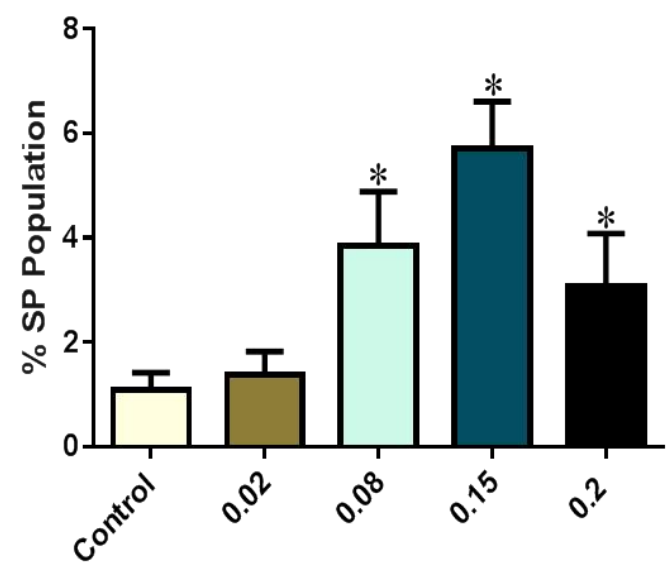

$\mu \mathrm{g} / \mathrm{cm}^{2}$

Figure VI: CNT-induced SP is dose dependent

SWCNT induced stem-like cells as indicated by side population (SP) phenotype in a dosedependent manner. A) Primary lung fibroblasts were treated with SWCNT $\left(0-0.20 \mu \mathrm{g} / \mathrm{cm}^{2}\right)$ for $48 \mathrm{~h}$ and stained with Hoechst 33342 dye for side population (SP) analysis as indicated by the \% population. SP fibroblasts were characterized and isolated by FACS. B) Quantitative analysis of $\%$ SP population in SWCNT-treated lung fibroblasts. Data are means \pm SD $(n=3) . * p<0.05$ compared to control cells. 


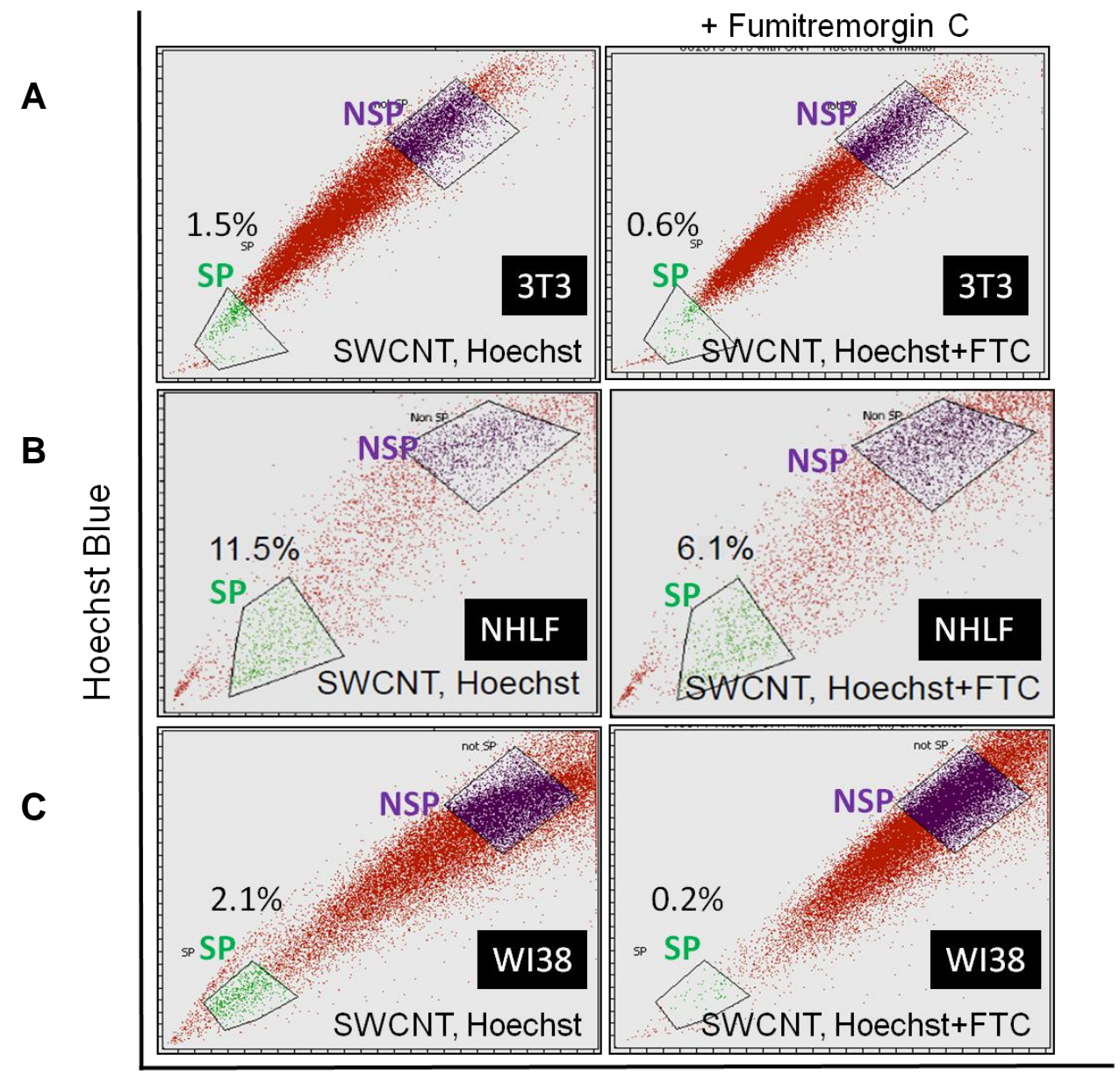

Hoechst Red

\section{Figure VII: CNT induced SP is cell type-dependent}

Fibroblast cells were treated with SWCNT $\left(0.15 \mu \mathrm{g} / \mathrm{cm}^{2}\right)$ for $48 \mathrm{~h}$ and stained with Hoechst 33342 dye for side population (SP) analysis with and without the inhibitor fumitremorgin C (FTC). Representative FACS micrographs showing A) \% SP population in SWCNT-treated primary human lung fibroblasts as compared to vehicle-treated control, B) \% SP population in SWCNT-treated $3 \mathrm{~T} 3$ mouse lung fibroblasts as compared to vehicle-treated control, and C) $\% \mathrm{SP}$ population in SWCNT-treated WI 38 human lung fibroblasts as compared to vehicle-treated control. 


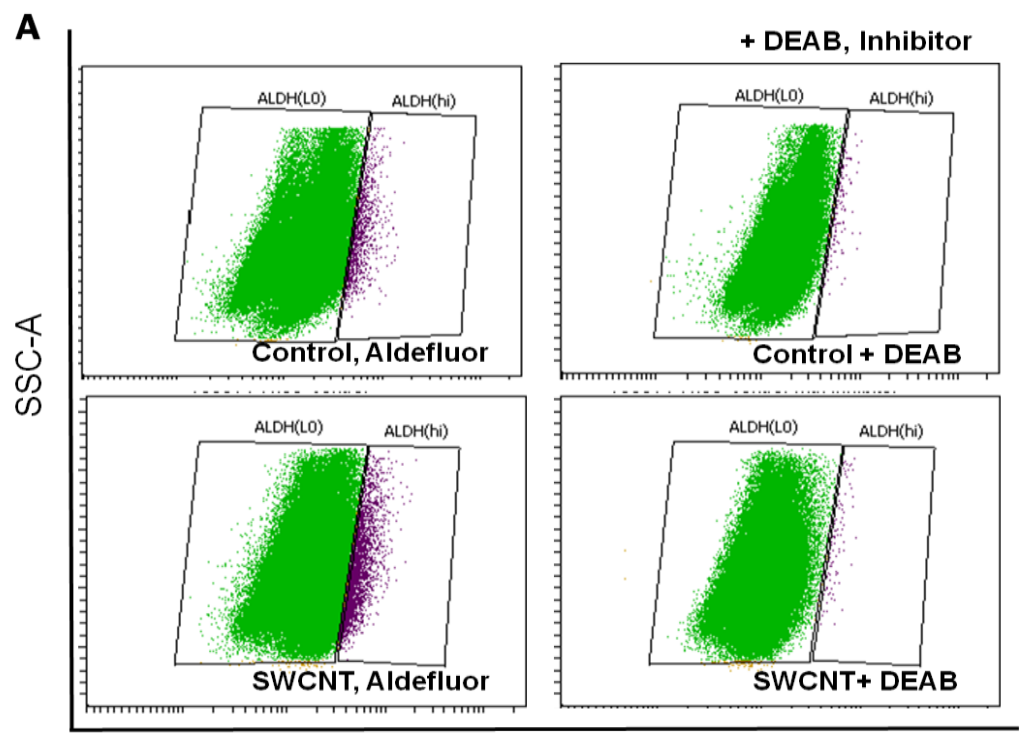

ALDH FITC-A

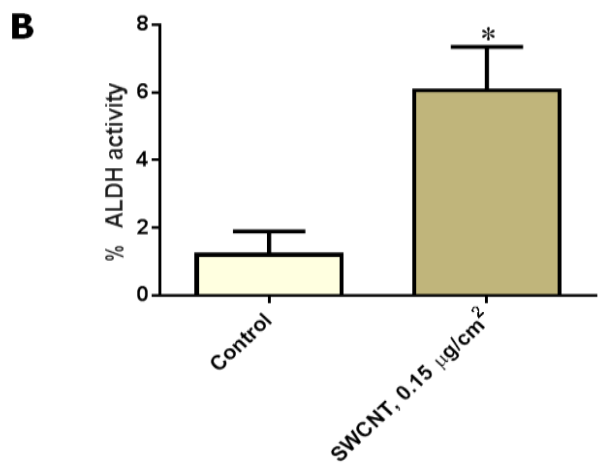

Figure VIII: CNT upregulate ALDH activity of lung fibroblasts

A) WI 38 human lung fibroblasts were treated with SWCNT $\left(0.15 \mu \mathrm{g} / \mathrm{cm}^{2}\right)$ for $24 \mathrm{~h}$ and stained with Aldeflour dye in the presence or absence of $1.5 \mathrm{mM}$ ALDH inhibitor, diethylaminobenzaldehyde (DEAB) for ALDH activity analysis. Cells with increased ALDH activity were characterized and isolated by FACS. B) Quantitative analysis of \% ALDH activity in SWCNT-treated lung fibroblasts compared to control. Data are means $\pm \mathrm{SD}(\mathrm{n}=3) .{ }^{*} p<0.05$ compared to control cells. 
CHAPTER 3 


\section{CHAPTER 3: ROLE OF REACTIVE OXYGEN SPECIES IN STEMNESS DEVELOPMENT AND FIBROGENESIS INDUCED BY CARBON NANOTUBES}

\section{Abstract}

The unique physicochemical and electrical properties of carbon nanotubes (CNTs) make them highly desirable in a variety of commercial and biomedical applications. However, these novel properties of CNTs are fraught with concerns for environmental and occupational exposure. Changes in their structural and physicochemical properties can lead to changes in biological activities including reactive oxygen species (ROS) generation; one of the most frequently reported CNT-associated toxicities. CNT exposure results in ROS-dependent activation of several transcription factors and signaling pathways involved in the regulation of inflammation and fibrosis. ROS are known to regulate several cellular responses such as collagen production, fibroblast to myofibroblast activation, and angiogenesis implicated in CNT-induced fibrosis. We have previously demonstrated the existence of fibroblast stem-like cells (FSCs) and their role in CNT-induced fibrogenesis. It is unknown whether CNT-induced oxidative stress is essential for the development of stemness phenotype of FSCs. We hypothesized that this process is under the regulation of ROS and that such stemness phenotype is essential to the fibrogenic activity of FSCs that contributes to fibrosis. Normal human lung fibroblasts were treated with single-walled CNTs in the presence or absence of various known ROS modulators, and FSCs were identified by their side population (SP) and isolated by fluorescence activated cell sorting (FACS). Our results demonstrated that i) SWCNTs induced ROS generation in human lung fibroblasts, ii) such induction, particularly peroxides, are required for the generation of FSCs, iii) the fibrogenic activity of these FSCs is under the regulation of ROS, iv) effect of fiber length and surface modification on SWCNT-induced oxidative stress, and v) SWCNT-induced FSCs exhibited 
substantial downregulation of antioxidant enzymes including catalase, glutathione peroxidase and superoxide dismutase. These findings indicate a novel mechanism of CNT fibrogenesis regulation through ROS-dependent induction of FSCs, which may be targeted for disease intervention.

Keywords: Reactive oxygen species (ROS), fibrosis, fibroblast stem-like cell (FSC), N-acetyl cysteine (NAC), oxidative stress, SWCNT 


\section{Introduction}

Uncontrolled regulation of reactive oxygen species (ROS) generation has been implicated in the pathogenesis of several diseases including lung inflammation and fibrosis.[1,2] Increased ROS generation leading to oxidative stress and cellular damage is one of the most frequently reported toxicity endpoints caused by carbon nanotube (CNT) exposure.[3-6] Oxidative stress may be caused directly by CNT-induced ROS in the vicinity or inside the cell, or indirectly due to the effect of internalized CNTs on mitochondrial respiration $[7,8]$ or depletion of ROS scavengers and antioxidant enzymes within the cell.[9] Incomplete phagocytosis of CNTs, presence of transition metals such as iron, cobalt and nickel introduced within the CNTs during their synthesis, and specific reactive groups on the CNT surface are key drivers of ROS generation.[7, 10, 11] Nanoparticle-induced ROS responses have been reported to orchestrate a series of pathological events such as genotoxicity [12, 13], inflammation [14], fibrosis [5, 15], and carcinogenesis.[16] For instance, CNT-induced oxidative stress triggers cellular signaling pathways such as NF-кB, STAT-1, MAPK, and RTK resulting in increased expression of proinflammatory and fibrotic cytokines.[15, 17-20] CNT-induced ROS generation has also been shown to regulate several cellular events such as collagen production, fibroblast to myofibroblast transition, and angiogenesis, which have been implicated in the pathogenesis of lung fibrosis.[5, 15, 21] Previous studies by our group also indicate the involvement of ROS in CNT-induced fibrogenesis. $[15,22]$ We demonstrated the pathogenic role of fibroblast stem-like cells (FSCs) in SWCNT-induced fibrogenic response in chapter 1. Recent studies indicate the differentiation of stem cells into myofibroblasts and their contribution to tissue fibrosis.[23-25] Interestingly, ROS have been shown to play an essential role in the fate and physiology of normal stem cells; there is evidence demonstrating that ROS production promotes proliferation and survival of both 
stem and progenitor cells.[26] Currently, there is no information linking CNT-induced oxidative stress and stemness development. This study was undertaken, in part, to evaluate whether CNTinduced oxidative stress is essential for the development and maintenance of stemness phenotype of FSCs during SWCNT-induced fibrogenesis.

The relationship between ROS and stem cell development is not well understood, although ROS have been suggested to play a role in the differentiation and maintenance of stem cells.[27] ROS and antioxidants are essential to maintain a redox balance within cells and tissues. Many cellular processes including proliferation, differentiation, apoptosis, and response to injury are governed via intracellular ROS.[28] The redox environment is particularly important for stem cell differentiation and self-renewal.[29] Low ROS level within stem cells has been reported to maintain their stemness, whereas a high level promotes differentiation, proliferation and survival.[30] However, normal stem cells are generally thought to maintain low ROS level to protect against damage.[31] High ROS levels are detrimental to cells and tissues. As a result, just as oxidative stress is associated with multiple disorders; elevated ROS levels have been implicated in the progression of stem cell-associated pathologies.[27] For instance, ROS promote stem cell expansion in colorectal cancer.[32] Increased oxidative status has been shown to drive stem cell activity of neuroepithelial and skin stem cells.[33, 34] Currently, stem cells continue to be pursued as potential therapy for regeneration and tissue repair; however, they have both adaptive and maladaptive responses to oxidative stress. For example, acute bursts of ROS to embryonic stem cells (ESCs) in culture facilitate differentiation toward cardiomyocyte phenotype, whereas prolonged exposure to $\mathrm{H}_{2} \mathrm{O}_{2}$ inhibits differentiation.[35] The effect of ROS has been reasonably studied in certain stem cell types; however their effect on the differentiation of stem-like cells into myofibroblasts during lung fibrosis is not known. Whether oxidative stress 
drives the stem-like cell induction associated with CNT-induced fibrosis remains to be explored. Unveiling such regulation could lead to the identification of novel biomarkers or drug targets for disease treatment and prevention. We hypothesized that ROS are involved in the development of fibroblast stem-like cells during CNT-induced fibrosis. In this part of the study, we investigated whether ROS regulate the stem phenotype of lung fibroblasts during CNT exposure and identified the specific ROS important for the stemness development. 


\section{Experimental Section}

\section{SWCNT Preparation}

SWCNTs were prepared by plasma purified chemical vapor deposition process and were obtained from Cheap Tubes Inc. (Brattleboro, VT, USA). They were dispersed in culture medium containing $5 \%$ serum by water-bath sonication. Before exposure to the cells, the SWCNT dispersion was lightly sonicated (Sonic Vibra Cell Sonicator, Sonic \& Material Inc., Newtown, CT, USA) with the power, frequency, and amplitude settings of $130 \mathrm{~W}, 20 \mathrm{kHz}$, and $60 \%$ respectively for $10 \mathrm{~s}$.

\section{Chemicals and Reagents}

Antibodies for collagen type I and TGF- $\beta$ were obtained from Fitzgerald (Concord, MA, USA) and Cell Signaling Technology (Beverly, MA, USA), respectively. $\beta$-actin antibody and horseradish peroxidase (HRP)-conjugated secondary antibodies were obtained from Santa Cruz Biotechnology (Santa Cruz, CA, USA). Mn (III) tetrakis (4-benzoic acid) porphyrin (MnTBAP) was obtained from Calbiochem (La Jolla, CA). Catalase (CAT) was from Roche Molecular Biochemicals (Indianapolis, IN). The oxidative probes, dichlorodihydrofluorescein diacetate (DCF-DA) and dihydroethidium (DHE) were from Molecular Probes (Eugene, OR). All other chemicals and reagents including $N$-acetyl cysteine (NAC) were from Sigma-Aldrich (St. Louis, MO).

Energy Dispersive X-ray Spectroscopy (EDX-S) (Some experiments were performed in the laboratory of Dr. Cerasela-Zoica Dinu)

EDX-S was used to perform elemental analysis of SWCNT samples. Data were collected on a LEO 1530 VP scanning electron microscope equipped with an energy-dispersive X-ray analyzer 
(Hitachi S-4700 Field Emission Scanning Electron Microscope, Hitachi High Technologies Co., Tokyo, Japan). A few drops of SWCNT dispersion in cell culture medium were placed on a silicon wafer and allowed to air-dry. The silicon wafer was then mounted on an aluminum stub for EDX-S analysis.

Atomic Force Microscopy (AFM) (Some experiments were performed in the laboratory of Dr. Cerasela-Zoica Dinu)

AFM was used to determine the length and diameter distribution of SWCNT samples using Digital Instrument Nanoscope II (Model No. MFP-3D-AFM, Asylum Research, Goleta, CA, USA). A Si tip (50-90 kHz AC240TS, Asylum Research, Goleta, CA, USA) was used to perform tapping mode in air. SWCNT samples were deposited on mica surfaces $(9.5 \mathrm{~mm}$ diameter, 0.15 $0.21 \mathrm{~mm}$ thickness, Electron Microscopy Sciences, Hatfield, PA, USA) and allowed to dry overnight under vacuum. Scan angel was set as 0 , scan rate was set as $0.5 \mathrm{~Hz}$, and resolution was set as 512 . Scan images of $20 \times 20$ or $10 \times 10 \mu \mathrm{m}$ areas were acquired. For each sample, at least 30 individual SWCNT particles were counted and measured to obtain average length and diameter distribution.

\section{Cell Culture}

Normal human lung fibroblasts (NHLFs) were obtained from Lonza (Walkersville, MD, USA). The cells were maintained in Fibroblast Basal Medium (Lonza, CC-4126) containing growth supplements. The cells were cultured at $37{ }^{\circ} \mathrm{C}$ in $5 \% \mathrm{CO}_{2}$ incubator and were passaged at preconfluent densities using a medium containing $0.05 \%$ trypsin. 


\section{Isolation of FSCs using Flow Cytometry}

Cell subsets markedly enriched for stem cell activity are characterized by their ability to efflux the vital dye Hoechst 33342 via multidrug-like transporter ABCG2. After specific treatments, cells were harvested using $0.05 \%$ trypsin and stained with Hoechst dye at the final concentration of $5 \mu \mathrm{g} / \mathrm{ml}$. Flow cytometry experiments included Hoechst-stained lung fibroblasts, unstained fibroblasts, and cell suspensions incubated with Hoechst 33342 and the dye uptake inhibitor, fumitremorgin C (FTC). Gates were set according to the controls. The Hoechst dye was excited with a UV laser and its fluorescence was measured with both 450/20 filter (Hoechst Blue) and 675 LP filter (Hoechst Red), sorting was performed using FACS ARIA (BD Biosciences, San Jose, CA, USA).

\section{Western Blot Analysis}

Collagen protein expression was determined by Western blotting. After specific treatments, cells were incubated in lysis buffer containing $20 \mathrm{mM}$ Tris- $\mathrm{HCl}(\mathrm{pH} 7.5), 1 \%$ Triton $\mathrm{X}-100,150 \mathrm{mM}$ sodium chloride, $10 \%$ glycerol, $1 \mathrm{mM}$ sodium orthovanadate, $50 \mathrm{mM}$ sodium fluoride, $100 \mathrm{mM}$ phenylmethylsulfonyl fluoride, and a commercial protease inhibitor mixture (Roche Molecular Biochemicals, Indianapolis, IN, USA) at $4{ }^{\circ} \mathrm{C}$ for $20 \mathrm{~min}$. Cell lysates were collected and protein concentrations were determined using a bicinchoninic acid protein assay kit (Pierce Biotechnology, Rockford, IL, USA). Equal amount of protein per sample (40 $\mu \mathrm{g})$ was resolved under denaturing conditions by $10 \%$ SDS-PAGE and transferred onto a nitrocellulose membrane. The membranes were blocked for $1 \mathrm{~h}$ in $5 \%$ nonfat dry milk in TBST ( $25 \mathrm{mM}$ Tris-HCl, $\mathrm{pH} 7.4$, $125 \mathrm{mM}$ sodium chloride, $0.05 \%$ Tween 20 ) and incubated with appropriate primary antibodies

at $4{ }^{\circ} \mathrm{C}$ for $12 \mathrm{~h}$. Membranes were washed thrice with TBST for $10 \mathrm{~min}$ and incubated with HRPlabeled isotype-specific secondary antibodies for $1 \mathrm{~h}$ at room temperature. The immune 
complexes were then detected by enhanced chemiluminescence detection system (Supersignal ${ }^{\circledR}$ West Pico, Pierce, Rockford, IL, USA). The bands were quantified via densitometry using Image J software, version 10.2 (GraphPad Software Inc., La Jolla, CA, USA). Mean densitometry data from independent experiments were normalized to results in cells from control experiments.

Fluorometric Assay for ROS Detection

Intracellular ROS was determined fluorometrically using DCF-DA and DHE as fluorescent probes. After treatment with SWCNTs, the cells were incubated with the probes $(5 \mathrm{mM})$ for 30 $\min$ at $37^{\circ} \mathrm{C}$, after which they were analyzed for fluorescence intensity using a multi-well plate reader (FLUOstar OPTIMA BMG LABTECH Inc., Durham, NC, USA) at the excitation/emission wavelengths of 485/535 and 485/610 nm for DHE and DCF fluorescence measurements, respectively.

\section{Statistical Analysis}

The data represent mean \pm S.D. from three or more independent experiments. ANOVA was performed to determine statistical significance between treatment and control groups using Graph Pad Prism 6.0 (GraphPad Software Inc., La Jolla, CA, USA) at a confidence level of $* p<$ 0.05 . 


\section{Results}

\section{Effect of SWCNTs on Cellular Oxidative Stress}

Since oxidative stress has been implicated as an underlying mechanism for pulmonary fibrosis [36], we investigated the effect of SWCNTs on cellular ROS generation as an indicator of oxidative stress. Cells were treated with SWCNTs and analyzed for ROS generation by fluorometry using DCF-DA and DHE as fluorescent probes for hydrogen peroxide and superoxide radicals, respectively (Figure 1). SWCNTs induced a dramatic increase in cellular DCF fluorescence intensities, indicative of peroxide formation (Figure 1A), but had negligible effect on DHE fluorescence, indicative of superoxide formation (Figure 1B). Pretreatment of the cells with general antioxidant $\mathrm{N}$-acetyl cysteine (NAC) strongly inhibited the ROS-inducing effect of SWCNTs (Figure 1A). Likewise, pretreatment of the cells with catalase, a peroxide scavenger, effectively inhibited the ROS generation (Figure 1A), indicating the induction of peroxides by SWCNTs and the specificity of peroxide detection by DCF fluorescence measurements in the tested cell system. Figure 1B shows the inhibitory effect of MnTBAP, a superoxide scavenger, on SWCNT-induced DHE fluorescence, confirming the specificity of superoxide detection and the limited induction of superoxide anions by SWCNTs. Together, these results indicate the ROS-inducing effect of SWCNTs, particularly peroxides, in cultured human lung fibroblasts.

\section{Effect of Length and Surface Modification on SWCNT-Induced ROS Generation}

Certain physicochemical properties of nanoparticles (NPs), such as prooxidant functional groups and surface activity, have been suggested as key determinants of NP-induced ROS generation.[37, 38] In this study, we further investigated the effect of fiber length and functionalization on SWCNT-induced ROS generation. Lung fibroblasts were treated with 
SWCNTs of different lengths and functionalities, and analyzed for ROS generation by fluorometry. As compared to pristine, non-functionalized (NF) SWCNTs of similar length, the modified SWCNTs, including $\mathrm{COOH}$, nitrogen-containing and $\mathrm{OH}$ elicited a weaker ROS response (Figure 2A). Both short and long SWCNTs induced ROS generation as indicated by their increased cellular DCF fluorescence intensities over control level. However, long SWCNTs were more potent inducers of ROS generation compared to short SWCNTs (Figure 2B). In all experiments, pretreatment of the cells with NAC or catalase strongly inhibited the DCF fluorescence signals (Figure 2A, 2B), indicating the general ability of SWCNTs of different lengths and surface modifications to induce ROS.

\section{Role of ROS in SWCNT-Induced Fibrogenesis}

Oxidative stress signaling has been linked to excessive accumulation of extracellular matrix (ECM).[39] Previous work from our group demonstrated that CNTs induce a ROS-dependent fibrogenic effect on lung fibroblasts by upregulating collagen expression and cell proliferation.[15] To determine the role of ROS in SWCNT-induced fibrogenic effect, fibroblasts were treated with SWCNTs of various lengths and surface modifications in the presence or absence of the antioxidant NAC. All forms of SWCNTs were able to induce collagen expression with the unmodified CNTs being most potent (Figure 3A, 3C). Long SWCNTs induced a more robust collagen response than short SWCNTs (Figure 3B, 3D). Moreover, NAC pretreatment abrogated the collagen-inducing effect of all forms of SWCNTs, supporting the role of ROS in SWCNT-induced fibrogenesis.

\section{Role of ROS in CNT-Induced Fibroblast Stem-like Cell (FSC) Generation}

Previous studies have identified a stem-like side population (SP) of cells using flow cytometry.[40, 41] SP is the cell population identified by its capacity to efflux Hoechst dye that 
is highly enriched for stem/progenitor cell activity. SP cells appear "off to the side" of the main population of cells due to their relative absence of staining.[42] Our previous study from chapter 1 demonstrated the ability of SWCNTs to induce stem-like fibroblasts as evidenced by their side population phenotype. Furthermore, these cells also express stem cell markers, including ALDH1A1 and ABCG2. In order to determine the role of ROS on stemness induction, human lung fibroblasts were treated with SWCNTs with or without antioxidant pretreatment, and subsequently sorted into SP and NSP by FACS. NAC and catalase pretreatment significantly inhibited SP induced by SWCNTs, whereas superoxide scavenger MnTBAP pretreatment had minor effect (Figure 4A, 4B), supporting the role of peroxides in the induction of FSCs by SWCNTs.

\section{Role of ROS in Fibrogenic Activity of Fibroblast Stem-like Cells}

SWCNT-treated lung fibroblasts were subjected to FACS and isolated into SP and NSP with and without antioxidant pretreatment. NAC and catalase pretreatment, in addition to inhibiting SP (Figure 4A, 4B), also downregulated collagen I expression in SWCNT-treated SP fibroblasts (Figure 4C, 4D and 4E, 4F). These results indicate the linkage between stem cell induction and collagen production as well as their regulation by ROS.

\section{Identification of Specific Antioxidant Enzymes in Fibroblast Stem-like Cells}

Stem cells have been shown to possess special antioxidant defense mechanisms in order to ward off elevated ROS levels and thus maintain their genomic identity.[27] To test the role of antioxidant enzymes in FSC induction, human lung fibroblasts were exposed to SWCNTs, and their SP and non-SP fractions were isolated by flow cytometry and subsequently analyzed for their expression of antioxidant enzymes including catalase, superoxide dismutase and glutathione peroxidase by Western blotting (Figure 5A). Interestingly, the expression of catalase, GPX1, 
SOD1 and SOD2 were downregulated in SP versus non-SP cells, suggesting that higher amounts of antioxidant enzymes may be required to rescue the increased ROS production in CNT-induced SP versus non-SP cells (Figure 5B, 5C). Furthermore, SP and non-SP cells isolated via flow cytometry were analyzed for ROS generation by fluorometry using DCF-DA as fluorescent probe for hydrogen peroxide. SP induced substantially higher DECF fluorescence intensities compared to non-SP suggestive of peroxide anion formation (Figure 5D). The increased ROS response in SP versus non-SPs could potentially explain the reduced antioxidant enzyme expression in these stem-like cells. 


\section{Discussion}

ROS-dependent activation of transcription factors and signaling pathways has been shown to regulate fibrosis.[19] CNTs have been shown to induce ROS generation in various cell types $[6,15,43,44]$ mediating important cellular processes including inflammation, cell injury, apoptosis, and activation of cellular signaling pathways implicated in the pathogenesis of lung fibrosis. ROS have also been shown to be key regulators of stem cell renewal and differentiation.[26-28] Previous studies have demonstrated the involvement of ROS in CNTinduced fibrogenic effects.[5, 15, 21, 22] However, whether ROS and stemness are associated during CNT-induced fibrosis is not known. In this study, we demonstrated that ROS are essential for inducing FSCs in human lung fibroblasts upon SWCNT exposure. Our findings are in good agreement with previous studies indicating that stem cells maintain their genomic identity by maintaining certain intracellular ROS levels.

Regulation of oxidative stress is critical for maintaining "stemness" and differentiation of stem cells, as well as in progression of stem cell-associated disorders.[26, 27] In our model of CNT-induced stem-like fibroblasts, ROS scavengers NAC and catalase successfully abrogated the generation of FSCs from fibroblasts as evidenced by SP assay, implying that redox status of the FSCs has a significant role in maintaining their identity (Figure 4A and 4B). Furthermore, the SP fibroblasts generated from antioxidant pretreatment showed downregulation of collagen I levels compared to SP without antioxidant pretreatment, revealing a novel role of ROS in CNTinduced stemness phenotype and the resulting fibrogenicity (Figure 4C and 4E). Thus, our findings suggest that oxidative stress could potentially drive the CNT-induced stem cell activity; moreover, the SP-driven fibrogenic effects are under the direct regulation of ROS. 
Next we investigated key antioxidant enzymes involved in the induction of FSCs and maintenance of stemness during SWCNT-induced fibrogenesis. Interestingly, SWCNT-induced SP fibroblasts down-regulated the expression of peroxide and superoxide-scavenging enzymes as compared to non-SP fibroblasts which may likely occur in order to rescue the elevated ROS response in SP over non-SP cells. In an event of increased oxidative stress, stem cells possess antioxidant defense systems including ROS scavengers and antioxidants to rescue the decline in their cellular properties and restore the functional properties.[45-47] Pluripotent stem cells (PSCs) have been shown to possess limited ROS levels and superior antioxidant defense systems to maintain their stemness via downregulation of antioxidant enzymes.[48] Moreover, a study on human induced pluripotent stem cells (iPSCs) derived from Parkinson's disease patients demonstrated reduced efficiency of their antioxidant defense activity in disease-relevant conditions.[49] These studies may possibly explain the reduced antioxidant enzyme expression in SP versus non-SP fibroblasts observed in our study (Figure 5B, 5C) since we have demonstrated the pathogenic role of SWCNT-derived FSCs in fibrogenesis.

The regulatory role of ROS in pulmonary fibrosis remains under intense investigations. Since increased ROS production is tightly linked with pulmonary fibrosis [50], we investigated the effect of SWCNTs on cellular ROS. SWCNTs induce substantial increase in cellular DCF fluorescence, indicative of peroxide formation which was successfully abrogated by NAC and catalase; but had minimal effect on DHE fluorescence indicative of superoxide formation.

One of the ways through which CNTs induce ROS includes the oxidant-generating property of particles due to the presence of prooxidant functional groups on the reactive surface.[7] Surface reactivity of CNTs is a key property enhancing their applicability.[51] During their interaction with cells and tissues, surface chemistry plays a key role in determining the 
toxic responses. Surface charge present on acid-functionalized CNTs elicits inflammatory and ROS response.[14, 52, 53] While comparing the ROS response between pristine and surfacemodified SWCNTs, pristine SWCNTs mounted a more robust ROS response compared to nitrogen-containing and $\mathrm{OH}-$ functionalized SWCNTs. Variances within pristine and surfacemodified SWCNT-induced ROS response could be attributed to their differential cellular uptake as the larger load of internalized CNTs may be responsible for the increased disruption of cell membrane and intracellular organelles.[53, 54] Some authors have indicated an inverse relationship between toxicity and purity of CNTs.[55] The SWCNTs used in this study were of high purity (>99\% w/w) (Table 1). Clearly, apart from functionalization, many factors including CNT uptake, internalization and phagocytosis influence the toxicity of CNTs.

Apart from surface modification, length also plays a key role in SWCNT-induced ROS responses. As compared to control, both short and long SWCNTs induced a stronger oxidative stress response (Figure 2B). Long SWCNTs elicited more robust ROS and fibrogenic responses than short SWCNTs, indicating a length-dependent effect not associating with metal content (Figure 3B, 3D). It is generally accepted that the presence of transition metal impurities such as iron and nickel contributes to the oxidative stress and fibrotic effect of CNTs.[6, 56] In this study, we used well characterized CNTs with known metal impurities to study the effects of fiber length on ROS generation and fibrosis. Elemental analysis indicated low iron content for both short $(0.12 \mathrm{wt} \%)$ and long $(0.13 \mathrm{wt} \%)$ SWCNTs compared to those reported in the previous studies. Besides, no significant difference was observed in the elemental composition of the two SWCNT samples used in this study (Table 2). Variances within short and long SWCNT-induced ROS response could be attributed to their differential cellular uptake [54] or frustrated phagocytosis.[57] Moreover, the difference observed between the short and long SWCNTs could 
be attributable to different cellular signaling pathways targeted by the two CNTs. [58] The higher toxicity of long SWCNTs could be due to lipid peroxidation following the interaction between cells and long SWCNTs.[59]

Interestingly, the antioxidant NAC significantly inhibited collagen production induced by SWCNTs of varying lengths and surface modifications, indicating the involvement of ROS in SWCNT-induced fibrogenic response (Figure 3). Moreover, ROS, particularly peroxides were found to regulate FSCs and their collagen-producing activity (Figures 4, 5). These results suggest the potential utility of ROS and FSC generation as rapid screening tools for fibrogenicity testing of CNTs. In our study, SP fibroblasts derived after NAC pre-treatment downregulated collagen expression compared to those without the NAC exposure, indicating that NAC possibly promoted the differentiation of SP phenotype. Previous studies have shown that NAC facilitates the differentiation of various cell types including neuronal cells, mouse embryonic stem cells and ovary carcinoma cells among many others.[60-64] Our findings suggest a putative role played by NAC in the self renewal of FSCs.

In addition to the direct ROS-inducing effect of CNTs, these nanomaterials can stimulate lung inflammatory response leading to infiltration of inflammatory and immune cells such as neutrophils and macrophages that can act as additional sources of ROS production.[65, 66] Thus, inclusion of these cells in the fibroblast cell model system may increase the reliability and predictability of the test model for CNT fibrogenicity assessment.

To summarize the findings from this study, we demonstrated that i) ROS, particularly peroxides, are crucial for the induction of FSCs by SWCNTs, ii) the fibrogenic activity of these cells is under the regulation of ROS, iii) SWCNT-mediated ROS response was dependent upon their fiber length and surface modification, and iv) SWCNT-induced collagen expression was 
also length and functionalization dependent, and was regulated by ROS. Since FSCs possess high fibrogenic activity and are the potential sources of fibroblasts and myofibroblasts, clarifying their regulation is fundamental to the understanding of fibrosis mechanisms and the development of effective treatment strategies. 


\section{References}

1. Kisseleva T, Brenner DA. Mechanisms of fibrogenesis. Exp Biol Med (Maywood). 2008 02;233(2):109-22.

2. Beaver LM, Stemmy EJ, Schwartz AM, Damsker JM, Constant SL, Ceryak SM, et al. Lung inflammation, injury, and proliferative response after repetitive particulate hexavalent chromium exposure. Environ Health Perspect. 2009 12;117(12):1896-902.

3. Shvedova AA, Kisin E, Murray AR, Johnson VJ, Gorelik O, Arepalli S, et al. Inhalation vs. aspiration of single-walled carbon nanotubes in C57BL/6 mice: Inflammation, fibrosis, oxidative stress, and mutagenesis. Am J Physiol Lung Cell Mol Physiol. 2008 10;295(4):L552-65.

4. Pulskamp K, Diabaté S, Krug HF. Carbon nanotubes show no sign of acute toxicity but induce intracellular reactive oxygen species in dependence on contaminants. Toxicol Lett. 2007 01/10;168(1):5874.

5. He X, Young S, Schwegler-Berry D, Chisholm WP, Fernback JE, Ma Q. Multiwalled carbon nanotubes induce a fibrogenic response by stimulating reactive oxygen species production, activating NF$\kappa \mathrm{B}$ signaling, and promoting fibroblast-to-myofibroblast transformation. Chem Res Toxicol. 2011 12/19;24(12):2237-48.

6. Pacurari M, Yin XJ, Zhao J, Ding M, Leonard SS, Schwegler-Berry D, et al. Raw single-wall carbon nanotubes induce oxidative stress and activate MAPKs, AP-1, NF-kappaB, and akt in normal and malignant human mesothelial cells. Environ Health Perspect. 2008 09;116(9):1211-7.

7. Knaapen AM, Borm PJA, Albrecht C, Schins RPF. Inhaled particles and lung cancer. part A: Mechanisms. Int J Cancer. 2004 05/10;109(6):799-809.

8. Xia T, Kovochich M, Liong M, Zink JI, Nel AE. Cationic polystyrene nanosphere toxicity depends on cell-specific endocytic and mitochondrial injury pathways. ACS Nano. 2008 01;2(1):85-96.

9. Park E, Choi J, Park Y, Park K. Oxidative stress induced by cerium oxide nanoparticles in cultured BEAS-2B cells. Toxicology. 2008 03/12;245(1-2):90-100.

10. Le Goff A, Holzinger M, Cosnier S. Enzymatic biosensors based on SWCNT-conducting polymer electrodes. Analyst. 2011 04/07;136(7):1279-87.

11. Warheit DB, Laurence BR, Reed KL, Roach DH, Reynolds GAM, Webb TR. Comparative pulmonary toxicity assessment of single-wall carbon nanotubes in rats. Toxicol Sci. 2004 01;77(1):11725.

12. Patlolla A, Knighten B, Tchounwou P. Multi-walled carbon nanotubes induce cytotoxicity, genotoxicity and apoptosis in normal human dermal fibroblast cells. Ethn Dis. 2010 10;20(1):S1,65-72.

13. Patlolla AK, Hussain SM, Schlager JJ, Patlolla S, Tchounwou PB. Comparative study of the clastogenicity of functionalized and nonfunctionalized multiwalled carbon nanotubes in bone marrow cells of swiss-webster mice. Environ Toxicol. 2010 12;25(6):608-21. 
14. Clichici S, Biris AR, Tabaran F, Filip A. Transient oxidative stress and inflammation after intraperitoneal administration of multiwalled carbon nanotubes functionalized with single strand DNA in rats. Toxicol Appl Pharmacol. 2012 03/15;259(3):281-92.

15. Azad N, Iyer AKV, Wang L, Liu Y, Lu Y, Rojanasakul Y. Reactive oxygen species-mediated p38 MAPK regulates carbon nanotube-induced fibrogenic and angiogenic responses. Nanotoxicology. 2013 03;7(2):157-68.

16. Van Berlo D, Clift MJD, Albrecht C, Schins RPF. Carbon nanotubes: An insight into the mechanisms of their potential genotoxicity. Swiss Med Wkly. 2012 11/05;142:w13698-.

17. Li JJ, Muralikrishnan S, Ng C, Yung LL, Bay B. Nanoparticle-induced pulmonary toxicity. Exp Biol Med (Maywood). 2010 09;235(9):1025-33.

18. Bonner JC. The epidermal growth factor receptor at the crossroads of airway remodeling. Am J Physiol Lung Cell Mol Physiol. 2002 09;283(3):L528-30.

19. Bonner JC. Lung fibrotic responses to particle exposure. Toxicol Pathol. 2007 01;35(1):148-53.

20. Manna SK, Sarkar S, Barr J, Wise K, Barrera EV, Jejelowo O, et al. Single-walled carbon nanotube induces oxidative stress and activates nuclear transcription factor-kappaB in human keratinocytes. Nano Lett. 2005 09;5(9):1676-84.

21. He X, Young S, Fernback JE, Ma Q. Single-walled carbon nanotubes induce fibrogenic effect by disturbing mitochondrial oxidative stress and activating NF- $\kappa \mathrm{B}$ signaling. J Clinic Toxicol. 2012;S5(005).

22. Manke A, Luanpitpong S, Dong C, Wang L, He X, Battelli L, et al. Effect of fiber length on carbon nanotube-induced fibrogenesis. Int J Mol Sci. 2014 04/29;15(5):7444-61.

23. Hashimoto N, Jin H, Liu T, Chensue SW, Phan SH. Bone marrow-derived progenitor cells in pulmonary fibrosis. J Clin Invest. 2004 01;113(2):243-52.

24. LeBleu VS, Taduri G, O'Connell J, Teng Y, Cooke VG, Woda C, et al. Origin and function of myofibroblasts in kidney fibrosis. Nat Med. 2013 08;19(8):1047-53.

25. Phillips RJ, Burdick MD, Hong K, Lutz MA, Murray LA, Xue YY, et al. Circulating fibrocytes traffic to the lungs in response to CXCL12 and mediate fibrosis. J Clin Invest. 2004 08;114(3):438-46.

26. Bigarella CL, Liang R, Ghaffari S. Stem cells and the impact of ROS signaling. Development. 2014 $11 ; 141(22): 4206-18$.

27. Chaudhari P, Ye Z, Jang Y. Roles of reactive oxygen species in the fate of stem cells. Antioxid Redox Signal. 2014 04/20;20(12):1881-90.

28. Dröge W. Free radicals in the physiological control of cell function. Physiol Rev. 2002 01;82(1):4795.

29. Li T, Marbán E. Physiological levels of reactive oxygen species are required to maintain genomic stability in stem cells. Stem Cells. 2010 07;28(7):1178-85. 
30. Urao N, Ushio-Fukai M. Redox regulation of stem/progenitor cells and bone marrow niche. Free Radic Biol Med. 2013 01;54:26-39.

31. Carr WJ, Oberley-Deegan R, Zhang Y, Oberley CC, Oberley LW, Dunnwald M. Antioxidant proteins and reactive oxygen species are decreased in a murine epidermal side population with stem cell-like characteristics. Histochem Cell Biol. 2011 03;135(3):293-304.

32. Pelicci PG, Dalton P, Giorgio M. The other face of ROS: A driver of stem cell expansion in colorectal cancer. Cell Stem Cell. 2013 06/06;12(6):635-6.

33. Choi H, Kang Y, Shin J, Na J, Huh C, Park K. Redox status is critical for stemness in skin equivalents. Oxid Med Cell Longev. 2012;2012:819623.

34. Le Belle J,E., Orozco NM, Paucar AA, Saxe JP, Mottahedeh J, Pyle AD, et al. Proliferative neural stem cells have high endogenous ROS levels that regulate self-renewal and neurogenesis in a PI3K/Aktdependant manner. Cell Stem Cell. 2011 01/07;8(1):59-71.

35. Yao E, Yu Y, Fukuda N. Oxidative stress on progenitor and stem cells in cardiovascular diseases. Curr Pharm Biotechnol. 2006 04;7(2):101-8.

36. Kinnula VL, Fattman CL, Tan RJ, Oury TD. Oxidative stress in pulmonary fibrosis: A possible role for redox modulatory therapy. Am J Respir Crit Care Med. 2005 08/15;172(4):417-22.

37. Risom L, Møller P, Loft S. Oxidative stress-induced DNA damage by particulate air pollution. Mutat Res. 2005 12/30;592(1-2):119-37.

38. Manke A, Wang L, Rojanasakul Y. Mechanisms of nanoparticle-induced oxidative stress and toxicity. Biomed Res Int. 2013;2013:942916.

39. Todd NW, Luzina IG, Atamas SP. Molecular and cellular mechanisms of pulmonary fibrosis. Fibrogenesis Tissue Repair. 2012 07/23;5(1):11.

40. Summer R, Kotton DN, Sun X, Fitzsimmons K, Fine A. Translational physiology: Origin and phenotype of lung side population cells. Am J Physiol Lung Cell Mol Physiol. 2004 09;287(3):L477-83.

41. Banerjee ER, Henderson, William Reed,,Jr. Characterization of lung stem cell niches in a mouse model of bleomycin-induced fibrosis. Stem Cell Res Ther. 2012 05/29;3(3):21.

42. Majka SM, Beutz MA, Hagen M, Izzo AA, Voelkel N, Helm KM. Identification of novel resident pulmonary stem cells: Form and function of the lung side population. Stem Cells. 2005 09;23(8):1073-81.

43. Sharma CS, Sarkar S, Periyakaruppan A, Barr J, Wise K, Thomas R, et al. Single-walled carbon nanotubes induces oxidative stress in rat lung epithelial cells. J Nanosci Nanotechnol. 2007 07;7(7):246672.

44. Kagan VE, Tyurina YY, Tyurin VA, Konduru NV, Potapovich AI, Osipov AN, et al. Direct and indirect effects of single walled carbon nanotubes on RAW 264.7 macrophages: Role of iron. Toxicol Lett. 2006 08/01;165(1):88-100. 
45. Madhavan L, Ourednik V, Ourednik J. Increased "vigilance" of antioxidant mechanisms in neural stem cells potentiates their capability to resist oxidative stress. Stem Cells. 2006 09;24(9):2110-9.

46. Bai X, Yan Y, Canfield S, Muravyeva MY, Kikuchi C, Zaja I, et al. Ketamine enhances human neural stem cell proliferation and induces neuronal apoptosis via reactive oxygen species-mediated mitochondrial pathway. Anesth Analg. 2013 04;116(4):869-80.

47. Jang Y, Sharkis SJ. A low level of reactive oxygen species selects for primitive hematopoietic stem cells that may reside in the low-oxygenic niche. Blood. 2007 10/15;110(8):3056-63.

48. Armstrong L, Tilgner K, Saretzki G, Atkinson SP, Stojkovic M, Moreno R, et al. Human induced pluripotent stem cell lines show stress defense mechanisms and mitochondrial regulation similar to those of human embryonic stem cells. Stem Cells. 2010 04;28(4):661-73.

49. Nguyen HN, Byers B, Cord B, Shcheglovitov A, Byrne J, Gujar P, et al. LRRK2 mutant iPSC-derived DA neurons demonstrate increased susceptibility to oxidative stress. Cell Stem Cell. 2011 03/04;8(3):267-80.

50. Inghilleri S, Morbini P, Oggionni T, Barni S, Fenoglio C. In situ assessment of oxidant and nitrogenic stress in bleomycin pulmonary fibrosis. Histochem Cell Biol. 2006 Jun;125(6):661-9.

51. Tasis D, Tagmatarchis N, Bianco A, Prato M. Chemistry of carbon nanotubes. Chem Rev. 2006 03;106(3):1105-36.

52. Saxena RK, William W, Mcgee JK, Daniels MJ, Boykin E, Gilmour MI. Enhanced in vitro and in vivo toxicity of poly-dispersed acid-functionalized single-wall carbon nanotubes. Nanotoxicology. 2007;1(4):291-300.

53. Li R, Wang X, Ji Z, Sun B, Zhang H, Chang CH, et al. Surface charge and cellular processing of covalently functionalized multiwall carbon nanotubes determine pulmonary toxicity. ACS Nano. 2013 03/26;7(3):2352-68.

54. Liu D, Wang L, Wang Z, Cuschieri A. Different cellular response mechanisms contribute to the length-dependent cytotoxicity of multi-walled carbon nanotubes. Nanoscale Res Lett. 2012 07/02;7(1):361.

55. Tian F, Cui D, Schwarz H, Estrada GG, Kobayashi H. Cytotoxicity of single-wall carbon nanotubes on human fibroblasts. Toxicol In Vitro. 2006 10;20(7):1202-12.

56. Shvedova AA, Castranova V, Kisin ER, Schwegler-Berry D, Murray AR, Gandelsman VZ, et al. Exposure to carbon nanotube material: Assessment of nanotube cytotoxicity using human keratinocyte cells. J Toxicol Environ Health A. 2003 10/24;66(20):1909-26.

57. Poland CA, Duffin R, Kinloch I, Maynard A, Wallace WAH, Seaton A, et al. Carbon nanotubes introduced into the abdominal cavity of mice show asbestos-like pathogenicity in a pilot study. Nat Nanotechnol. 2008 07;3(7):423-8.

58. Tabet L, Bussy C, Amara N, Setyan A, Grodet A, Rossi MJ, et al. Adverse effects of industrial multiwalled carbon nanotubes on human pulmonary cells. J Toxicol Environ Health A. 2009;72(2):60-73. 
59. Ding L, Stilwell J, Zhang T, Elboudwarej O, Jiang H, Selegue JP, et al. Molecular characterization of the cytotoxic mechanism of multiwall carbon nanotubes and nano-onions on human skin fibroblast. Nano Lett. 2005 12;5(12):2448-64.

60. Qian H, Yang Y. Neuron differentiation and neuritogenesis stimulated by N-acetylcysteine (NAC). Acta Pharmacol Sin. 2009 07;30(7):907-12.

61. Berniakovich I, Laricchia-Robbio L, Izpisua Belmonte JC. N-acetylcysteine protects induced pluripotent stem cells from in vitro stress: Impact on differentiation outcome. Int J Dev Biol. 2012;56(9):729-35.

62. Jun JH, Lee S, Kwak HB, Lee ZH, Seo S, Woo KM, et al. N-acetylcysteine stimulates osteoblastic differentiation of mouse calvarial cells. J Cell Biochem. 2008 03/01;103(4):1246-55.

63. Paranjpe A, Cacalano NA, Hume WR, Jewett A. N-acetylcysteine protects dental pulp stromal cells from HEMA-induced apoptosis by inducing differentiation of the cells. Free Radic Biol Med. 2007 11/15;43(10):1394-408.

64. Parasassi T, Brunelli R, Bracci-Laudiero L, Greco G, Gustafsson AC, Krasnowska EK, et al. Differentiation of normal and cancer cells induced by sulfhydryl reduction: Biochemical and molecular mechanisms. Cell Death Differ. 2005 10;12(10):1285-96.

65. Fadeel B, Kagan VE. Apoptosis and macrophage clearance of neutrophils: Regulation by reactive oxygen species. Redox Rep. 2003;8(3):143-50.

66. Lee H, Shin D, Song H, Yuk J, Lee Z, Lee S, et al. Nanoparticles up-regulate tumor necrosis factoralpha and CXCL8 via reactive oxygen species and mitogen-activated protein kinase activation. Toxicol Appl Pharmacol. 2009 07/15;238(2):160-9. 
Figures
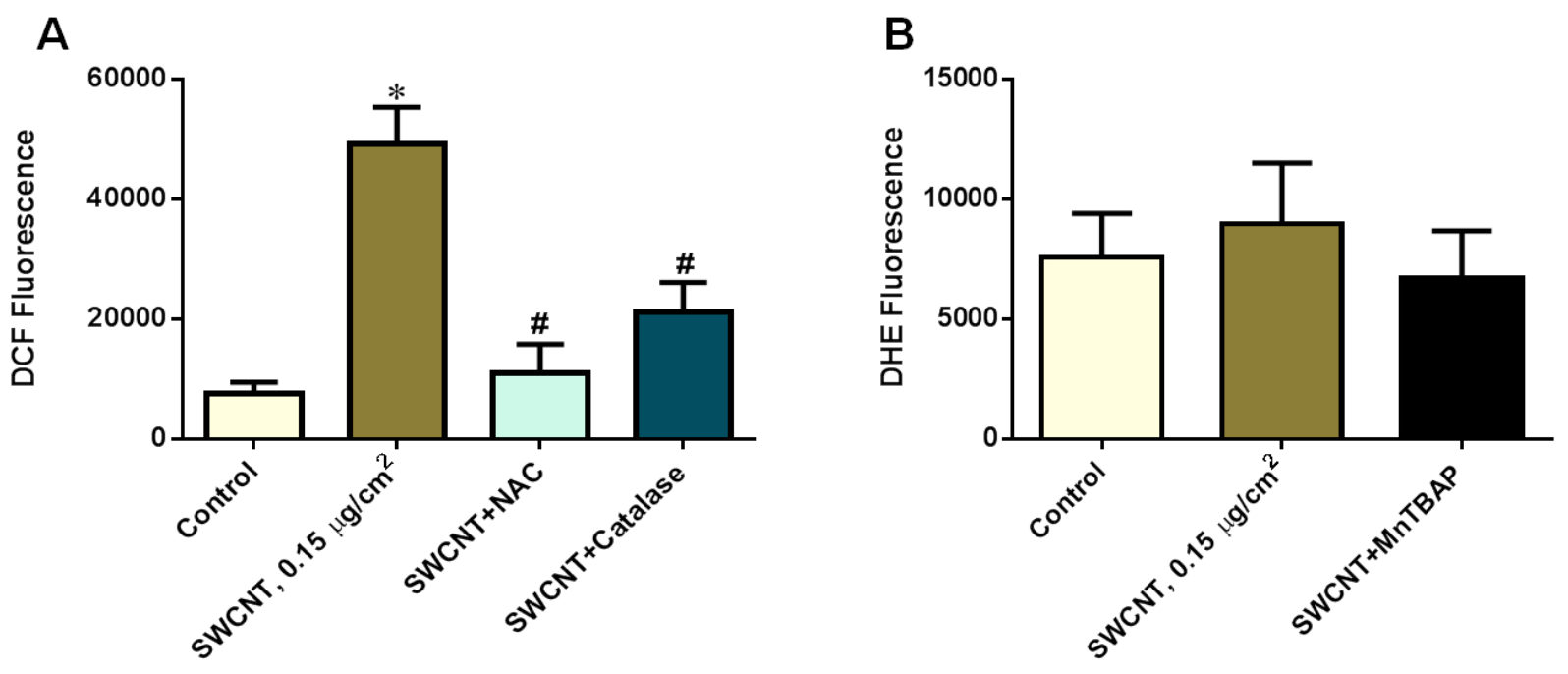

\section{Figure I: Effect of SWCNT on ROS generation}

A) NHLF cells were treated with SWCNT at the surface area dose of $0.15 \mu \mathrm{g} / \mathrm{cm}^{2}$ for $2 \mathrm{~h}$, after which they were incubated with dichlorodihydrofluorescein (DCF) and analyzed for fluorescence intensity. In some cases, cells were pretreated with $N$-acetyl cysteine $(10 \mathrm{mM})$ or catalase $(1000 \mathrm{U} / \mathrm{mL})$ for $1 \mathrm{~h}$, and then treated with SWCNT and analyzed for DCF fluorescence as described. B) Cells were pretreated with MnTBAP $(50 \mu \mathrm{M})$ for $1 \mathrm{~h}$ and then treated with SWCNT $\left(0.15 \mu \mathrm{g} / \mathrm{cm}^{2}\right)$ for $2 \mathrm{~h}$, after which they were incubated with dihydroethidium (DHE) and analyzed for fluorescence intensity. Plots are mean \pm S.D. $(n=4) ; * p<0.05$ as compared to untreated control; \# $p<0.05$ compared to SWCNT only. 

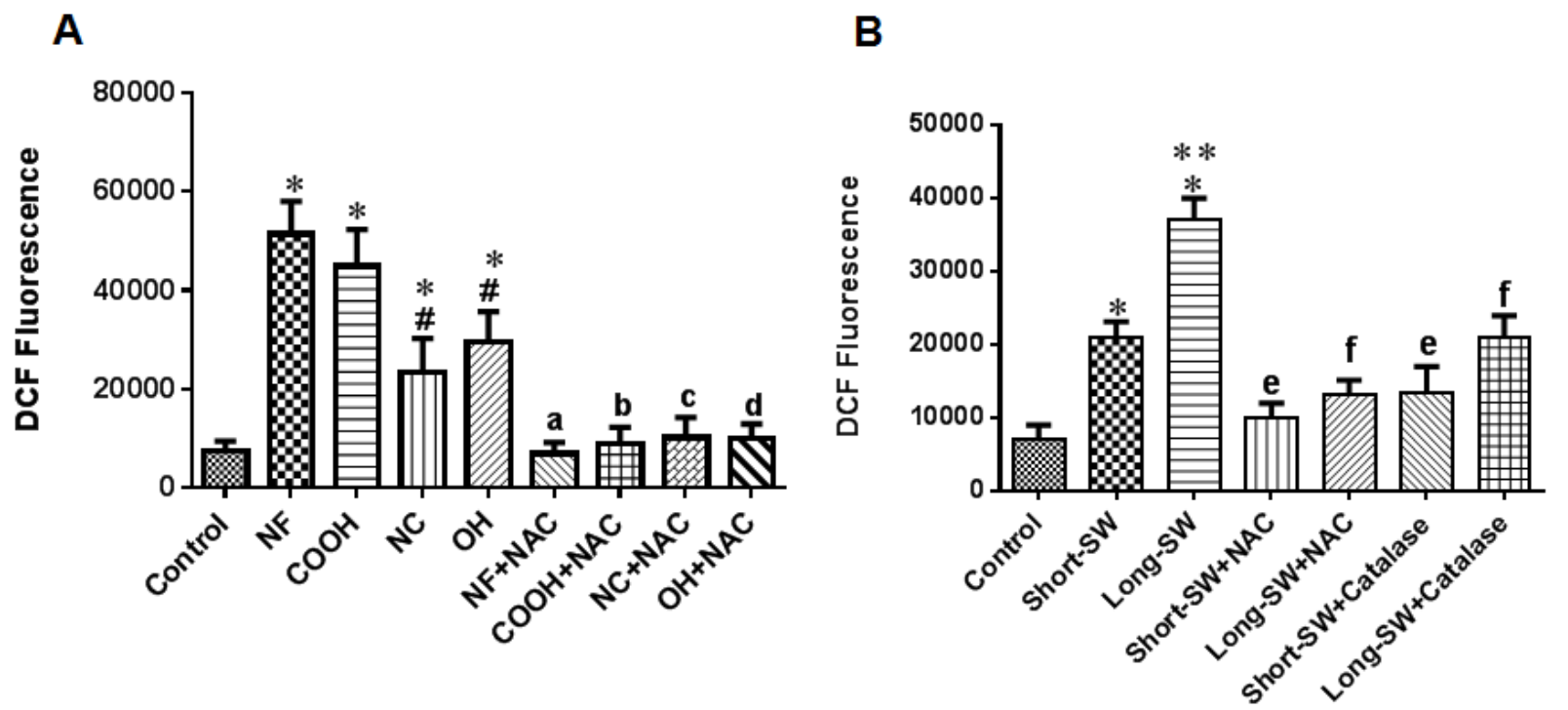

Figure II: Effect of SWCNT surface modification and length on ROS generation

After treatment with different SWCNTs at $0.06 \mu \mathrm{g} / \mathrm{cm}^{2}$, NHLF cells were incubated with dichlorodihydrofluorescein (DCF) and fluorescence intensity was measured at $2 \mathrm{~h}$ post-treatment. In some experiments, cells were pretreated for $1 \mathrm{~h}$ with $\mathrm{N}$-acetyl cysteine $(10 \mathrm{mM})$ or catalase $(1000 \mathrm{U} / \mathrm{mL})$ and then treated with SWCNT and analyzed for DCF fluorescence as described. A) Effect of SWCNT surface modification. B) Effect of SWCNT length. Plots are mean \pm S.D. $(n=4) ; * p<0.05$ as compared to control; \# $p<0.05 v s$. pristine-SW only; $\mathbf{a}, p<0.05$ compared to NF-SW only; $\mathbf{b}, p<0.05$ compared to COOH-SW only; c, $p<0.05$ compared to NC-SW only; d, $p<0.05$ compared to OH-SW only. ** $p<$ 0.05 compared to Short-SW only; $\mathbf{e}, p<0.05$ compared to Short-SW only; $\mathbf{f}, p<0.05$ compared to LongSW only. 
A

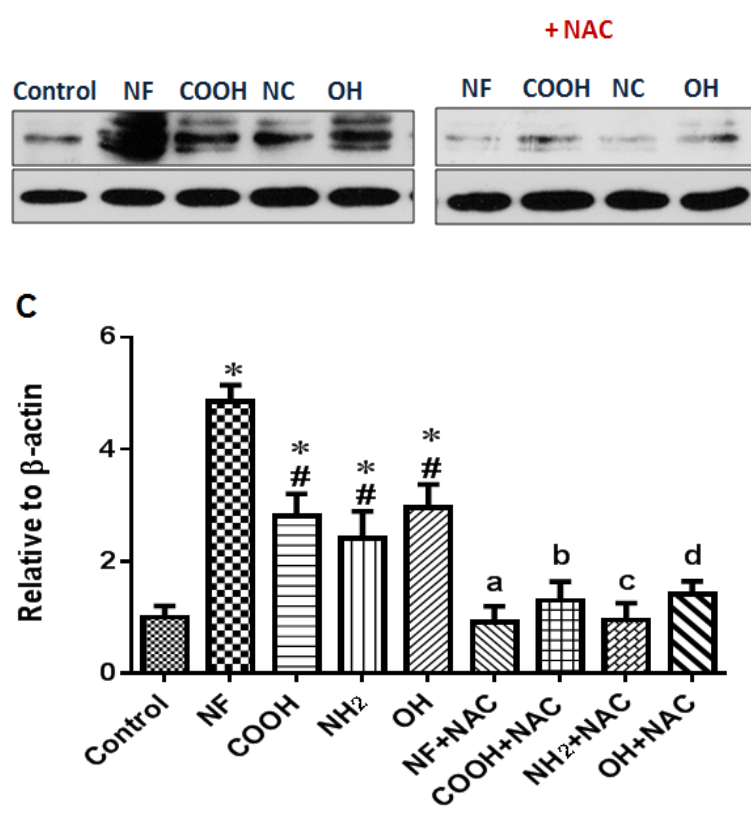

B

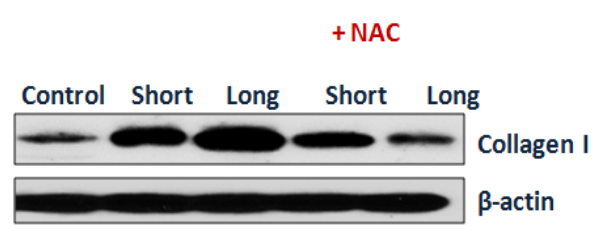

D

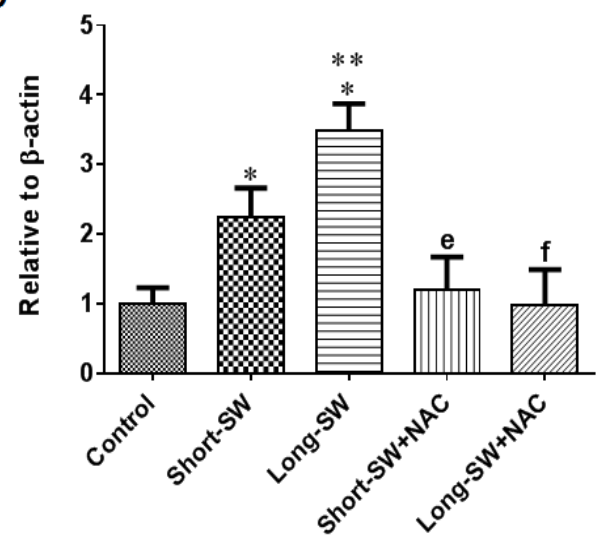

Figure III: Effect of ROS on SWCNT-induced fibrogenic response

NHLFs were pretreated for $1 \mathrm{~h}$ with NAC $(10 \mathrm{mM})$ and then treated with SWCNTs for $48 \mathrm{~h}$ and analyzed for collagen I expression by Western blotting. Blots were reprobed with $\beta$-actin antibody to confirm equal loading of the samples. The immunoblot signals were quantified by Image J. A) Effect of SWCNT functionalization. B) Effect of SWCNT length. C) Quantitative analysis of collagen I for SWCNTs of different functionalization. D) Quantitative analysis of collagen I for SWCNTs of different lengths. Plots are mean \pm S.D. $(n=3) ;{ }^{*} p<0.05$ as compared to control; \# $p<0.05 v s$. pristine(NF)-SW only; a, $p<$ 0.05 compared to NF-SW only; $\mathbf{b}, p<0.05$ compared to COOH-SW only; $\mathbf{c}, p<0.05$ compared to NCSW only; $\mathbf{d}, p<0.05$ compared to OH-SW only. ** $p<0.05$ compared to Short-SW only; e, $p<0.05$ compared to Short-SW only; f, $p<0.05$ compared to Long-SW only. 


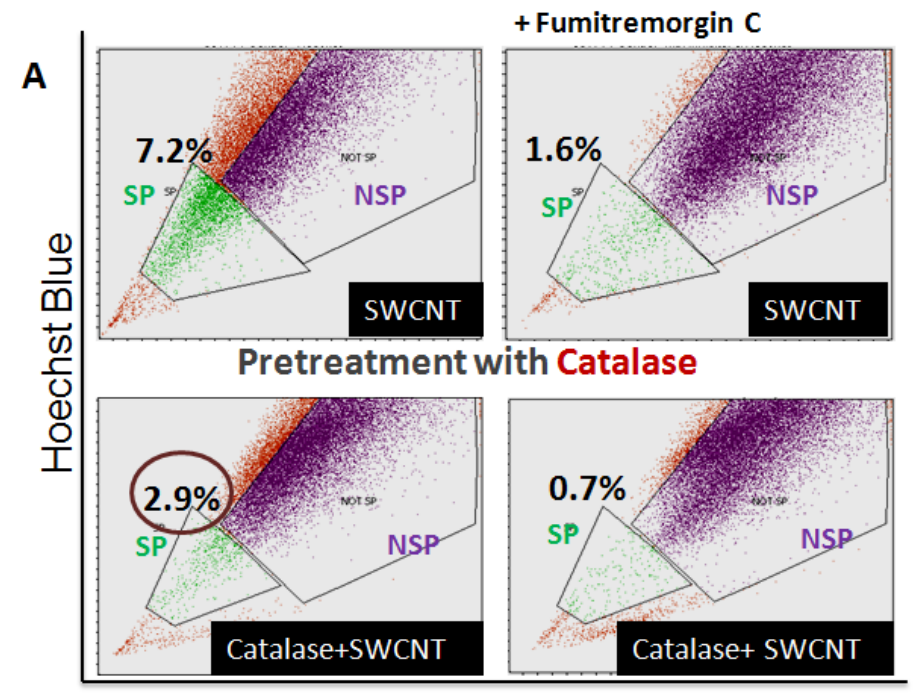

Hoechst Red

C

(SP) Catalase

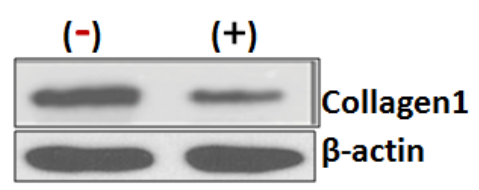

E

(SP) NAC

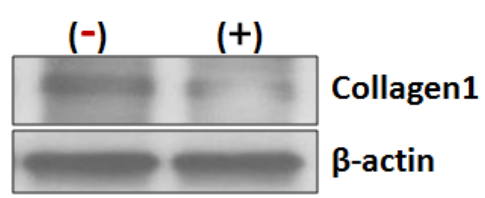

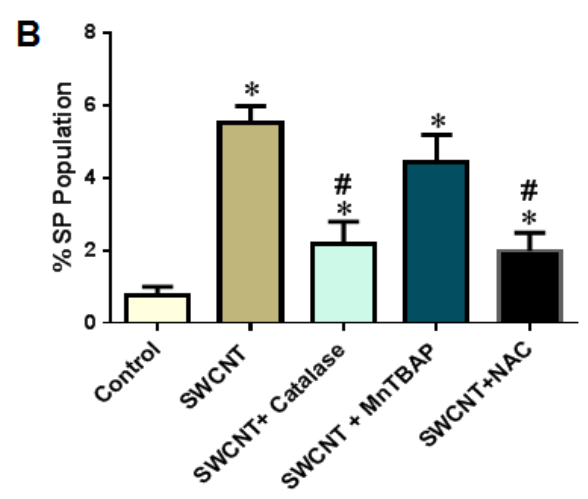
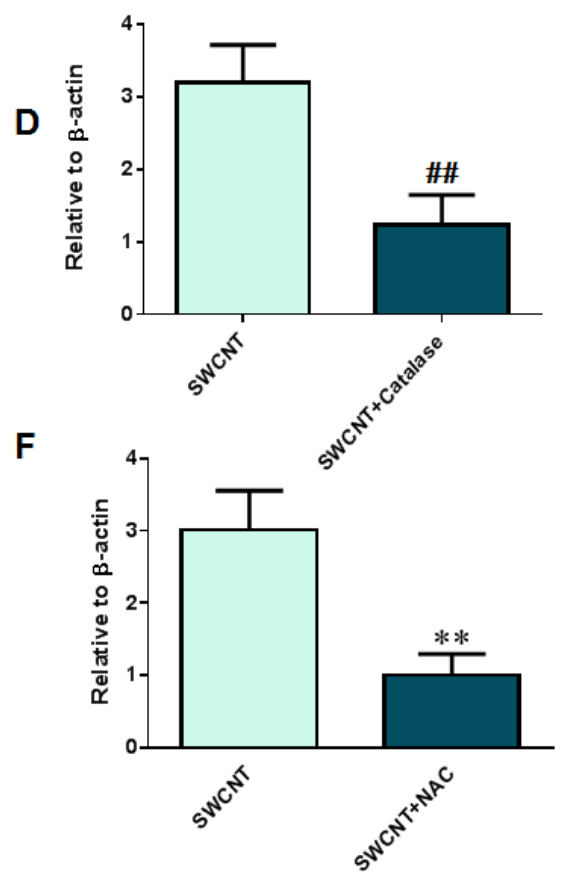

Figure IV: Role of ROS in SWCNT-induced fibroblast stem-like cells

A) SWCNT-treated NHLF cells isolated into SP and NSP with and without the inhibitor fumitremorgin C (FTC) as indicated by the $\%$ population in the presence or absence of catalase $(1000 \mathrm{U} / \mathrm{ml}), \mathrm{NAC}(10$ $\mathrm{mM})$ or MnTBAP $(50 \mu \mathrm{M})$. B) Redox-dependent FSC generation quantified by $\%$ SP population as evidenced by treatment with various ROS scavengers. C) Type 1 collagen expression (relative to $\beta$-actin) in SP cells with and without catalase treatment. D) Quantitative analysis of collagen I in SP cells E) Type 1 collagen expression (relative to $\beta$-actin) in SP cells with and without NAC treatment. F) Quantitative 
analysis of collagen I in SP cells The immunoblot signals were quantified by Image J. Plots are mean \pm S.D. $(n=3), * p<0.05$ as compared to control; \# $p<0.05$ compared to SWCNT-treated SP cells; \#\# $p<$ 0.05 as compared to SP cells without catalase treatment; ** $p<0,05$ as compared to SP cells without NAC treatment. 
A

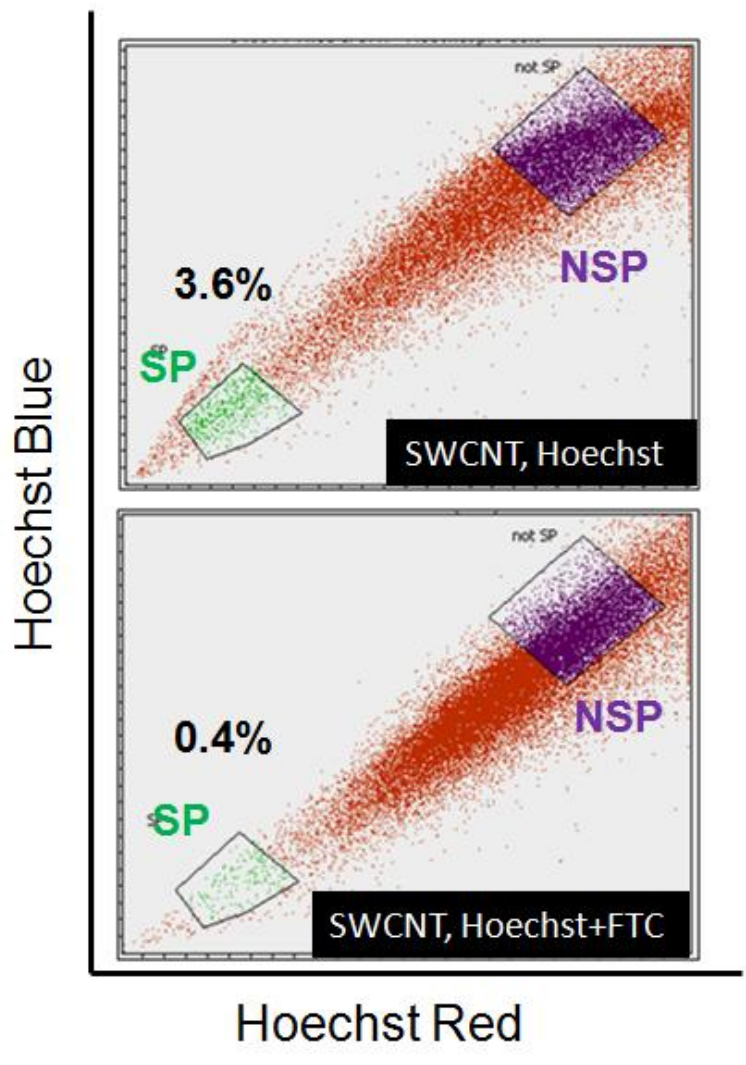

B

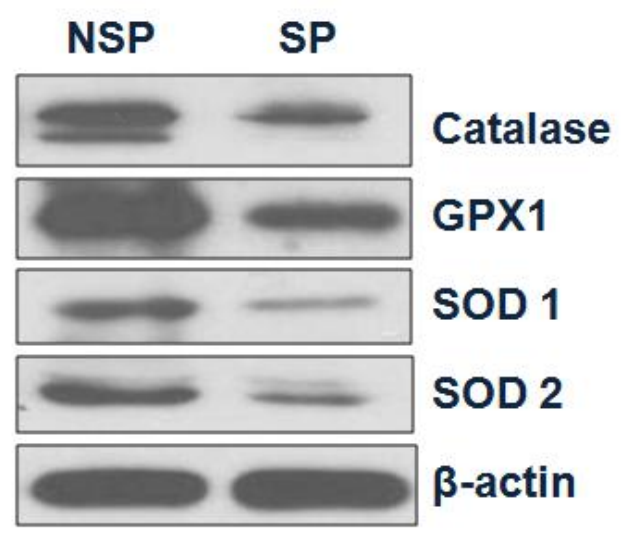

C
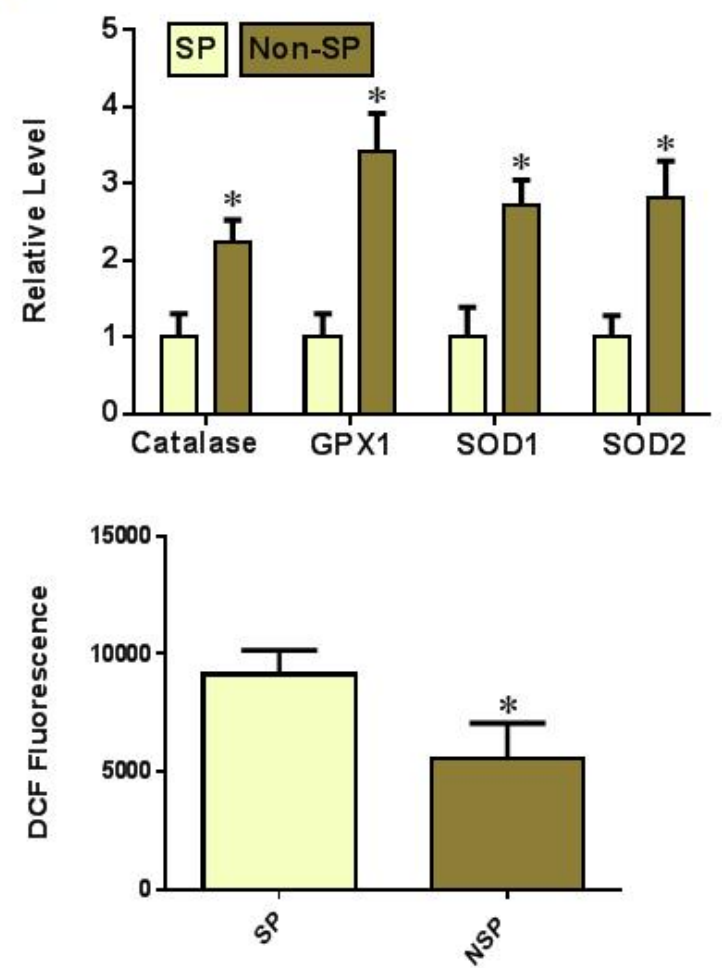

Figure V: Antioxidant enzyme expression in SWCNT-induced fibroblast stem-like cells

A) SWCNT-treated NHLF cells isolated into SP and NSP with and without the inhibitor fumitremorgin C (FTC). B) Differential antioxidant enzyme expression in SP and non-SP cells. Blots were reprobed with $\beta$-actin antibody to confirm equal loading of the samples. C) The immunoblot signals were quantified by Image J. D) SP and non-SP cells isolated via flow cytometry were incubated with 
dichlorodihydrofluorescein (DCF) and fluorescence intensity was measured at $2 \mathrm{~h}$ post-treatment. Plots are mean \pm S.D. $(n=3),{ }^{*} p<0.05$ as compared to SP cells. 


\section{Supplemental Data}

Table 1: Physicochemical characterization of SWCNTs

\begin{tabular}{|c|c|c|c|c|}
\hline Sample & Purity & $\begin{array}{c}\text { Length in solution } \\
\text { form }(\boldsymbol{\mu m})\end{array}$ & $\begin{array}{c}\text { Length in dry form } \\
(\boldsymbol{\mu m})\end{array}$ & $\begin{array}{c}\text { Diameter (nm) } \\
\text { (Dispersed form) }\end{array}$ \\
\hline Pristine & $>99 \%$ & $12.71 \pm 0.48$ & $12.9 \pm 0.55$ & $18.76 \pm 8.62$ \\
\hline $\mathrm{COOH}$ & $>99 \%$ & $12.41 \pm 0.47$ & $11.5 \pm 0.47$ & $18.77 \pm 8.63$ \\
\hline $\mathrm{NH} 2$ & $>99 \%$ & $9.176 \pm 0.48$ & $11.7 \pm 0.49$ & $13.2 \pm 5.92$ \\
\hline $\mathrm{OH}$ & $>99 \%$ & $11.92 \pm 0.34$ & $11.8 \pm 0.53$ & $17.71 \pm 8.67$ \\
\hline Long SWCNT & $>90 \%$ & $12.31 \pm 0.53$ & $13.4 \pm 0.62$ & $11.3 \pm 6.20$ \\
\hline Short SWCNT & $>90 \%$ & $1.13 \pm 0.39$ & $0.89 \pm 0.21$ & $10.8 \pm 5.41$ \\
\hline
\end{tabular}

Table 2: Elemental analysis for short and long SWCNTs

\begin{tabular}{ccc}
\hline \multirow{2}{*}{ Element } & \multicolumn{2}{c}{ SWCNT type } \\
\cline { 2 - 3 } $\mathrm{C}$ & Short (wt \%) & Long (wt \%) \\
$\mathrm{O}$ & 92.82 & 90.9 \\
$\mathrm{Al}$ & 0.77 & 8 \\
$\mathrm{Si}$ & 0.06 & 0.01 \\
$\mathrm{~S}$ & 0.11 & 0.08 \\
$\mathrm{Cl}$ & 0.3 & 0.1 \\
$\mathrm{Ca}$ & 0.1 & 0.2 \\
$\mathrm{Cr}$ & 0.16 & 0.12 \\
$\mathrm{Fe}$ & 0.13 & 0.31 \\
$\mathrm{Co}$ & 0.48 & 0.12 \\
$\mathrm{Mg}$ & - & 0.1 \\
\hline
\end{tabular}


CHAPTER 4 


\title{
CHAPTER 4: EFFECTS OF FIBER LENGTH AND SURFACE MODIFICATION ON CARBON NANOTUBE-INDUCED FIBROBLAST STEM-LIKE CELLS AND LUNG FIBROSIS
}

\begin{abstract}
Carbon nanotubes (CNTs) have increasing been used for a wide variety of applications, however, given their extremely small size and light weight, these nanomaterials can be readily inhaled by human lungs resulting in increased rates of pulmonary disorders, particularly fibrosis. Although the fibrogenic potential of CNTs is well established, there is a lack of consensus regarding the contribution of physicochemical attributes of CNTs on the underlying fibrotic outcome. We have previously demonstrated the existence of fibroblast stem-like cells (FSCs) and their characteristic role in single-walled (SW) CNT-induced fibrogenesis (Chapters 2, 3). However, it is not known if these CNT characteristics including surface functionalization and fiber length influence the ability of SWCNTs to induce FSCs. This study was designed to investigate whether SWCNT functionalization and fiber length drive the stemness phenotype and the resulting fibrogenic response. Our findings demonstrated that pristine SWCNT induced higher FSCs and collagen expression compared to their chemically modified counterparts; however the difference was moderate and not statistically significant. Whereas, long SWCNTs were significantly more potent than short SWCNTs in terms of collagen production and stemness induction as evidenced by elevated aldehyde dehydrogenase (ALDH) enzyme activity and side population (SP) generation. Furthermore, our findings on the length-dependent in vitro fibrogenic response were validated by the in vivo lung fibrosis outcome, thus supporting the predictive value of the FSC in vitro model. Our results also demonstrated the key role of FSCs in SWCNT-induced collagen expression, indicating the potential mechanisms of length-dependent CNT-induced lung fibrosis.
\end{abstract}


Together, our study provides evidence that CNT-induced stem-like cell induction offers a new rapid cell-based model for fibrogenicity testing of nanomaterials with the ability to predict pulmonary fibrogenic response in vivo.

Keywords: SWCNT, functionalization, fiber length, fibroblast stem-like cell, fibrosis

\section{Introduction}

Because of their unique physicochemical properties such as high conductivity, extraordinary tensile strength, and light weight, carbon nanotubes (CNTs) have emerged as one of the most promising and best studied materials in nanotechnology [1, 2]. However, pristine CNTs display low solubility and dispersibility in both organic and inorganic solutions, which makes these materials difficult to handle and process during commercial use, thereby limiting their widespread applications [3]. To overcome this issue, CNT surface can be functionalized by introducing hydrophilic chemical groups, thus imparting higher dispersibility and biocompatibility and conferring them new functions that cannot otherwise be acquired by pristine CNTs [4]. As a result, they are widely used as additives [5], catalysts [6], sensors [7], absorbents [8], intracellular carriers [9, 10], electrodes [11], and imaging agents [12]. However, the rapid growth in functionalized CNT applications has necessitated an understanding of the accompanying adverse health effects, which are currently being pursued by in vitro and in vivo risk assessment studies [13]. For instance, CNT-elicited inflammation, ROS production, and fibrosis are likely to be influenced by their physicochemical properties such as particle size, dispersion status, fiber length, surface activity and presence of metal contaminants [2, 14]. Current literature reveals that functionalized CNTs exert considerable variations in their biological effects, including cellular uptake [2, 15], clearance [16], genotoxicity [17], inflammation, [18] and fibrogenicity [2] based on their surface charge. For instance, pristine 
CNTs demonstrated an increased inflammatory and fibrotic responses compared to those of carboxylated [19], pluronic-coated [20], taurine [21] and polystyrene-functionalized CNTs [22]. In a recent study, in comparison to pristine CNTs, strong cationic polyethylene imine (PEI)MWCNTs induced significant lung fibrosis, whereas carboxylation of the CNTs significantly decreased the extent of fibrosis [2]. Similarly, another study showed that amine-modified CNTs lead to increased pulmonary collagen deposition along with increased production of TGF- $\beta 1$ and IL-6 [23]. Given these contradictory outcomes and the paucity for studies outlining a clear effect of functionalization on CNT-induced fibrosis, the need for systematic investigations of the adverse effects of surface charge is imperative. Previous studies have suggested the role of cellular uptake [2] and inflammasome activation [24, 25] for functionalization-dependent toxicities, but the direct effect of SWCNT functionalization on fibrosis and its underlying mechanisms need further investigations.

Besides surface reactivity, a number of studies have illustrated CNT length-dependent effects on pleural inflammation and granuloma formation [26, 27], cytotoxicity [28], and inflammasome activation [24]. Additionally, fiber length has been shown to regulate CNT retention and clearance from the lungs [27, 29]. While recent studies have suggested incomplete phagocytosis as a paradigm for CNT length-mediated toxic effects, the direct effect of SWCNT length on fibrosis and the underlying mechanisms remain to be elucidated.

Recent findings from our lab indicate that fiber length [30] and surface functionalities can influence CNT-induced fibrogenic response. We have previously demonstrated the existence of fibroblast stem-like cells (FSCs) and their characteristic role in SWCNT-induced fibrogenesis (Chapters 2 and 3). However, it is not known if these CNT characteristics, including surface functionalization and fiber length, can influence the ability of CNTs to induce FSCs from lung 
fibroblasts. The main objective of this study was to investigate whether CNT functionalization and fiber length influence stemness induction and the resulting fibrogenic response. To do this, we employed SWCNTs of varying lengths and different functionalities, including pristine, carboxyl $(\mathrm{COOH})$, nitrogen-containing, and hydroxyl $(\mathrm{OH})$. The latter part of this study involved developing a model to determine whether the stemness phenotype of FSCs is predictive of the fibrogenic response, which will in part also contribute towards the validation of Aim 1. 


\section{Experimental Section}

\section{SWCNT Preparation}

SWCNTs were prepared by plasma purified chemical vapor deposition process and were obtained from Cheap Tubes Inc. (Brattleboro, VT, USA). They were dispersed in culture medium containing $5 \%$ serum by water-bath sonication. Before exposure to the cells, the SWCNT dispersion was lightly sonicated (Sonic Vibra Cell Sonicator, Sonic \& Material Inc., Newtown, CT, USA) with the power, frequency, and amplitude settings of $130 \mathrm{~W}, 20 \mathrm{kHz}$, and $60 \%$ respectively for $10 \mathrm{~s}$.

\section{Chemicals and Reagents}

Antibody for collagen type I was obtained from Fitzgerald (Concord, MA, USA). $\beta$-actin antibody and horseradish peroxidase (HRP)-conjugated secondary antibodies were obtained from Santa Cruz Biotechnology (Santa Cruz, CA, USA). Hoechst 33342 was obtained from Sigma Aldrich (St. Louis, MO). Aldefluor® kit was obtained from Stem Cell Technologies (Vancouver, BC, Canada).

Energy Dispersive X-ray Spectroscopy (EDX-S) (Some experiments were performed in the laboratory of Dr. Cerasela-Zoica Dinu)

EDX-S was used to perform elemental analysis of SWCNT samples. Data were collected on a LEO 1530 VP scanning electron microscope equipped with an energy-dispersive X-ray analyzer (Hitachi S-4700 Field Emission Scanning Electron Microscope, Hitachi High Technologies Co., Tokyo, Japan). A few drops of SWCNT dispersion in cell culture medium were placed on a silicon wafer and allowed to air-dry. The silicon wafer was then mounted on an aluminum stub for EDX-S analysis. 
Atomic Force Microscopy (AFM) (Some experiments were performed in the laboratory of Dr. Cerasela-Zoica Dinu)

AFM was used to measure the length and diameter distribution of SWCNT samples using Digital Instrument Nanoscope II (Model No. MFP-3D-AFM, Asylum Research, Goleta, CA, USA). A Si tip (50-90 kHz AC240TS, Asylum Research, Goleta, CA, USA) was used to perform tapping mode in air. SWCNT samples were deposited on mica surfaces $(9.5 \mathrm{~mm}$ diameter, $0.15-0.21 \mathrm{~mm}$ thickness, Electron Microscopy Sciences, Hatfield, PA, USA) and allowed to dry overnight under vacuum. Scan angel was set as 0 , scan rate was set as $0.5 \mathrm{~Hz}$, and resolution was set as 512. Scan images of $20 \times 20$ or $10 \times 10 \mu \mathrm{m}$ areas were acquired. For each sample, at least 30 individual SWCNTs were counted and measured to obtain average length and diameter distribution.

\section{Cell Culture}

Normal human lung fibroblasts (NHLFs) were obtained from Lonza (Walkersville, MD, USA). The cells were maintained in Fibroblast Basal Medium (Lonza, CC-4126, Walkersville, MD, USA) containing growth supplements. Lung diploid human fibroblasts WI-38 (\#CCL-75) were obtained from American Type Culture Collection (Manassas, VA, USA). The cells were maintained in Minimum Essential Medium (Life Technologies, Grand Island, NY, USA). They were cultured at $37{ }^{\circ} \mathrm{C}$ in $5 \% \mathrm{CO}_{2}$ incubator and were passaged at preconfluent densities using a medium containing $0.05 \%$ trypsin.

Cytotoxicity Assay

Cytotoxicity assay was carried out using WST-1 cell viability assay kit (Roche Molecular Biochemicals, Indianapolis, IN, USA) as per the manufacturer's instructions. Cells were plated 
in triplicate in 96-well plates at the density of $2.0 \times 10^{4}$ cells/well in CS-C medium. Following overnight culture, the cells were incubated with the indicated concentrations of SWCNT for $48 \mathrm{~h}$. After incubation, WST-1 reagent was added and the cells were incubated for an additional $4 \mathrm{~h}$. The plates were then read at the wavelength of $420 \mathrm{~nm}$ using a microplate reader (Model 3550; BioRad, Richmond, CA, USA).

Sircol $^{\circledR}$ Collagen Assay

Soluble collagen content was determined by Sircol $^{\circledR}$ assay (Biocolor Ltd., Belfast, UK), according to the manufacturer's protocol. Briefly, lung fibroblasts $\left(1 \times 10^{5}\right.$ cells/well $)$ were cultured in 6-well plates and treated with SWCNTs of different lengths at the indicated concentrations for 24 and 48 h. Equal amounts of Sirius red reagent (Biocolor Ltd., Belfast, UK) and cell culture supernatant $(50 \mu \mathrm{L})$ were added together and mixed for $30 \mathrm{~min}$. The collagendye complex was then precipitated by centrifugation at $13,000 \times g$ for $5 \mathrm{~min}$, washed with ethanol, and dissolved in $0.5 \mathrm{M} \mathrm{NaOH}$. A $200 \mu \mathrm{L}$ aliquot of the mixture was transferred to a 96well plate and analyzed for optical absorbance at $540 \mathrm{~nm}$.

\section{Western Blot Analysis}

Collagen protein expression was determined by Western blotting. After specific treatments, cells were incubated in lysis buffer containing $20 \mathrm{mM}$ Tris- $\mathrm{HCl}(\mathrm{pH} 7.5), 1 \%$ Triton X-100, $150 \mathrm{mM}$ sodium chloride, $10 \%$ glycerol, $1 \mathrm{mM}$ sodium orthovanadate, $50 \mathrm{mM}$ sodium fluoride, $100 \mathrm{mM}$ phenylmethylsulfonyl fluoride, and a commercial protease inhibitor mixture (Roche Molecular Biochemicals, Indianapolis, IN, USA) at $4{ }^{\circ} \mathrm{C}$ for $20 \mathrm{~min}$. Cell lysates were collected and protein concentrations were determined using a bicinchoninic acid protein assay kit (Pierce Biotechnology, Rockford, IL, USA). Equal amount of protein per sample (40 $\mu \mathrm{g})$ was resolved under denaturing conditions by $10 \%$ SDS-PAGE and transferred onto a nitrocellulose membrane. 
The membranes were blocked for $1 \mathrm{~h}$ in 5\% nonfat dry milk in TBST $(25 \mathrm{mM}$ Tris- $\mathrm{HCl}, \mathrm{pH} 7.4$, $125 \mathrm{mM}$ sodium chloride, $0.05 \%$ Tween 20 ) and incubated with appropriate primary antibodies at $4{ }^{\circ} \mathrm{C}$ for $12 \mathrm{~h}$. Membranes were washed thrice with TBST for $10 \mathrm{~min}$ and incubated with HRPlabeled isotype-specific secondary antibodies for $1 \mathrm{~h}$ at room temperature. The immune complexes were then detected by enhanced chemiluminescence detection system (Supersignal ${ }^{\circledR}$ West Pico, Pierce, Rockford, IL, USA). The bands were quantified via densitometry using Image J. software, version 10.2 (GraphPad Software Inc., La Jolla, CA, USA). Mean densitometry data from independent experiments were normalized to results in cells from control experiments.

\section{Isolation of FSCs using Flow Cytometry}

Cell subsets enriched for stem cell activity were characterized by their ability to efflux the vital dye Hoechst 33342 via multidrug-like transporter ABCG2. Following appropriate treatments, the cells were harvested using $0.05 \%$ trypsin. Hoechst dye was added at a final concentration of 5 $\mu \mathrm{g} / \mathrm{mL}$ to stain the lung fibroblasts. To ensure that SP is the accurate stem cell population, lung fibroblasts should be co-stained Hoechst as well as with conjugated isotype-matched control antibody which does not stain SP cells but stains a large fraction of the lung fibroblast pool. Controls for flow cytometry included Hoechst-stained lung fibroblasts, unstained cells and cell suspensions incubated with Hoechst 33342 and the dye uptake inhibitor FTC. Gates were set according to the controls. The Hoechst dye was excited with a UV laser and its fluorescence was measured with both 450/20 filter (Hoechst Blue) and 675 LP filter (Hoechst Red), sorting was performed using FACS ARIA (BD Biosciences, San Jose, CA, USA). 


\section{Aldehyde Dehydrogenase Assay}

Human lung fibroblasts exposed to SWCNT for $24 \mathrm{~h}$ were analyzed using an Aldefluor ${ }^{\circledR}$ assay kit (Stem Cell Technologies, Vancouver, B.C., Canada). Dead cells, cell debris, doublets and aggregates were excluded by forward and side scattering and pulse-width gating. Cells were suspended in Aldefluor assay buffer containing ALDH substrate, BODIPYTM-aminoacate (BAA) $(1 \mu \mathrm{M})$ for $30-60$ min per $1 \times 10^{6}$ cells. After staining cells with the activated Aldefluor ${ }^{\circledR}$ reagent, the single cell dissociation was maintained on ice during all subsequent procedures. In each experiment, a sample of cells was stained under identical conditions with $1.5 \mathrm{mM}$ of the specific ALDH inhibitor diethylaminobenzaldehyde (DEAB) as a negative control. Flow cytometric sorting was conducted using a FACS ARIA (BD Biosciences, San Jose, CA, USA). Aldefluor fluorescence was excited at $488 \mathrm{~nm}$, and fluorescence emission was detected using a standard fluorescein isothiocyanate (FITC) 530/30-nm band-pass filter by a FACS Calibur ${ }^{\mathrm{TM}}$ machine (BD Biosciences, San Jose, CA). High side scatter $\mathrm{ALDH}^{\mathrm{tve}}$ and low $\mathrm{ALDH}^{-\mathrm{ve}}$ were selected.

\section{SWCNT Animal Model (Some experiments were conducted at NIOSH, Morgantown)}

Pathogen-free male C57BL/6J mice (Jackson Laboratories, Bar Harbor, ME, USA) weighing 25$30 \mathrm{~g}$ were used in this study. Animals were housed in an "Association for Assessment and Accreditation of Laboratory Animal Care" (AAALAC)-accredited, specific-pathogen-free, environmentally controlled facility at National Institute for Occupational Safety and Health (NIOSH). All experimental procedures were conducted in accordance with the protocol \#11-LRM-018 approved by the Institutional Animal Care and Use Committee (IACUC). The animals were treated with SWCNTs by pharyngeal aspiration. Briefly, animals were anesthetized by an intraperitoneal injection of ketamine and xylazine (45 and $8 \mathrm{mg} / \mathrm{kg}$ ) and placed on a board in the supine position. The animal's tongue was extended with padded forceps. A suspension of the test 
material (40 $\mu \mathrm{g} / 50 \mu \mathrm{L}$ per mouse) was placed on the back of the tongue. A slight pull of the tongue results in a reflex gasp and aspiration of the droplet. The tongue was held, and the animal was monitored for a few breaths after aspiration. At 90 days post-exposure, mice were sacrificed and lung tissues were isolated, homogenized, lysed and analyzed for collagen content by Sircol $^{\circledR}$ assay. For histopathology studies, paraffin-embedded lung sections were stained with Sirius red and examined under a light microscope.

\section{Statistical Analysis}

The data represent mean \pm S.D. from three or more independent experiments. ANOVA was performed to determine statistical significance between treatment and control groups using Graph Pad Prism 6.0 (GraphPad Software Inc., La Jolla, CA, USA) at a confidence level of * $p<$ 0.05 . 


\section{Results}

\section{Physicochemical Characterization of Single-Walled Carbon Nanotubes}

SWCNT samples of different lengths and surface functionalization were characterized using atomic force microscopy (AFM) and energy dispersive X-ray spectroscopy (EDX-S) for size measurements and elemental analysis, respectively. Table 1 provides information on the purity, length and diameter characteristics for the SWCNT samples used in this study. The different surface modified SWCNTs did not vary substantially in their diameter and lengths except in the case of nitrogen-containing SWCNTs. Short and long SWCNTs differed slightly in their diameter but very substantially in their length both in the solution and dry forms. For each SWCNT type, particle lengths were comparable in the solution and dry forms, suggesting that they were efficiently dispersed in the culture medium. Table 2 provides quantitative elemental analysis for the SWCNT samples. Short SWCNTs were 92.82 wt \% elemental carbon with 5.7 wt \% oxygen, whereas long SWCNTs were 90.9 wt $\%$ carbon with 8 wt $\%$ oxygen. Both short and long SWCNTs were similar in their elemental composition. Similarly, AFM was used to characterize SWCNT samples of different functionalities.

\section{FTIR Analysis for Identification of Various Functional Groups (Some experiments were} performed in the laboratory of Dr. Nianqiang Wu)

To confirm surface modification of SWCNTs via different functional groups, solid state FTIR was performed to show the presence of the peaks that characterize each of these functional groups on the nanotube surface (Figure 1). Pristine SWCNTs show the typical IR peaks, where i) the $3420 \mathrm{~cm}^{-1}$ peak is assigned to the $\mathrm{O}-\mathrm{H}$ stretching vibration, ii) $2850 \mathrm{~cm}^{-1}$ and $2970 \mathrm{~cm}^{-1}$ peaks are ascribed to the asymmetric and symmetric vibrations of $\mathrm{C}-\mathrm{H}$, respectively, iii) whereas the $1643 \mathrm{~cm}^{-1}$ and $1590 \mathrm{~cm}^{-1}$ peaks are due to the benzene ring skeleton vibrations, and iv) $1170 \mathrm{~cm}^{-1}$ 
and $1140 \mathrm{~cm}^{-1}$ peaks are from the C-O stretching vibration. Similar peaks were observed in other SWCNT samples. However, the COOH-modified SWCNTs were observed to have a strong stretching vibration peak of $\mathrm{C}=\mathrm{O}$ around $1730 \mathrm{~cm}^{-1}$ which was not evident in other SWCNTs. OH-modified SWCNTs reveal a strong stretching vibration peak of $\mathrm{O}-\mathrm{H}$ around $3450 \mathrm{~cm}^{-1}$. Moreover, the nitrogen-containing SWCNTs display the characteristic N-H wagging at $883 \mathrm{~cm}^{-1}$, two characteristic peaks at $3760 \mathrm{~cm}^{-1}$ and $3650 \mathrm{~cm}^{-1}$ depicting asymmetric and symmetric N-H stretch respectively, peaks at $1070 \mathrm{~cm}^{-1}$ and $1120 \mathrm{~cm}^{-1}$ suggesting $\mathrm{C}-\mathrm{N}$ stretch vibrations of aliphatic amines and a small peak observed at $1380 \mathrm{~cm}^{-1}$ which may imply of the C-N stretch vibration of aromatic amines. The IR spectra suggest that our nitrogen-containing could potentially be a mixture of aliphatic and aromatic amines.

\section{Effect of SWCNTs on Cell Viability}

This study was performed to optimize the experimental doses of SWCNTs that are relevant to in vivo lung fibrosis. Lung fibroblasts were treated with different concentrations of SWCNTs for 48 $\mathrm{h}$ and analyzed for cell viability by WST-1 assay (Figure 2). The doses of $0.02-0.2 \mu \mathrm{g} / \mathrm{cm}^{2}$ were used in this study since they are physiologically relevant and derived from pulmonary exposure data in mice, i.e., $10-80 \mu \mathrm{g} /$ mouse which corresponds to $0.02-0.16 \mu \mathrm{g} / \mathrm{cm}^{2}$ of mouse lung alveolar surface area $[19,31,32]$. At the low-dose exposures of $0.02-0.06 \mu \mathrm{g} / \mathrm{cm}^{2}, \mathrm{SWCNT}$ samples with various functional groups and lengths induced a reduction in cell viability; yet this effect in cytotoxicity was relatively lower than that of $0.2 \mu \mathrm{g} / \mathrm{cm}^{2}$ which resulted in a significant inhibition of cell proliferation (Figure 2A and 2B). The vehicle-treated control cells showed minimal reduction in cell viability (Figure 2A and 1B). Both short and long SWCNTs induced a dose-dependent decrease in cell viability of the cultured fibroblasts (Figure 2B). At equal dosing, 
long SWCNTs induced slightly more cellular toxicity than short SWCNTs, although the difference was not statistically significant under the test conditions (Figure 2B).

\section{Effect of SWCNTs on Type I Collagen Expression}

Fibrosis is a fibroproliferative disorder characterized by excessive accumulation of ECM proteins, especially collagens [33]. To determine the effect of SWCNT surface functionalization and fiber length on fibrogenic response, human lung fibroblasts were exposed to SWCNTs for 48 $\mathrm{h}$ and type I collagen expression was determined by Western blotting, which was performed on the basis of equal protein content, and the results were normalized by $\beta$-actin content (Figure 3). Both pristine and modified SWCNTs substantially induced collagen expression compared to untreated control (Figure 3A, 3C). Pristine SWCNTs were more potent in inducing collagen expression compared to nitrogen-containing- and OH SWCNTs (Figure 3A and 3C). Moreover, COOH-SWCNTs induced significantly higher collagen expression compared to nitrogencontaining-SWCNTs. Western blot data for SWCNT-induced collagen were validated via Sircol $^{\circledR}$ assay at $48 \mathrm{~h}$ post-SWCNT exposure. Analysis of total collagen content in SWCNTtreated cell supernatants by Sircol ${ }^{\circledR}$ collagen assay showed a similar functionalization-dependent effect on soluble collagen content (Figure 3E). Figures 3B, 3D show that both long and short SWCNTs induced a substantial increase in collagen production as determined by Western blot assay. Analysis of soluble collagen content by Sircol ${ }^{\circledR}$ assay confirmed the result and indicated the collagenic activity of SWCNTs (Figure 3F). Long SWCNTs were substantially more fibrogenic than short SWCNTs based on the Western blot and Sircol ${ }^{\circledR}$ results.

\section{Effect of Surface Functionalization on SWCNT-Induced FSC Generation}

Recent evidence suggests that aldehyde dehydrogenase (ALDH) activity is a hallmark of adult stem and progenitor cells isolated from bone marrow, brain, breast and possibly other tissues 
measurable by the Aldefluor assay [34]. ALDH activity plays a functional role in stem cell survival, differentiation, expansion and oxidative stress response [35]. WI-38 human lung fibroblasts were treated with pristine or surface modified SWCNTs at the dose of $0.15 \mu \mathrm{g} / \mathrm{cm}^{2}$ for $24 \mathrm{~h}$, after which they were incubated with $0.3 \mathrm{mM}$ activated Aldeflour dye in the presence or absence of $1.5 \mathrm{mM}$ ALDH inhibitor, DEAB (Figure 4). All SWCNT samples induced a significantly increased ALDH activity compared to untreated control (Figure 4A, 4B). SWCNT treatment generated ALDH +ve cells in a functionalization-dependent manner similar to their fibrogenic response in vitro. Pristine SWCNTs induced substantial FSC generation and significantly higher FSC level compared to nitrogen-containing- and OH-SWCNTs, however the difference was not significant between pristine and COOH SWCNTs (Figure 4B).

\section{Effect of Fiber Length on SWCNT-Induced FSC Generation}

To determine the effect of fiber length on SWCNT-induced SP generation, human lung fibroblasts were treated with SWCNTs of different lengths, and stem or stem-like cells were isolated according to their SP phenotype using flow cytometry based cell sorting (Figure 5A, 5B). Both short and long SWCNTs generated substantially higher SP subpopulation compared to vehicle-treated control. The percentage of long SWCNT-induced SP was significantly higher compared to short SWCNT, thus indicating the role of fiber length in stemness induction (Figure 5A, 5B). Similarly, WI-38 human lung fibroblasts were treated with long and short SWCNTs at the dose of $0.15 \mu \mathrm{g} / \mathrm{cm}^{2}$ for $24 \mathrm{~h}$, after which they were incubated with $0.3 \mathrm{mM}$ activated Aldeflour dye in the presence or absence of $1.5 \mathrm{mM}$ ALDH inhibitor, DEAB. Long SWCNTs induced a substantially higher ALDH activity than short SWCNTs, confirming the effect of fiber

length on stemness phenotype (Figure 6A, B). However, both short and long SWCNTs induced a significantly higher ALDH activity than the untreated control (Figure 6B). 


\section{Stemness Phenotype is Predictive of the Fibrogenic Response in vitro and in vivo}

To determine if our in vitro model of stemness induction is a suitable tool to assess the fibrogenic response of SWCNTs. C57BL/6J mice were exposed to short and long SWCNTs via pharyngeal aspiration and analyzed for lung fibrosis by Sircol ${ }^{\circledR}$ collagen assay and histopathology. Occupationally relevant dose of $40 \mu \mathrm{g}$ /mouse and exposure time of 3 months were used to ensure a robust fibrogenic response based on previous findings [36-38]. Lung collagen content as determined by $\operatorname{Sircol}^{\circledR}$ assay was substantially upregulated in the SWCNTtreated mice compared to control mice (Figure 5B).

Long SWCNTs induced a higher fibrogenic response in mice than short SWCNTs, consistent with the in vitro finding (Figure 7A, 7B). Histopathological analysis of lung tissue sections by Sirius red staining confirmed the biochemical findings showing greater accumulation and thickening of collagen fibers in the SWCNT-treated lung sections (Figure 7C). As compared to alveolar tissue sections from vehicle (BSA)-treated lungs, both short and long SWCNTs induced more collagen fibers which were condensed around SWCNT-deposited areas (observed throughout the alveolar interstitial space) (Figure 7D).

Increased SP generation (Figure 5) and ALDH enzyme activity (Figure 6) correlated well with the elevated length-dependent fibrogenic response of SWCNTs in vivo, thereby validating our fibroblast stem cell model of CNT-induced fibrogenesis. The findings from this study also indicate the role of fiber length as a key physicochemical determinant of CNT-induced stemness and lung fibrosis, whereby the stemness model was predictive of the in vivo fibrogenic response. 


\section{Discussion}

Lung fibrosis induced by SWCNTs has been well documented [19, 31, 32, 39-43], but the effect of specific SWCNT properties on lung fibrosis remains controversial and largely undefined [44]. Revealing the physicochemical properties influencing CNT fibrogenicity is essential due to the promise surrounding CNT exploitation. For instance, functionalized CNTs are generally considered more biocompatible than pristine CNTs because of their improved hydrophilicity and dispersion in biological media making them easier to use for a variety of commercial applications [5]. However, the potential adverse effects of functionalized CNTs have not been well characterized or systematically explored. Several potential mechanisms of CNTinduced fibrosis have been suggested, including epithelial mesenchymal transition [40], profibrogenic mediators [41], and oxidative stress [42]. The direct effect of functionalization on CNT-generated fibrogenicity remains inconclusive owing to the contradictory reports in the literature. Besides surface reactivity, length has been suggested to play a critical role in the biological reactivity of CNTs. Although a few studies have reported the length effect of CNTs on lung toxicity and while recent studies have suggested incomplete phagocytosis as a paradigm for CNT length-mediated toxicities, the effect of fiber length on SWCNT-induced lung fibrosis and its underlying mechanism have not been reported.

Based on the results from Chapters 2 and 3, we demonstrated a functional role of stemlike fibroblasts in CNT-induced fibrogenic response. Furthermore, the isolated stem-like fibroblasts were potential key source for collagen and $\alpha$-SMA production, thus playing a crucial role in fibrogenesis. The present study was designed to evaluate whether surface functionalization and fiber length influenced FSC generation during CNT-induced fibrosis and to develop an in vitro model based on the FSC generation to predict the fibrogenic response in vivo. 
Our results showed that 1) pristine SWCNTs induced a higher level of FSCs compared to their chemically modified counterparts; 2) long SWCNTs induced substantially higher stem cell activity compared to short SWCNTs; and 3) the ability of SWCNTs with different lengths to induce FSCs mimicked their fibrogenic activity in vivo, suggesting that CNT-induced stemness phenotype is predictive of their fibrogenicity in vivo.

Identifying the cells that are responsible for repairing the injured tissue and are the source of ECM production is fundamental to the understanding of fibrosis mechanisms $[45,46]$. Recent studies have demonstrated the pathogenic role of stem-like cells in lung fibrosis; however, the concept of stemness in the light of nanomaterial-induced fibrosis remains to be explored [47, 48]. Furthermore, the existence and role of fibroblast-derived stem cells have not been described. As mentioned before, ALDH activity has been shown to act as a functional marker for stem/progenitor cells [35]. Our model aimed at critically analyzing the ability of SWCNTs of various lengths and surface modifications to induce high levels of ALDH activity. Pristine SWCNTs induced a substantially higher ALDH activity compared to their modified forms. Additionally, this effect of CNT functionalization on stem cell induction correlated well with the fibrogenic response in vitro. Likewise, compared to short SWCNTs, long SWCNTs exhibited a stronger stem cell-inducing effect, as evidenced by their increased SP generation and ALDH activity. The increased stem cell activity was corroborated by the fibrogenic response of long SWCNTs both in vitro and in vivo, thus supporting the predictive value of our stem cell model for the detection of fibrogenic effect of nanomaterials.

We reported the effect of CNT fiber length on lung fibrosis in vivo as determined by histological analysis of Sirius Red stained lung sections from control and three-month short and long SWCNT aspiration. Additionally, long SWCNTs were potent inducer of collagen 
expression than short SWCNTs in vitro as determined by Western blot and Sircol ${ }^{\circledR}$ assays. Similarly, pristine SWCNTs mounted a strong fibrogenic response compared to nitrogencontaining and $\mathrm{OH}$ SWCNTs in vitro. Our surface modification-dependent fibrogenic results are in agreement with previous studies where functionalized CNT demonstrate reduced pulmonary inflammation and fibrosis [20-22, 49]. Whereas recent reports showed that functionalized tubes such as $\mathrm{NH}_{2}$, amide-CNTs and PEI-CNTs, are capable of inducing robust fibrogenic responses compared to their pristine counterparts $[2,23,50]$. Although surface charge is a potential factor responsible for the variable in vivo fibrogenic responses, these inconsistencies response outcomes could be attributed to the complex and multivariate differences in the tube structure derived from different suppliers and method of functionalization [2].

The collagen-inducing effect of SWCNTs (Figure 3A, 3B) was not due to their proliferative activity since fibroblast cell growth was not increased by the SWCNT treatment as indicated by WST-1 assay (Figure 2A, 2B). Moreover, all collagen expression data presented in this study were normalized against $\beta$-actin or cellular content as described in the Experimental section. We observed that the fibrogenic response elicited via SWCNTs of various functionalities and lengths corresponded in good agreement with their ability to induce FSCs (Figure 3A, 3B). Since collagen deposition is a hallmark of lung fibrosis, cellular collagen content could be used as a functional assay for nanoparticle fibrogenicity in vitro.

An additional key finding from this study was the correlation between the in vitro and in vivo SWCNT length-dependent responses, indicating the potential usefulness of the in vitro stemness induction model as a predictive screening tool for fibrogenicity testing of nanomaterials. The three-month aspiration study in mice demonstrated a length-dependent fibrogenicity in vivo as evidenced from the histopathological and biochemical studies showing 
greater fibrogenicity of long over short SWCNTs (Figure 7C, 7D). Furthermore, long SWCNTs induced significantly higher FSCs compared to short SWCNTs, supporting the fiber length paradigm [51] in stemness induction (Figures 5A, 5B and 6A, 6B). These findings validate the reliability of our in vitro stemness phenotype model to be used as an alternative assay to predict the fibrogenicity of CNTs and other nanomaterials for their safer design and risk assessment.

The described in vitro model is based on the use of lung fibroblasts which are the main cellular source of collagen production whose accumulation epitomizes lung fibrosis [33]. However, because of the lack of inflammatory and epithelial cells in the test system which are involved in the fibrogenic process, future studies incorporating these cells to better mimic the in vivo conditions are warranted. Currently, there is a need for simple and rapid in vitro models for fibrogenicity testing of nanomaterials since traditional assays which rely on the use of animal models are time consuming, laborious, and costly. They are not suitable for screening a large number of nanomaterials currently being used or developed. Developing a reliable and predictive screening model apriori is beneficial for understanding the influence of physicochemical parameters on pulmonary fibrosis before performing targeted animal experiments. Our study presents a predictive toxicological paradigm for comparing multiple parameters of CNTs in a single round of experimentation via assessment of mechanistic endpoint of stemness induction and collagen expression, critical in the pathogenesis of fibrosis. 


\section{References}

1. Shnorr JM, Swager TM. Emerging applications of carbon nanotubes. Chem Mater. 2011;23:646-57.

2. Li R, Wang X, Ji Z, Sun B, Zhang H, Chang CH, et al. Surface charge and cellular processing of covalently functionalized multiwall carbon nanotubes determine pulmonary toxicity. ACS Nano. 2013 03/26;7(3):2352-68.

3. Wu HC, Chang XL, Liu L, Zhao F, Zhao YL. Chemistry of carbon nanotubes in biomedical applications. J Mater,Chem. 2010;20:1036-52.

4. Tasis D, Tagmatarchis N, Bianco A, Prato M. Chemistry of carbon nanotubes. Chem Rev. 2006 03;106(3):1105-36.

5. Liu WB, Pei SF, Du JH, Liu BL, Gao LB, Su Y, et al. Additive-free dispersion of singlewalled carbon nanotubes and its application for transparent conductive films. Adv Func Mater. 2011;21:2330-7.

6. Vairavapandian D, Vichchulada P, Lay MD. Preparation and modification of carbon nanotubes: Review of recent advances and applications in catalysis and sensing. Anal Chim Acta. 2008 09/26;626(2):119-29.

7. Kauffman DR, Star A. Carbon nanotube gas and vapor sensors. Angew Chem Int Ed Engl. 2008;47(35):6550-70.

8. Upadhyayula VKK, Deng S, Mitchell MC, Smith GB. Application of carbon nanotube technology for removal of contaminants in drinking water: A review. Sci Total Environ. 2009 12/15;408(1):1-13.

9. Li R, Wu R, Zhao L, Wu M, Yang L, Zou H. P-glycoprotein antibody functionalized carbon nanotube overcomes the multidrug resistance of human leukemia cells. ACS Nano. 2010 03/23;4(3):1399-408.

10. Li RB, Wu RA, Zhao LA, Hu ZY, Guo SJ, Pan XL, et al. Folate and iron difunctionalized multiwall carbon nanotubes as dual-targeted drug nanocarrier to cancer cells. Carbon. 2011;49:1797-805.

11. Saha MS, Kundu A. Functionalizing carbon nanotubes for proton exchange membrane fuel cells electrode. J Power Sources. 2010;195:6255-61.

12. Kostarelos K, Bianco A, Prato M. Promises, facts and challenges for carbon nanotubes in imaging and therapeutics. Nat Nanotechnol. 2009 10;4(10):627-33. 
13. Coccini T, Manzo L, Roda E. Safety evaluation of engineered nanomaterials for health risk assessment: An experimental tiered testing approach using pristine and functionalized carbon nanotubes. ISRN Toxicol. 2013 04/17;2013:825427.

14. Manke A, Wang L, Rojanasakul Y. Pulmonary toxicity and fibrogenic response of carbon nanotubes. Toxicol Mech Methods. 2013 03;23(3):196-206.

15. Lopez CF, Nielsen SO, Moore PB, Klein ML. Understanding nature's design for a nanosyringe. Proc Natl Acad Sci U S A. 2004 03/30;101(13):4431-4.

16. Bhirde AA, Patel S, Sousa AA, Patel V, Molinolo AA, Ji Y, et al. Distribution and clearance of PEG-single-walled carbon nanotube cancer drug delivery vehicles in mice. Nanomedicine (Lond). 2010 12;5(10):1535-46.

17. Patlolla AK, Hussain SM, Schlager JJ, Patlolla S, Tchounwou PB. Comparative study of the clastogenicity of functionalized and nonfunctionalized multiwalled carbon nanotubes in bone marrow cells of swiss-webster mice. Environ Toxicol. 2010 12;25(6):608-21.

18. Saxena RK, William W, Mcgee JK, Daniels MJ, Boykin E, Gilmour MI. Enhanced in vitro and in vivo toxicity of poly-dispersed acid-functionalized single-wall carbon nanotubes.

Nanotoxicology. 2007;1(4):291-300.

19. Wang L, Castranova V, Mishra A, Chen B, Mercer RR, Schwegler-Berry D, et al. Dispersion of single-walled carbon nanotubes by a natural lung surfactant for pulmonary in vitro and in vivo toxicity studies. Part Fibre Toxicol. 2010 10/19;7:31.

20. Wang X, Xia T, Duch MC, Ji Z, Zhang H, Li R, et al. Pluronic F108 coating decreases the lung fibrosis potential of multiwall carbon nanotubes by reducing lysosomal injury. Nano Lett. 2012 06/13;12(6):3050-61.

21. Wang X, Zang JJ, Wang H, Nie H, Wang TC, Deng XY, et al. Pulmonary toxicity in mice exposed to low and medium doses of water-soluble multi-walled carbon nanotubes. J Nanosci Nanotechnol. 2010 12;10(12):8516-26.

22. Tabet L, Bussy C, Setyan A, Simon-Deckers A, Rossi MJ, Boczkowski J, et al. Coating carbon nanotubes with a polystyrene-based polymer protects against pulmonary toxicity. Part Fibre Toxicol. 2011 01/21;8:3.

23. Roda E, Coccini T, Acerbi D, Barni S, Vaccarone R, Manzo L. Comparative pulmonary toxicity assessment of pristine and functionalized multi-walled carbon nanotubes intratracheally instilled in rats: Morphohistochemical evaluations. Histol Histopathol. 2011 03;26(3):357-67.

24. Palomäki J, Välimäki E, Sund J, Vippola M, Clausen PA, Jensen KA, et al. Long, needle-like carbon nanotubes and asbestos activate the NLRP3 inflammasome through a similar mechanism. ACS Nano. 2011 09/27;5(9):6861-70. 
25. Yang M, Flavin K, Kopf I, Radics G, Hearnden CHA, McManus GJ, et al. Functionalization of carbon nanoparticles modulates inflammatory cell recruitment and NLRP3 inflammasome activation. Small. 2013 12/20;9(24):4194-206.

26. Poland CA, Duffin R, Kinloch I, Maynard A, Wallace WAH, Seaton A, et al. Carbon nanotubes introduced into the abdominal cavity of mice show asbestos-like pathogenicity in a pilot study. Nat Nanotechnol. 2008 07;3(7):423-8.

27. Murphy FA, Poland CA, Duffin R, Al-Jamal K, Ali-Boucetta H, Nunes A, et al. Lengthdependent retention of carbon nanotubes in the pleural space of mice initiates sustained inflammation and progressive fibrosis on the parietal pleura. Am J Pathol. 2011 06;178(6):2587600.

28. Liu J, Legros S, Ma G, Veinot JGC, von dK, Hofmann T. Influence of surface functionalization and particle size on the aggregation kinetics of engineered nanoparticles. Chemosphere. 2012 05;87(8):918-24.

29. Vietti G, Ibouraadaten S, Palmai-Pallag M, Yakoub Y, Bailly C, Fenoglio I, et al. Towards predicting the lung fibrogenic activity of nanomaterials: Experimental validation of an in vitro fibroblast proliferation assay. Part Fibre Toxicol. 2013 10/10;10:52.

30. Manke A, Luanpitpong S, Dong C, Wang L, He X, Battelli L, et al. Effect of fiber length on carbon nanotube-induced fibrogenesis. Int J Mol Sci. 2014 04/29;15(5):7444-61.

31. Shvedova AA, Kisin ER, Mercer R, Murray AR, Johnson VJ, Potapovich AI, et al. Unusual inflammatory and fibrogenic pulmonary responses to single-walled carbon nanotubes in mice. Am J Physiol Lung Cell Mol Physiol. 2005 11;289(5):L698-708.

32. Murray AR, Kisin ER, Tkach AV, Yanamala N, Mercer R, Young S, et al. Factoring-in agglomeration of carbon nanotubes and nanofibers for better prediction of their toxicity versus asbestos. Part Fibre Toxicol. 2012 04/10;9:10.

33. Wynn TA. Cellular and molecular mechanisms of fibrosis. J Pathol. 2008 01;214(2):199-210.

34. Douville J, Beaulieu R, Balicki D. ALDH1 as a functional marker of cancer stem and progenitor cells. Stem Cells Dev. 2009 01/20;18(1):17-25.

35. Moreb JS. Aldehyde dehydrogenase as a marker for stem cells. Curr Stem Cell Res Ther. 2008 12;3(4):237-46.

36. Porter DW, Hubbs AF, Mercer RR, Wu N, Wolfarth MG, Sriram K, et al. Mouse pulmonary dose- and time course-responses induced by exposure to multi-walled carbon nanotubes.

Toxicology. 2010 03/10;269(2-3):136-47. 
37. Mercer RR, Hubbs AF, Scabilloni JF, Wang L, Battelli LA, Friend S, et al. Pulmonary fibrotic response to aspiration of multi-walled carbon nanotubes. Part Fibre Toxicol. 2011 07/22;8:21.

38. Lam C, James JT, McCluskey R, Hunter RL. Pulmonary toxicity of single-wall carbon nanotubes in mice 7 and 90 days after intratracheal instillation. Toxicol Sci. 2004 01;77(1):12634.

39. Shvedova AA, Kapralov AA, Feng WH, Kisin ER, Murray AR, Mercer RR, et al. Impaired clearance and enhanced pulmonary inflammatory/fibrotic response to carbon nanotubes in myeloperoxidase-deficient mice. PLoS One. 2012;7(3):e30923.

40. Chang C, Tsai M, Huang H, Chen C, Dai S. Epithelial-mesenchymal transition contributes to SWCNT-induced pulmonary fibrosis. Nanotoxicology. 2012 09;6(6):600-10.

41. Mangum JB, Turpin EA, Antao-Menezes A, Cesta MF, Bermudez E, Bonner JC. Singlewalled carbon nanotube (SWCNT)-induced interstitial fibrosis in the lungs of rats is associated with increased levels of PDGF mRNA and the formation of unique intercellular carbon structures that bridge alveolar macrophages in situ. Part Fibre Toxicol. 2006 11/29;3:15.

42. He X, Young S, Fernback JE, Ma Q. Single-walled carbon nanotubes induce fibrogenic effect by disturbing mitochondrial oxidative stress and activating NF- $\mathrm{KB}$ signaling. J Clinic Toxicol. 2012;S5(005).

43. Azad N, Iyer AKV, Wang L, Liu Y, Lu Y, Rojanasakul Y. Reactive oxygen speciesmediated p38 MAPK regulates carbon nanotube-induced fibrogenic and angiogenic responses. Nanotoxicology. 2013 03;7(2):157-68.

44. Johnston HJ, Hutchison GR, Christensen FM, Peters S, Hankin S, Aschberger K, et al. A critical review of the biological mechanisms underlying the in vivo and in vitro toxicity of carbon nanotubes: The contribution of physico-chemical characteristics. Nanotoxicology. 2010 06;4(2):207-46.

45. Leask A, Abraham DJ. TGF-beta signaling and the fibrotic response. FASEB J. 2004 05;18(7):816-27.

46. Bonniaud P, Margetts PJ, Kolb M, Schroeder JA, Kapoun AM, Damm D, et al. Progressive transforming growth factor beta1-induced lung fibrosis is blocked by an orally active ALK5 kinase inhibitor. Am J Respir Crit Care Med. 2005 04/15;171(8):889-98.

47. Phillips RJ, Burdick MD, Hong K, Lutz MA, Murray LA, Xue YY, et al. Circulating fibrocytes traffic to the lungs in response to CXCL12 and mediate fibrosis. J Clin Invest. 2004 08;114(3):438-46.

48. LeBleu VS, Taduri G, O'Connell J, Teng Y, Cooke VG, Woda C, et al. Origin and function of myofibroblasts in kidney fibrosis. Nat Med. 2013 08;19(8):1047-53. 
49. Wang X, Xia T, Ntim SA, Ji Z, Lin S, Meng H, et al. Dispersal state of multiwalled carbon nanotubes elicits profibrogenic cellular responses that correlate with fibrogenesis biomarkers and fibrosis in the murine lung. ACS Nano. 2011 12/27;5(12):9772-87.

50. Zhang Y, Deng J, Zhang Y, Guo F, Li C, Zou Z, et al. Functionalized single-walled carbon nanotubes cause reversible acute lung injury and induce fibrosis in mice. J Mol Med (Berl). 2013 01;91(1):117-28.

51. Donaldson K, Murphy FA, Duffin R, Poland CA. Asbestos, carbon nanotubes and the pleural mesothelium: A review of the hypothesis regarding the role of long fibre retention in the parietal pleura, inflammation and mesothelioma. Part Fibre Toxicol. 2010 03/22;7:5. 
Figures

\begin{tabular}{|c|c|c|c|c|}
\hline Sample & Purity & $\begin{array}{c}\text { Length in solution } \\
\text { form }(\boldsymbol{\mu m})\end{array}$ & $\begin{array}{c}\text { Length in dry form } \\
(\boldsymbol{\mu m})\end{array}$ & $\begin{array}{c}\text { Diameter (nm) } \\
\text { Dispersed form }\end{array}$ \\
\hline Pristine & $>99 \%$ & $12.71 \pm 0.48$ & $12.9 \pm 0.55$ & $18.76 \pm 8.62$ \\
\hline $\mathrm{COOH}$ & $>99 \%$ & $12.41 \pm 0.47$ & $11.5 \pm 0.47$ & $18.77 \pm 8.63$ \\
\hline $\mathrm{NH} 2$ & $>99 \%$ & $9.176 \pm 0.48$ & $11.7 \pm 0.49$ & $13.2 \pm 5.92$ \\
\hline OH & $>99 \%$ & $11.92 \pm 0.34$ & $11.8 \pm 0.53$ & $11.3 \pm 6.20$ \\
\hline Long SWCNT & $>90 \%$ & $12.31 \pm 0.53$ & $13.4 \pm 0.62$ & $10.8 \pm 5.41$ \\
\hline Short SWCNT & $>90 \%$ & $1.13 \pm 0.39$ & $0.89 \pm 0.21$ & 17.67 \\
\hline
\end{tabular}

Table I: Physicochemical characterization of Single walled carbon nanotubes (SWCNTs) of different surface modifications and lengths

Note: The table describes the purity, diameter and length distribution measured via AFM.

\begin{tabular}{ccc}
\hline \multirow{2}{*}{ Element } & \multicolumn{2}{c}{ SWCNT type } \\
\cline { 2 - 3 } $\mathrm{C}$ & Short (wt \%) & Long (wt \%) \\
$\mathrm{O}$ & 92.82 & 90.9 \\
$\mathrm{Al}$ & 5.77 & 8 \\
$\mathrm{Si}$ & 0.06 & 0.01 \\
$\mathrm{~S}$ & 0.06 & 0.08 \\
$\mathrm{Cl}$ & 0.11 & 0.1 \\
$\mathrm{Ca}$ & 0.3 & 0.2 \\
$\mathrm{Cr}$ & 0.1 & 0.12 \\
$\mathrm{Fe}$ & 0.16 & 0.31 \\
$\mathrm{Co}$ & 0.13 & 0.12 \\
$\mathrm{Mg}$ & 0.48 & 0.1 \\
\hline
\end{tabular}

Table II: Elemental analysis for short and long SWCNTs

Elemental analysis of SWCNTs of different lengths measured via EDX-S. 


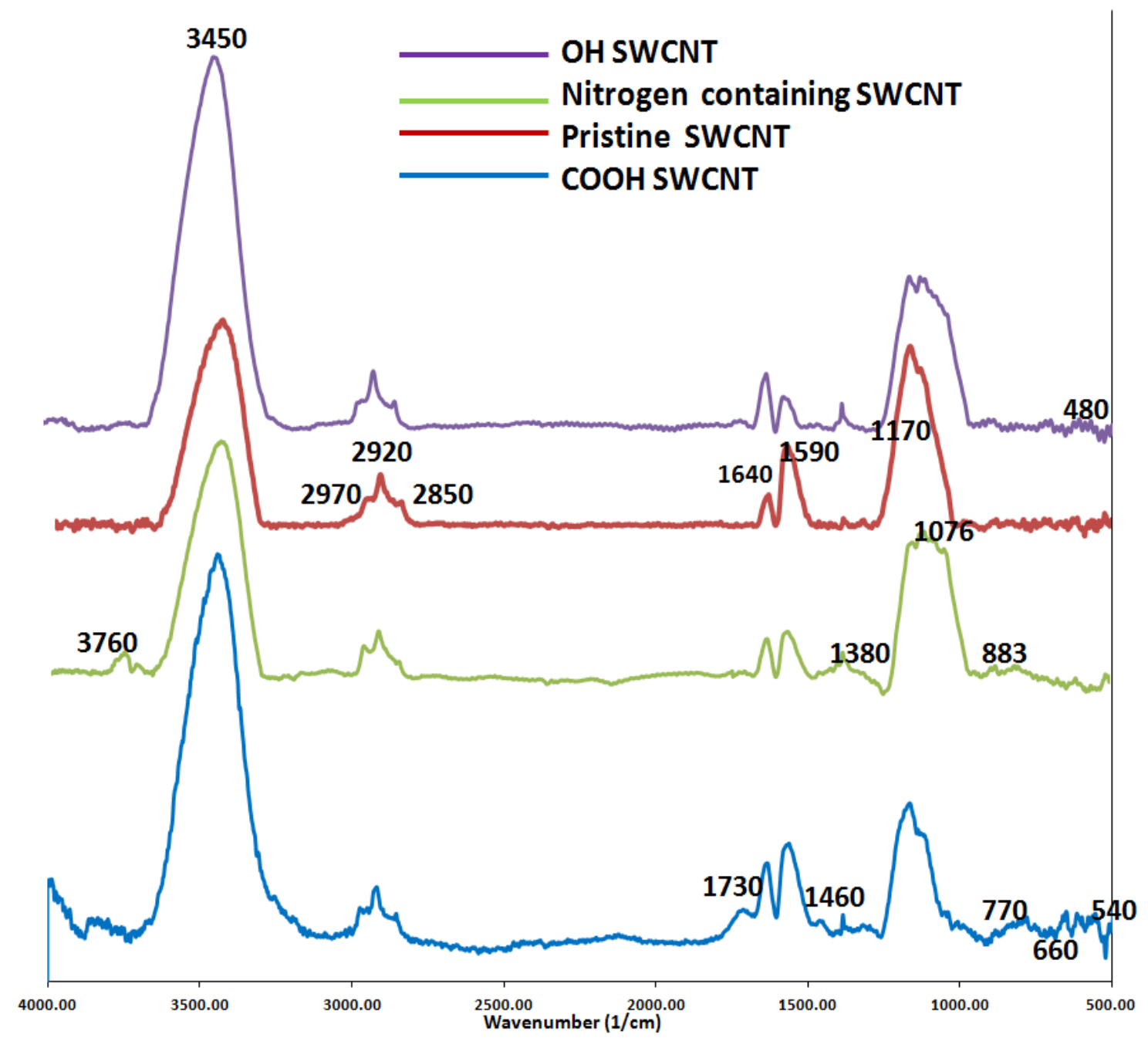

Figure I: FTIR spectra for pristine and surface modified Single walled carbon nanotubes (SWCNTS)

FTIR spectra for pristine and modified SWCNTs. Strong stretching vibration peak of $\mathrm{C}=\mathrm{O}$ around $1730 \mathrm{~cm}^{-1}$ as well as O-H stretching vibrations at $3430 \mathrm{~cm}^{-1}$ are in the COOH SWCNTs respectively. Characteristic N-H wagging at $883 \mathrm{~cm}^{-1}$ and a small peak observed at $1380 \mathrm{~cm}^{-1}$ resulting from the C-N stretch vibration found in nitrogen-containing SWCNTs. 
A

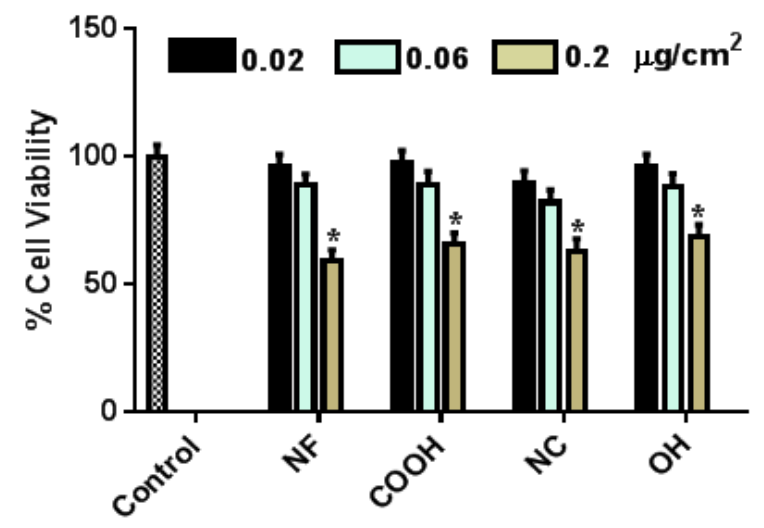

B

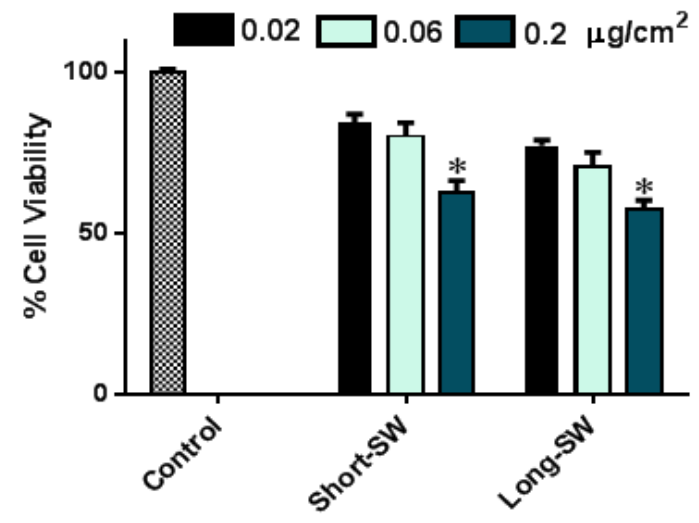

Figure II: Effect of SWCNTs on cell viability

Subconfluent cultures of normal human lung fibroblasts were exposed to SWCNTs of various lengths and surface modification for $48 \mathrm{~h}$ within the concentration range of $0.02-0.2 \mu \mathrm{g} / \mathrm{cm}^{2}$. Cell viability was determined by WST-1 assay and compared to untreated control. A) Effect of fiber length and B) surface modification on cell viability. Values are means $\pm \operatorname{SD}(n=3) ; * p<0.05$ vs. untreated control. 
A

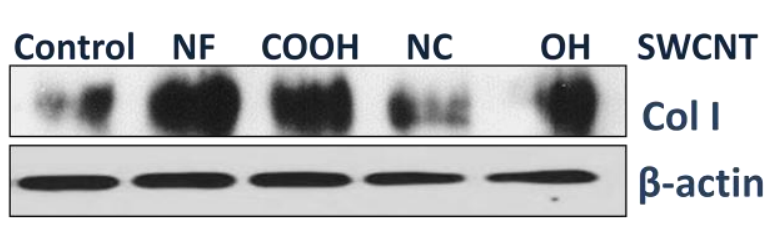

B

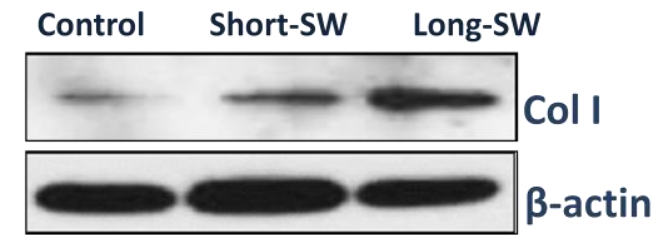

D

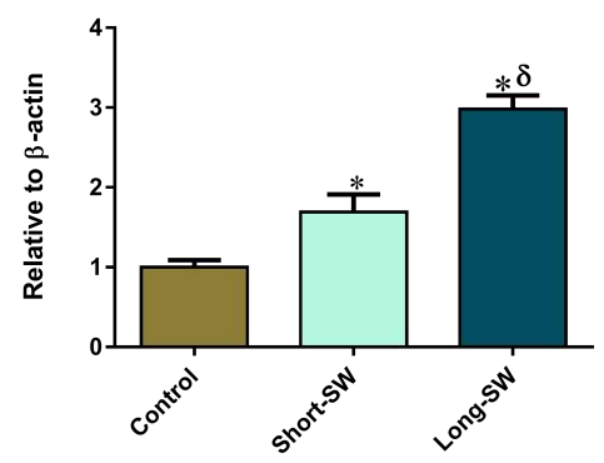

$\mathbf{E}$
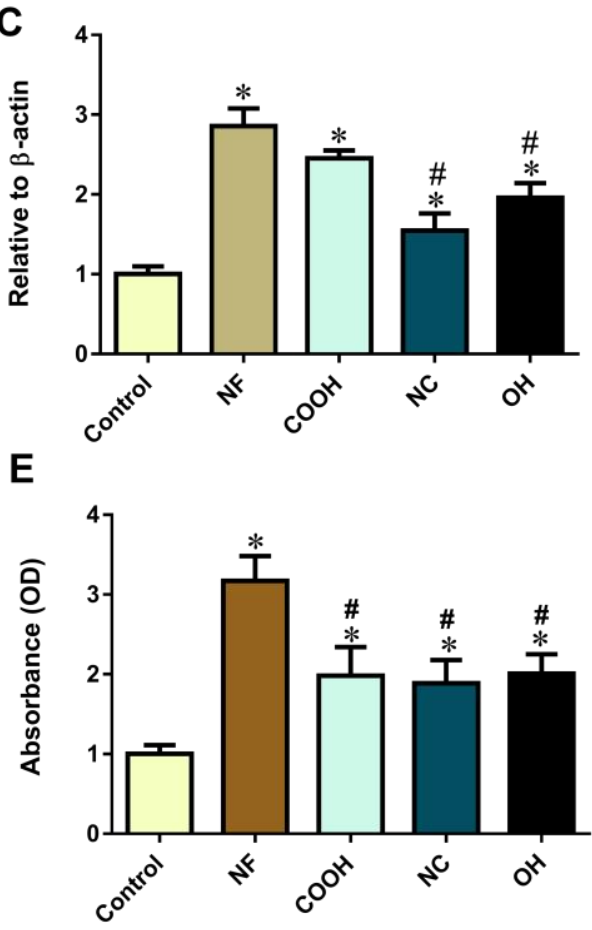

$\mathbf{F}$

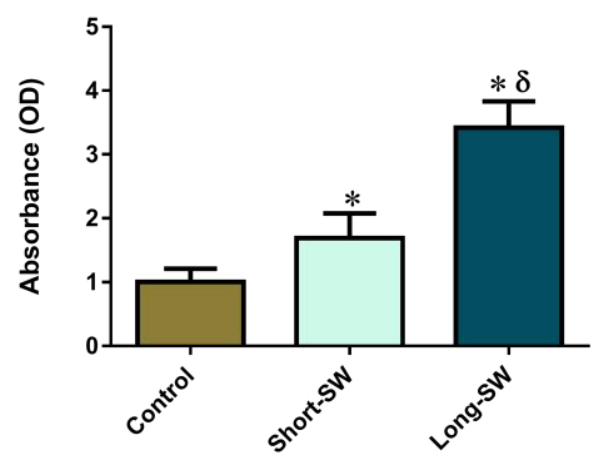

Figure III: Effect of SWCNTs on type I collagen expression

A) Western blots showing functionalization-dependent effect of SWCNTs on collagen I production. B) Western blots showing fiber length-dependent effect of SWCNTs on collagen I production. Subconfluent cultures of human lung fibroblasts were treated with SWCNTs with various functionalities and lengths for $48 \mathrm{~h}$ and analyzed for collagen I expression by Western blotting. Blots were reprobed with $\beta$-actin antibody to confirm equal loading of the samples. The immunoblot signals were quantified by Image J. C) and D) Relative protein quantification via Image J. Values are means $\pm \mathrm{SD}(n=3) ;{ }^{*} p<0.05$ vs. untreated control; \# $p<0.05$ vs. pristineSWCNT; $\boldsymbol{\delta} p<0.05$ vs. short-SWCNT. 

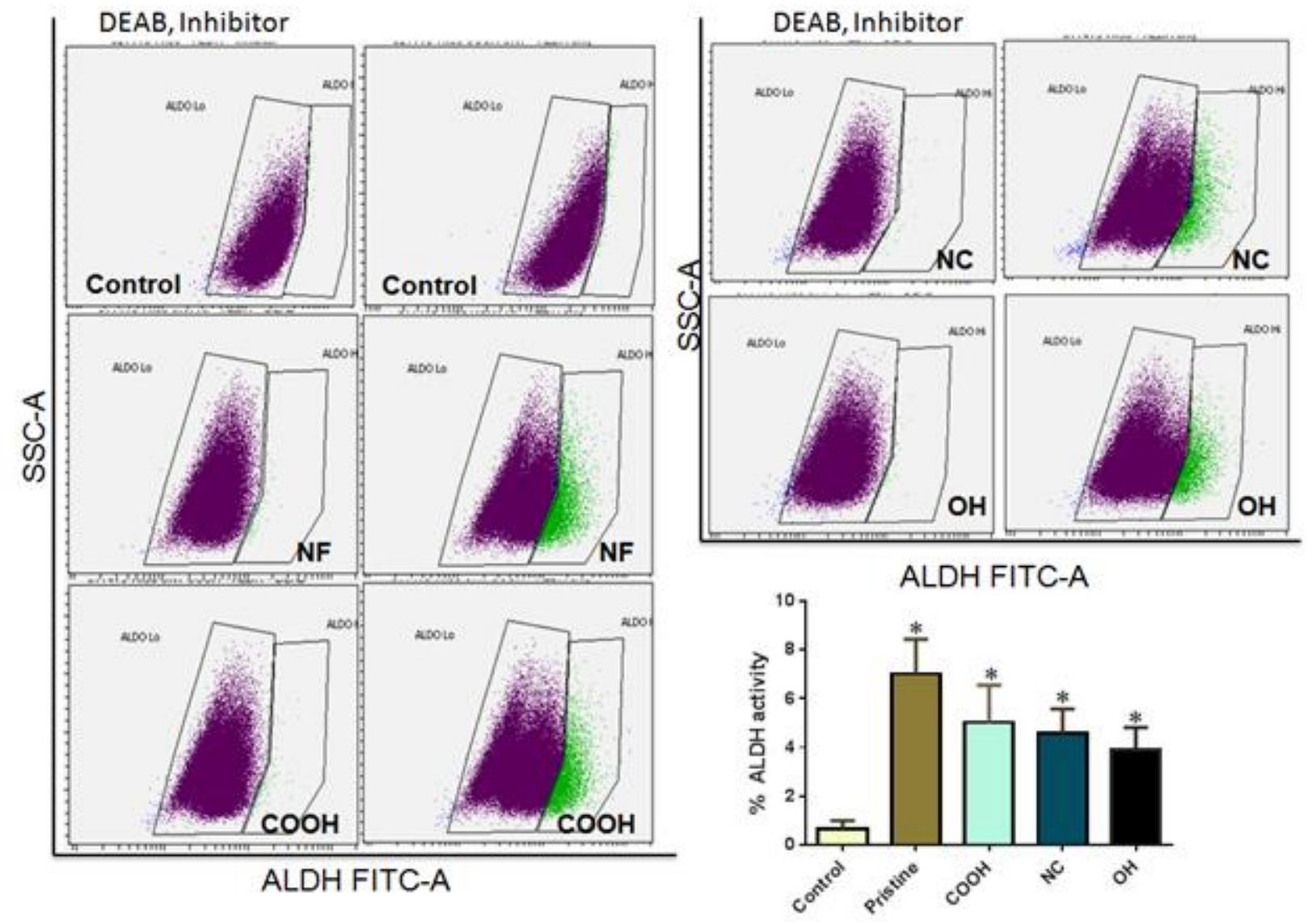

Figure IV: Effect of SWCNT surface modification on FSC generation via Aldefluor ${ }^{\circledR}$ assay

Human lung fibroblasts were treated with modified and pristine SWCNTs $\left(0.15 \mu \mathrm{g} / \mathrm{cm}^{2}\right)$ for $24 \mathrm{~h}$ and stained with Aldeflour ${ }^{\circledR}$ dye in the presence or absence of $1.5 \mathrm{mM}$ ALDH inhibitor, diethylaminobenzaldehyde (DEAB). A) Cells with increased ALDH activity (ALDH ${ }_{\mathrm{Hi}}$ ) were characterized and isolated by FACS. B) Quantitative analysis of \% ALDH activity in SWCNTtreated human lung fibroblasts compared to control. Data are means \pm SD $(n=3) .{ }^{*} p<0.05$ versus control cells. 


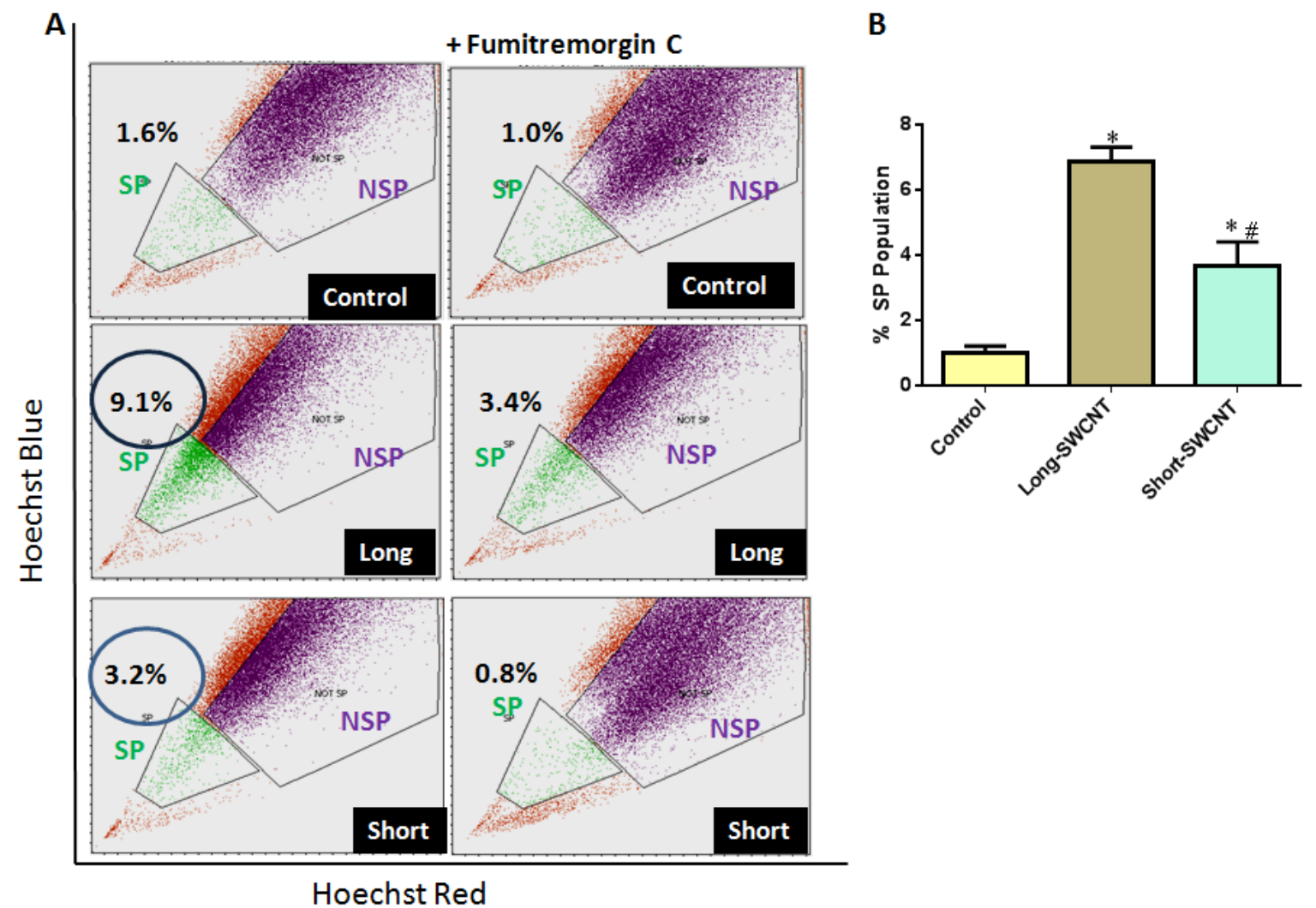

Figure V: Effect of SWCNT length on FSC induction determined by side population (SP) assay

A) Short and long SWCNT-treated human lung fibroblasts isolated into SP and NSP with or without the inhibitor fumitremorgin C (FTC) as indicated by \% population. B) \% SP population in short and long SWCNT-treated lung fibroblasts as compared to vehicle-treated control. Data are means $\pm \mathrm{SD}(n=3) . * p<0.05 v s$. control cells. $\# p<0.05 v s$. short-SWCNT. 


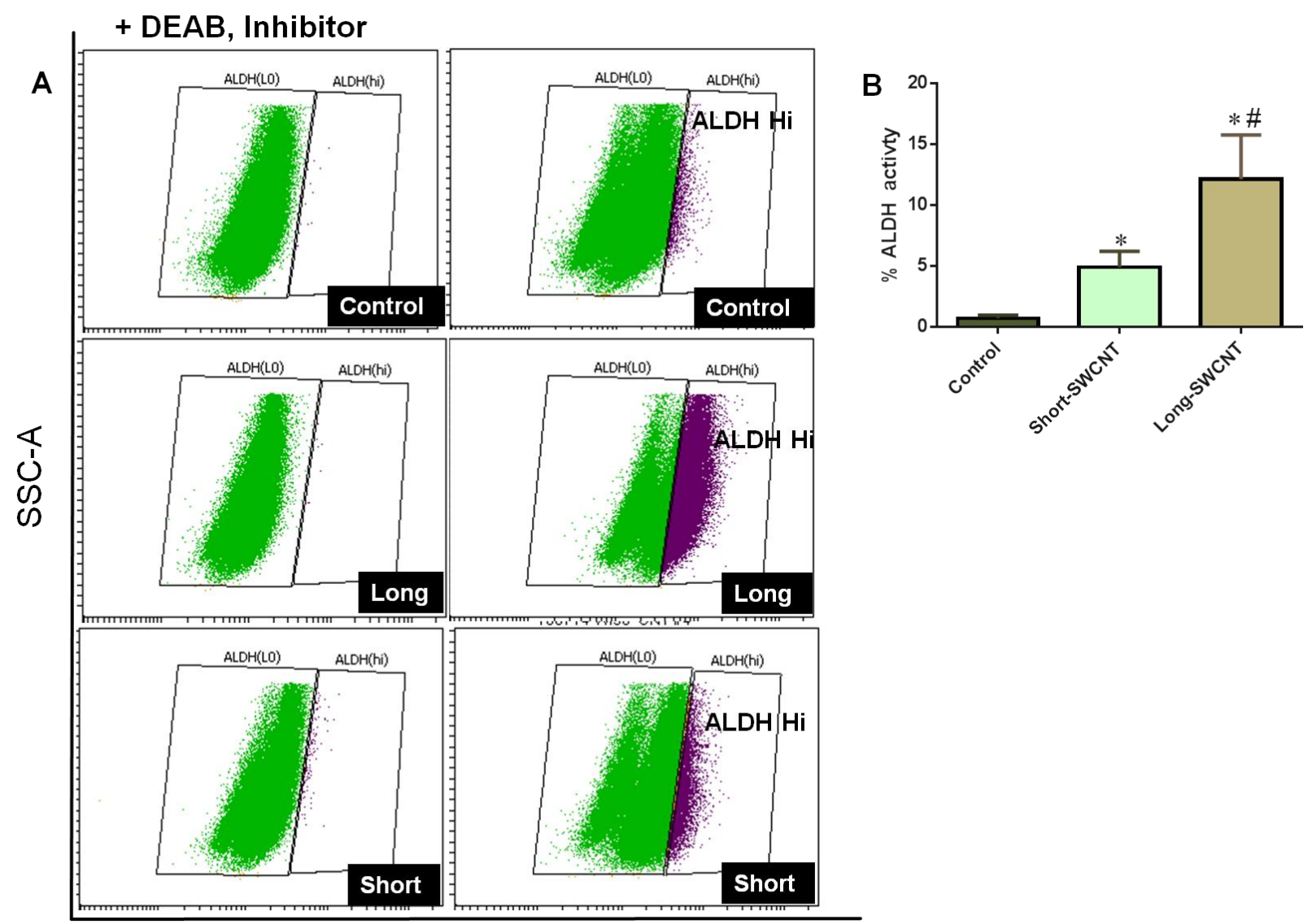

ALDH FITC-A

Figure VI: Effect of SWCNT length on FSC generation via Aldeflour ${ }^{\circledR}$ assay

WI-38 human lung fibroblasts were treated with SWCNTs of different lengths $\left(0.15 \mu \mathrm{g} / \mathrm{cm}^{2}\right)$ for $24 \mathrm{~h}$ and stained with the Aldeflour dye in the presence or absence of $1.5 \mathrm{mM}$ ALDH inhibitor, diethylaminobenzaldehyde (DEAB) for ALDH activity analysis. A) Cells with increased ALDH activity $\left(\mathrm{ALDH}_{\mathrm{Hi}}\right)$ were characterized and isolated by FACS. B) Quantitative analysis of $\%$ ALDH activity in SWCNT-treated lung fibroblasts compared to control. Data are means $\pm \mathrm{SD}(n$ $=3) . * p<0.05 v s$. control cells. \# $p<0.05 v s$. short-SWCNT. 
A

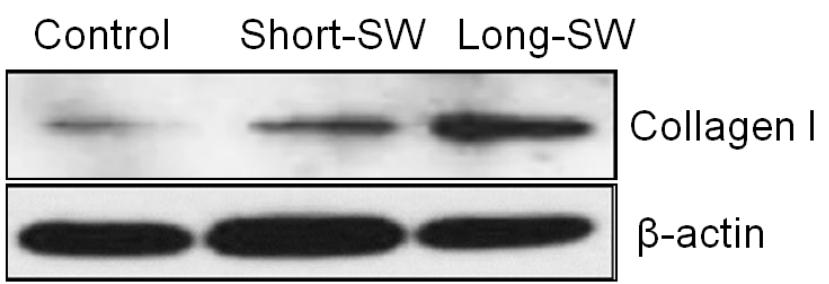

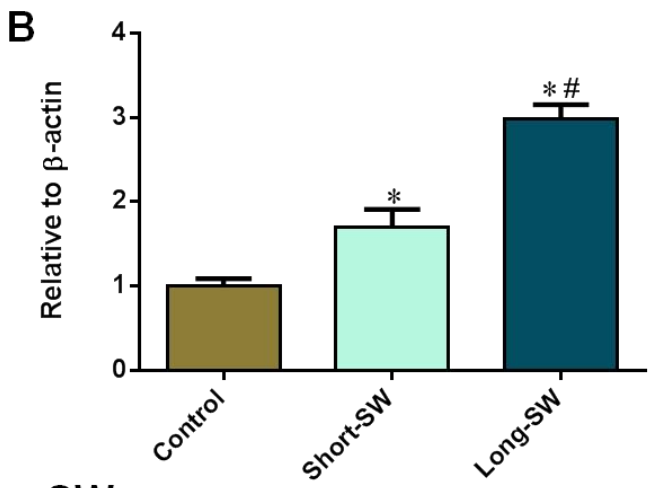
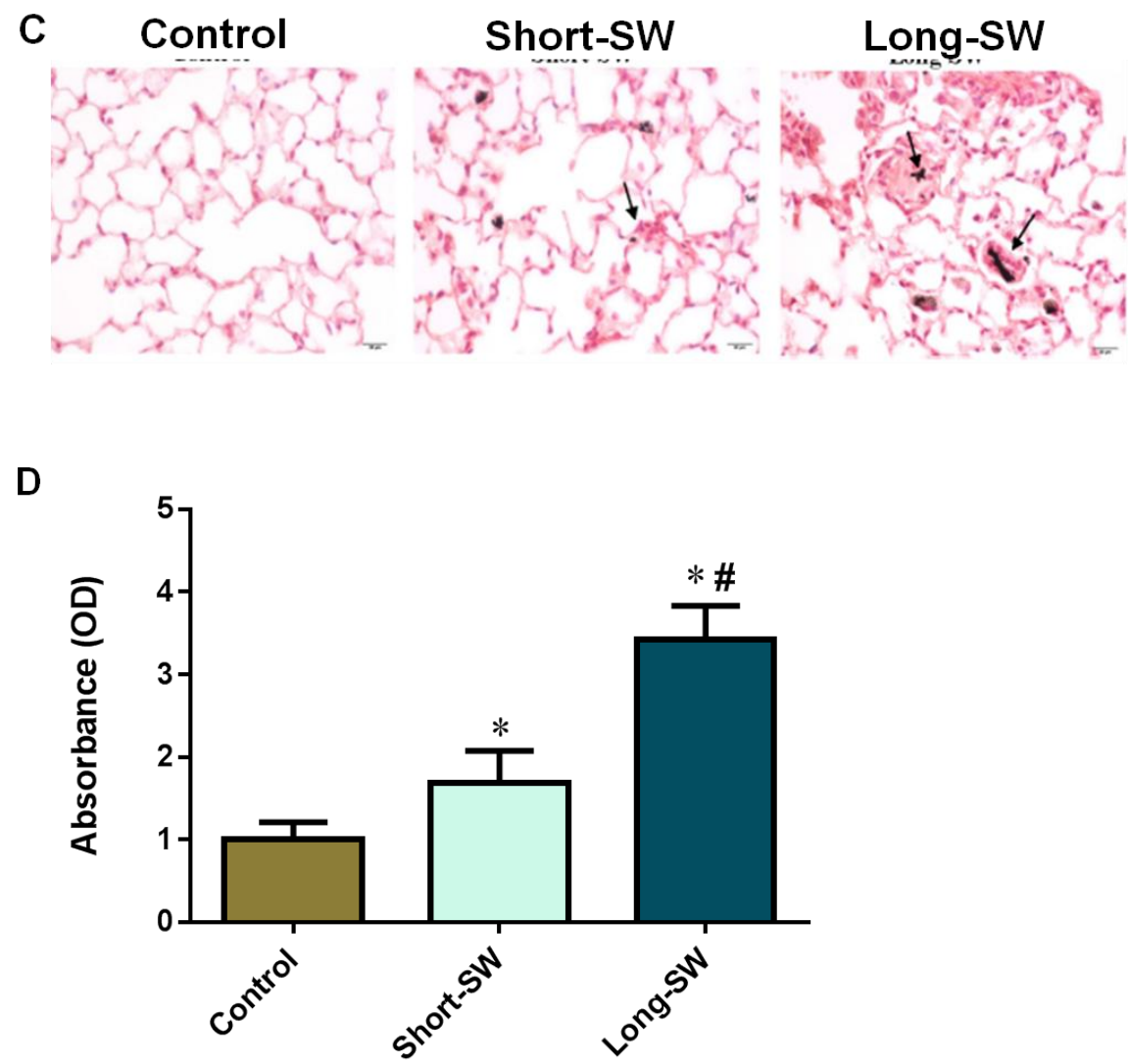

Figure VII: Effect of SWCNT length on fibrogenic response in vitro and in vivo

A) Western blots showing length-dependent effect of SWCNTs on collagen I production. Subconfluent cultures of human lung fibroblasts were treated with SWCNTs of different lengths for $48 \mathrm{~h}$ and analyzed for collagen I expression by Western blotting. Blots were reprobed with $\beta$ actin antibody to confirm equal loading of the samples. B) Quantitative analysis of collagen I expression. C) Mice were exposed to $50 \mu \mathrm{L}$ of dispersed SWCNT (40 $\mu \mathrm{g} / \mathrm{mouse}$ ) via pharyngeal 
aspiration for 90 days, after which the animals were sacrificed and the lungs were isolated, lysed and analyzed for histopathology after Sirius red staining. Scale bar $=20 \mu \mathrm{m}$; Arrows denote the thickening of collagen fibers around the CNTs. D) soluble collagen content by Sircol ${ }^{\circledR}$ assay. Values are means $\pm \mathrm{SD},(n=5$ mice/group $) ; * p<0.05 v s$. BSA/dipalmitoyl phosphatidylcholine (DPPC)-treated control; \# $p<0.05$ vs. short-SWCNT. 


\section{CHAPTER 5}




\section{CHAPTER 5: EXECUTIVE SUMMARY}

\section{Introduction}

Given their remarkable properties, carbon nanotubes (CNTs) have made their way through various industrial and medicinal applications. The overall production of CNTs and their products is expected to grow rapidly in the next decade, thus requiring an additional recruitment of workers [1-3]. However, their unique applications and desirable properties are fraught with concerns regarding occupational exposure. The concern about worker exposure to CNTs arises from the results of recent animal studies. Short-term and sub-chronic exposure studies in rodents have shown consistent adverse health effects such as pulmonary inflammation, granulomas, fibrosis, and mesothelioma [4-8]. Furthermore, physicochemical properties of CNTs such as aspect ratio, dispersion, and functionalization can significantly affect their pulmonary toxicity [9$11]$.

CNTs can evade phagocytosis, cross cell membranes and the blood-brain barrier and translocate to other sites of the body causing systemic side effects [12]. Once inhaled, CNTs can cross the alveolar interstitial barrier and typically end up in the interstitial compartment of the lung. Subsequent in vitro studies show that CNTs interact with interstitial fibroblast cells to induce excessive extracellular matrix (ECM) accumulation. The clearance rate of these nanomaterials is extremely low, owing to their non-biodegradable nature resulting in biopersistence and tissue burden, leading to a higher probability of adverse health effects [2, 4]. Considerable investigations in the literature demonstrate the fibrogenic effect of CNTs; however, the underlying mechanisms remain poorly understood.

Pulmonary fibrosis is a progressive and lethal lung disease characterized by excessive proliferation of fibroblasts and deposition of ECM [13]. Identifying the cells responsible for the 
enhanced ECM and collagen production is crucial for understanding fibrosis mechanisms. Growing research indicates the presence of putative stem cells in the pathogenesis of pulmonary fibrosis [14]. For instance, a recent study has indicated the stem cell induction at the early onset of lung fibrosis in a mouse model of bleomycin-induced fibrosis [15]. However, the role of stem cells in nanomaterial-induced pulmonary fibrosis has not been explored.

At present, human data regarding fibrogenicity assessment of CNTs is lacking and information on in vivo toxicity is limited. Murine models appear to be a gold standard for the assessment of lung fibrosis [16]. However, the rapidly expanding number of engineered nanomaterials makes it impossible to test them all in animals due to time constraints and prohibitive cost. Currently, there is a dire need for efficient and reliable in vitro models which can facilitate the rapid high-throughput assessment of nanomaterial fibrogenicity and disease mechanisms [17].

In order to elucidate the mechanism of CNT-induced fibrosis, we hypothesize that CNT exposure to fibroblasts induces FSCs which are crucial for the fibroblast to myofibroblast transformation and the development of fibrosis. The specific aims of this study are designed, first of all, to establish the evidence of fibroblast stem-like cells (FSCs) upon SWCNT exposure, characterize their role in the fibrogenesis, and lastly to evaluate whether oxidative stress and physicochemical parameters of CNTs influence the resulting stemness phenotype. Oxidative stress was specifically studied since it is the most commonly reported SWCNT toxicity endpoint and has been demonstrated to be a key player in stem cell fate and function. 


\section{Specific Aim 1: Characterize the role of fibroblast stem-like cells in CNT-induced lung}

\section{fibrosis}

\section{Background}

Currently the paradigm of stem cells is being evaluated in dysfunctional lung remodeling. Evolving research has demonstrated the pathogenic role of these stem/progenitor cells during the early onset of lung fibrosis in vivo [14, 15]. Stem cells triggered by environmental cues differentiate into myofibroblasts and contribute to disease progression. Understanding the molecular/cellular basis of these stem-like cells during lung fibrosis is of critical importance. Previous research findings and studies from our laboratory have shown the fibrogenic potential of CNTs [18-20]. However, the concept of stemness in the light of nanomaterial-induced fibrosis remains to be explored. Therefore, we proposed that fibroblasts can be a source of stem-like cells upon exposure to CNTs. The goal of this aim was to document the evidence of FSCs and their potential role in CNT-induced fibrogenic effects both in vivo and in vitro settings.

\section{Rationale}

Previous findings from our laboratory revealed the expression of universal stem cell markers ALDH1A1 and ABCG2 in human lung fibrotic tissues [21] as well as CNT-induced FSCs thus providing evidence for the clinical relevance of stem cells in fibrosis. These data provide preliminary supporting evidence for the role of stem cells in human lung fibrosis.

\section{Results}

SWCNTs induced the side population phenotype (indicative of the fibroblast stem-like cell phenotype) of primary lung fibroblasts. CNT-induced SP cells (FSCs) expressed a high level of both collagen I and $\alpha$-SMA compared to non-SP indicating that the stem-like fibroblasts are a 
potential key source of collagen production and may play a crucial role in fibrogenesis. The isolated FSCs displayed an elevated expression of fibrogenic and stem cell markers indicating the reliability of the stem cell isolation method via FACS as well as supporting their critical role in SWCNT-induced fibrogenesis. The study also developed and put forth an in vitro model of SWCNT-induced fibrotic nodule formation that correlates the development of stemness phenotype and onset of fibrosis.

Specific Aim 2: Determine whether reactive oxygen species (ROS) production is involved in CNT-induced stemness.

\section{Background}

Accumulating evidence suggests the redox potential of CNTs [22]. Nanoparticle exposure results in ROS-dependent activation of several transcription factors and signaling pathways involved in the regulation of inflammation and fibrosis [23]. ROS are known to regulate several cellular responses such as SWCNT-induced collagen production, fibroblast to myofibroblast activation, and angiogenesis, all implicated in the pathogenesis of fibrosis [18, 24]. ROS signaling has been shown to drive the metabolic state of stem cells thereby governing their stemness and differentiation as well as implicated in the progression of stem cell-associated diseases [25, 26]. However, it is unknown whether the oxidative stress induced by SWCNTs is essential for the development of stem phenotype of FSCs. This study was undertaken to evaluate whether ROS are critical for the development of stem phenotype during CNT-induced fibrogenesis. 


\section{Rationale}

Previous findings from our group indicate that ROS generation plays a key role in CNT-induced fibrogenesis $[18,19]$. Oxidative stress has also been shown to affect stem cell function and behavior [25].

\section{Results}

SWCNT-induced FSC generation was under the regulation of oxidative stress as indicated by i) antioxidants abrogated the effect of SWCNTs on FSC (SP) generation, ii) role of peroxides in SWCNT-induced FSC generation, iii) SWCNT-induced FSCs overexpressed collagen I, which was shown to be ROS-dependent, and iv) CNT length and surface modification dependent ROS responses. Overall, our findings indicate that ROS are essential for imparting stemness to SWCNT-treated fibroblasts.

\section{Specific Aim 3: Study the effects of fiber length and surface modification on carbon nanotube-induced fibroblast stem-like cells and lung fibrosis}

\section{Background}

The pathologic effects of CNTs such as inflammation, ROS production, and fibrosis are likely to be influenced by their physicochemical properties such as particle size, dispersion and surface activity with respect to their cellular uptake, internalization, phagocytosis and clearance from the body $[27,28]$. Studies from our laboratory as well as other groups have demonstrated the differential fibrogenic response owing to different sizes, dispersion status, and chemical functionalization of nanomaterials [9-11, 19]. SWCNT exposure causes FSC generation in human lung fibroblasts as demonstrated in chapter 1. However, it is not known if these CNT characteristics are capable of driving the stemness phenotype in SWCNT-treated lung 
fibroblasts. Thus, the major objective of this aim was to understand an association between SWCNT surface modification and fiber length and stemness development. This study also aimed to develop a model that determines whether stemness phenotype is predictive of the fibrogenic response in vivo.

\section{Results}

Long SWCNTs induced higher FSCs compared to short SWCNTs as evidenced by side population (SP) and (aldehyde dehydrogenase) ALDH assays, thus indicating a length-dependent effect on stemness phenotype. Pristine SWCNTs induced higher FSCs compared to modified SWCNTs; however the effect was not statistically different. Long SWCNTs induced greater fibrogenic response in vivo compared to short SWCNTs, supporting the potential utility of our in vitro FSC model to predict the fibrogenicity of CNTs.

\section{Clinical \& Translational Relevance}

The work presented in this study is innovative because it introduces the concept of fibroblast stem-like cells as a potential key player in the pathogenesis of pulmonary fibrosis. These cells, which possess stem property and high fibrogenic activity, were induced by CNTs and could serve as a potential key source of ECM production whose accumulation characterizes fibrosis. This work has a broad impact on stem cell development and is applicable to other nanomaterials and fibrogenic agents. It also provides new insight into the mechanisms of fibrosis which may help to identify novel biomarkers and drug targets for early diagnosis and treatment of the disease. Furthermore, the in vitro FSC model developed in this study may be utilized as a rapid screening tool for fibrogenicity testing of nanomaterials and anti-fibrotic agents. 


\section{References}

1. Oberdörster G. Safety assessment for nanotechnology and nanomedicine: Concepts of nanotoxicology. J Intern Med. 2010 01;267(1):89-105.

2. Lam C, James JT, McCluskey R, Arepalli S, Hunter RL. A review of carbon nanotube toxicity and assessment of potential occupational and environmental health risks. Crit Rev Toxicol. 2006 03;36(3):189-217.

3. Patel V. Global carbon nanotubes market outlook: Industry beckons. Nanotech Insights. 2011;2:31-5.

4. Lam C, James JT, McCluskey R, Hunter RL. Pulmonary toxicity of single-wall carbon nanotubes in mice 7 and 90 days after intratracheal instillation. Toxicol Sci. 2004 01;77(1):12634.

5. Shvedova AA, Kisin ER, Mercer R, Murray AR, Johnson VJ, Potapovich AI, et al. Unusual inflammatory and fibrogenic pulmonary responses to single-walled carbon nanotubes in mice. Am J Physiol Lung Cell Mol Physiol. 2005 11;289(5):L698-708.

6. Shvedova AA, Kisin E, Murray AR, Johnson VJ, Gorelik O, Arepalli S, et al. Inhalation vs. aspiration of single-walled carbon nanotubes in C57BL/6 mice: Inflammation, fibrosis, oxidative stress, and mutagenesis. Am J Physiol Lung Cell Mol Physiol. 2008 10;295(4):L552-65.

7. Mercer RR, Scabilloni J, Wang L, Kisin E, Murray AR, Schwegler-Berry D, et al. Alteration of deposition pattern and pulmonary response as a result of improved dispersion of aspirated single-walled carbon nanotubes in a mouse model. Am J Physiol Lung Cell Mol Physiol. 2008 01;294(1):L87-97.

8. Park E, Roh J, Kim S, Kang M, Han Y, Kim Y, et al. A single intratracheal instillation of single-walled carbon nanotubes induced early lung fibrosis and subchronic tissue damage in mice. Arch Toxicol. 2011 09;85(9):1121-31.

9. Wang L, Castranova V, Mishra A, Chen B, Mercer RR, Schwegler-Berry D, et al. Dispersion of single-walled carbon nanotubes by a natural lung surfactant for pulmonary in vitro and in vivo toxicity studies. Part Fibre Toxicol. 2010 10/19;7:31.

10. Vietti G, Ibouraadaten S, Palmai-Pallag M, Yakoub Y, Bailly C, Fenoglio I, et al. Towards predicting the lung fibrogenic activity of nanomaterials: Experimental validation of an in vitro fibroblast proliferation assay. Part Fibre Toxicol. 2013 10/10;10:52.

11. Li R, Wang X, Ji Z, Sun B, Zhang H, Chang CH, et al. Surface charge and cellular processing of covalently functionalized multiwall carbon nanotubes determine pulmonary toxicity. ACS Nano. 2013 03/26;7(3):2352-68. 
12. Shvedova AA, Kagan VE. The role of nanotoxicology in realizing the 'helping without harm' paradigm of nanomedicine: Lessons from studies of pulmonary effects of single-walled carbon nanotubes. J Intern Med. 2010 01;267(1):106-18.

13. Lu Y, Azad N, Wang L, Iyer AKV, Castranova V, Jiang B, et al. Phosphatidylinositol-3kinase/akt regulates bleomycin-induced fibroblast proliferation and collagen production. Am $\mathrm{J}$ Respir Cell Mol Biol. 2010 04;42(4):432-41.

14. LeBleu VS, Taduri G, O'Connell J, Teng Y, Cooke VG, Woda C, et al. Origin and function of myofibroblasts in kidney fibrosis. Nat Med. 2013 08;19(8):1047-53.

15. Banerjee ER, Henderson,William Reed,Jr. Characterization of lung stem cell niches in a mouse model of bleomycin-induced fibrosis. Stem Cell Res Ther. 2012 05/29;3(3):21.

16. Nel A, Xia T, Meng H, Wang X, Lin S, Ji Z, et al. Nanomaterial toxicity testing in the 21 st century: Use of a predictive toxicological approach and high-throughput screening. Acc Chem Res. 2013 03/19;46(3):607-21.

17. B Moore ,Bethany, Lawson WE, Oury TD, Sisson TH, Raghavendran K, Hogaboam CM. Animal models of fibrotic lung disease. Am J Respir Cell Mol Biol. 2013 08;49(2):167-79.

18. Azad N, Iyer AKV, Wang L, Liu Y, Lu Y, Rojanasakul Y. Reactive oxygen speciesmediated p38 MAPK regulates carbon nanotube-induced fibrogenic and angiogenic responses. Nanotoxicology. 2013 03;7(2):157-68.

19. Manke A, Luanpitpong S, Dong C, Wang L, He X, Battelli L, et al. Effect of fiber length on carbon nanotube-induced fibrogenesis. Int J Mol Sci. 2014 04/29;15(5):7444-61.

20. Wang L, Mercer RR, Rojanasakul Y, Qiu A, Lu Y, Scabilloni JF, et al. Direct fibrogenic effects of dispersed single-walled carbon nanotubes on human lung fibroblasts. J Toxicol Environ Health A. 2010;73(5):410-22.

21. Luanpitpong S, Wang L, Manke A, Martin KH, Ammer AG, Castranova V, et al. Induction of stemlike cells with fibrogenic properties by carbon nanotubes and its role in fibrogenesis. Nano Lett. 2014 06/11;14(6):3110-6.

22. Shvedova AA, Pietroiusti A, Fadeel B, Kagan VE. Mechanisms of carbon nanotube-induced toxicity: Focus on oxidative stress. Toxicol Appl Pharmacol. 2012 06/01;261(2):121-33.

23. Bonner JC. Lung fibrotic responses to particle exposure. Toxicol Pathol. 2007 01;35(1):14853.

24. He X, Young S, Schwegler-Berry D, Chisholm WP, Fernback JE, Ma Q. Multiwalled carbon nanotubes induce a fibrogenic response by stimulating reactive oxygen species production, activating NF- $\mathrm{KB}$ signaling, and promoting fibroblast-to-myofibroblast transformation. Chem Res Toxicol. 2011 12/19;24(12):2237-48. 
25. Bigarella CL, Liang R, Ghaffari S. Stem cells and the impact of ROS signaling. Development. 2014 11;141(22):4206-18.

26. Chaudhari P, Ye Z, Jang Y. Roles of reactive oxygen species in the fate of stem cells. Antioxid Redox Signal. 2014 04/20;20(12):1881-90.

27. Borm PJA, Robbins D, Haubold S, Kuhlbusch T, Fissan H, Donaldson K, et al. The potential risks of nanomaterials: A review carried out for ECETOC. Part Fibre Toxicol. 2006 08/14;3:11.

28. Oberdörster G, Maynard A, Donaldson K, Castranova V, Fitzpatrick J, Ausman K, et al. Principles for characterizing the potential human health effects from exposure to nanomaterials: Elements of a screening strategy. Part Fibre Toxicol. 2005 10/06;2:8. 